\title{
Catarrhines from the Middle Miocene (ca. 14.5 Ma) of Kipsaraman, Tugen Hills, Kenya
}

\author{
MARTIN PICKFORD ${ }^{1,2 *}$, YUTAKA KUNIMATSU ${ }^{3}$ \\ ${ }^{1}$ Département Histoire de la Terre, UMR 5143 du CNRS, Case postale 38, 57 rue Buffon, 75005, Paris, France \\ ${ }^{2}$ Collège de France, 11, Place Marcellin Berthelot, 75005, Paris, France \\ ${ }^{3}$ Primate Research Institute, Kyoto University, Aichi, Japan
}

Received 16 April 2003; accepted 13 April 2005

\begin{abstract}
The discovery of a rich and diverse vertebrate fauna in the Middle Miocene Muruyur Formation (ca. 14.5 Ma), Tugen Hills, Kenya, provides a rare view of the structure of the catarrhine fauna from this time period. Up to 2002, more than 140 catarrhine specimens have been collected from three sites (Kipsaraman, Keturo, and Cheparawa) represented by 199 teeth. At least six taxa are present, five 'apes' (hominoids sensu lato) and one cercopithecoid. Three of the taxa are new species. The Kipsaraman catarrhine fauna has some similarities to those of Maboko (ca. $15 \mathrm{Ma}$ ) and Fort Ternan (ca. $13.7 \mathrm{Ma}$ ), western Kenya, but it differs markedly from the Nachola (ca. $16 \mathrm{Ma}$ ) one, not only in the relative abundance of hominoids versus cercopithecoids, but also in the taxa represented. At Maboko and Kipsaraman, the most abundant catarrhine fossils are cercopithecoids, whereas these are rare at Nachola and unknown at Fort Ternan. At Kipsaraman, Maboko, and Fort Ternan, small 'ape' fossils are common, whereas they are absent from Nachola. Nyanzapithecus or a similar genus is present, but rare at all four sites. Kenyapithecus is present at Maboko, Fort Ternan, and Kipsaraman, but is absent from Nachola, its place being taken by Nacholapithecus which is abundant at the site. The catarrhine faunas from these Middle Miocene localities indicate that environmental conditions within East Africa were highly variable between 16 and $13.7 \mathrm{Ma}$.
\end{abstract}

Key words: Middle Miocene, Kenya, Kipsaraman, Catarrhines

\section{Introduction}

The Middle Miocene (ca. 14.5 Ma) localities at Kipsaraman, Keturo, and Cheparawa, Muruyur Formation, Tugen Hills, Kenya, (Figure 1, Figure 2) have previously yielded only a few catarrhine fossils. The first specimen found there was a talus of a large-bodied ape (Pickford, 1988). Hill et al. (1991) described two catarrhine teeth from the locality, one a small ape molar attributed to Kalepithecus cf. songhorensis, the other a lower molar of a large species identified as Proconsul cf. major, and they mentioned the existence of a fragmentary third tooth which they reported could be a deciduous molar of a small hominoid or a cercopithecid. This was followed in 1999 by the description of the holotype partial skeleton of Equatorius africanus, the same species that occurs at Maboko, Kenya (Ward S. et al., 1999). The erection of a new genus for this species has been the subject of debate (Begun, 2000; Benefit and McCrossin, 2000; Nakatsukasa et al., 2000; Retallack et al., 2002). Kelley et al. (2002) described the dentognathic remains of E. africanus from Kipsaraman in greater detail and responded in some measure to the points made by Benefit and McCrossin

* Corresponding author. e-mail: pickford@mnhn.fr phone: +33-1-40-79-30-03; fax: +33-1-40-79-35-80

Published online 9 August 2005

in J-STAGE (www.jstage.jst.go.jp) DOI: 10.1537/ase.00073

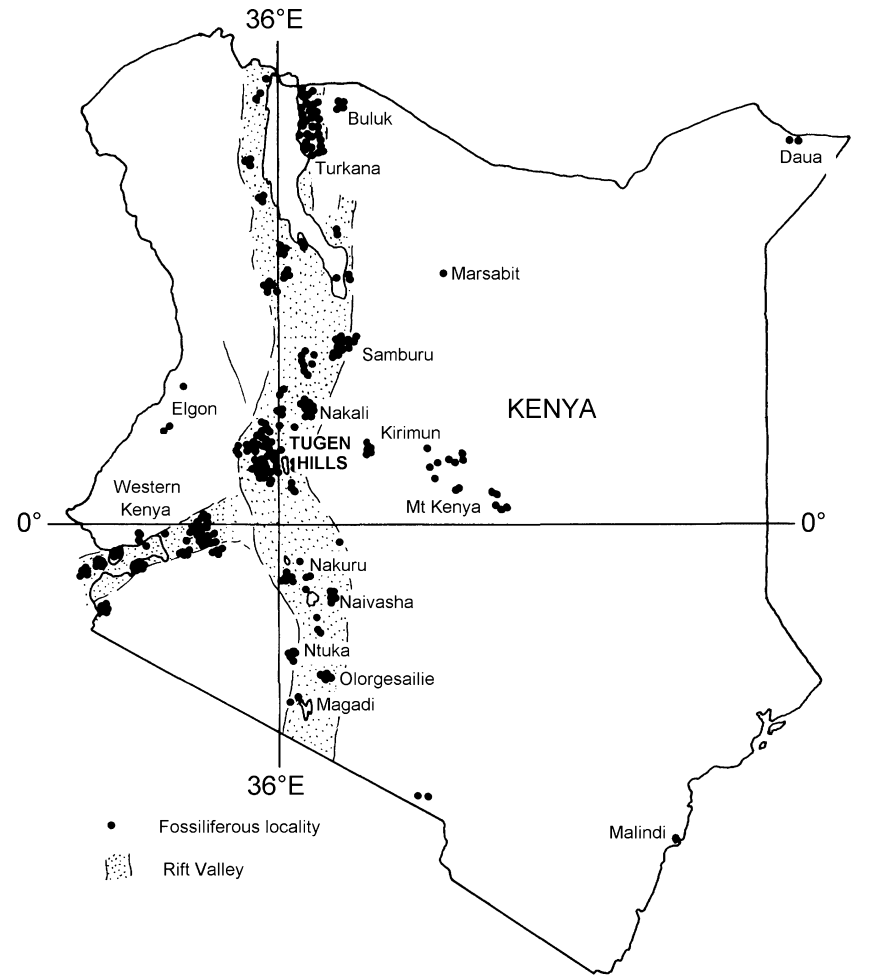

Figure 1. Location of the Tugen Hills in the Gregory Rift Valley, Kenya. 


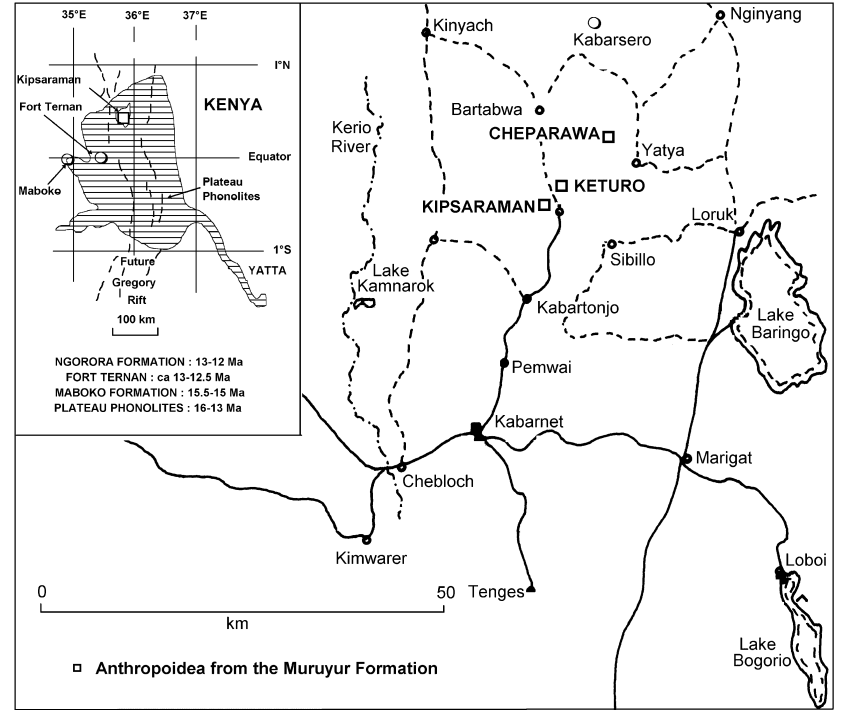

Figure 2. Location of Kipsaraman, Keturo and Cheparawa, Tugen Hills, Kenya.

(2000) and Begun (2000). They also attributed three isolated teeth from Kipsaraman to Nyanzapithecus sp., and they listed Victoriapithecus at the site for the first time, but without providing any details. In view of the relative poverty of all species at Kipsaraman, save for E. africanus, the discovery of over 140 new catarrhine dental specimens by the Kenya Palaeontology Expedition between 1999 and 2002 is of great interest, as it provides a more comprehensive view of the primate fauna from the deposits.

\section{Systematics}

Order Primates Linnaeus, 1758

Suborder Anthropoidea Mivart, 1864

Infraorder Catarrhini Geoffroy, 1812

Superfamily incertae sedis

Genus Nyanzapithecus Harrison, 1986

Species Nyanzapithecus cf. pickfordi Harrison, 1986

Synonymy. 2002-Nyanzapithecus sp. Kelley et al., 56, Figure 8.

Stratigraphy and age of referred material. Muruyur Formation, Middle Miocene, ca. 14.5 Ma, Faunal Set P IIIb (Pickford, 1981)

Material. I1/ Bar 217'02 (probably left); C1/ Bar 1999'02 (right); M*/ Bar 197'02 (right); ?M2/ Bar 1180'99 (right); M3/ Bar 92'99 (right) plus 3 specimens described by Kelley et al. (2002) (Appendix 1).

\section{Description}

The damaged upper central incisor, Bar 217'02 (probably left) (Figure 3-1), has two prominent central ridges reaching from the lingual tubercle towards apex, and the rest of the lingual surface is lightly wrinkled. The lingual surface is generally concave apart from the central ridges, and is bordered basally, mesially, and distally by a well-formed cingu-
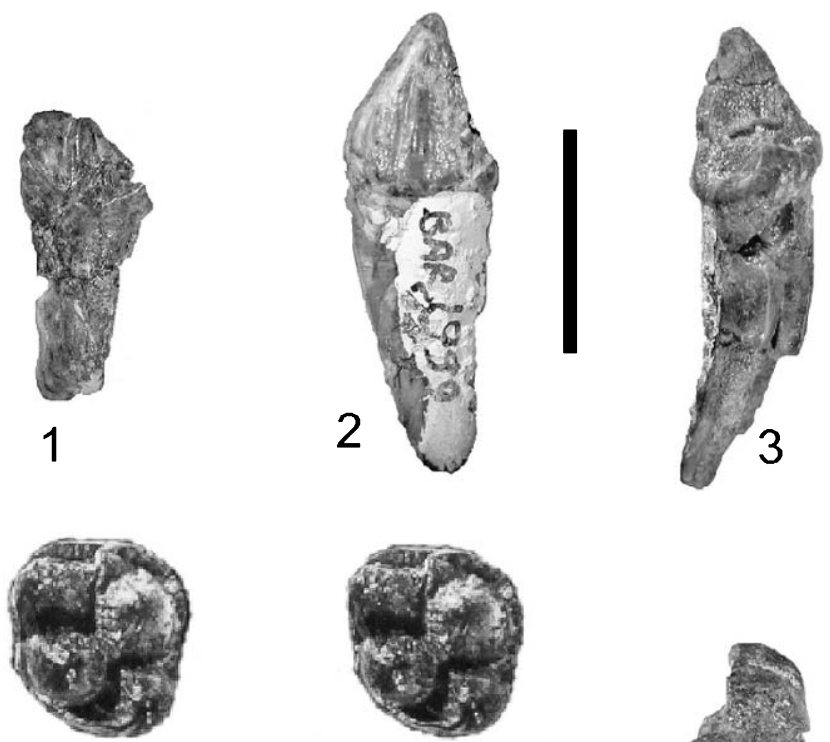

4
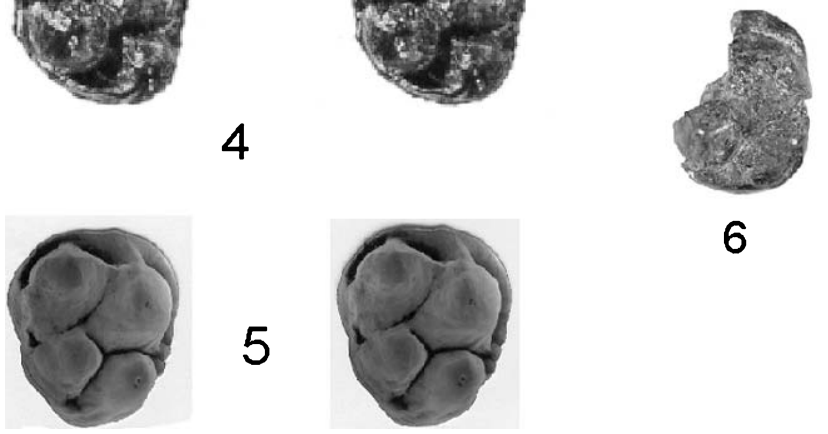

6

Figure 3. Nyanzapithecus cf. pickfordi from Kipsaraman, Tugen Hills, Kenya with length/breadth measurements (in mm) (5 is an SEM image) (Scale bar $10 \mathrm{~mm})$. (1) Bar 217'02, left I1/, $(7.0 \times-)$ lingual view; (2 and 3) Bar 1999'02, right C1/, $(7.4 \times 5.9)$ buccal and lingual views; (4) Bar 1180'99, right ?M2/, $(8.5 \times 7.6)$ stereo occlusal view; (5) Bar 92'99, right $\mathrm{M} 3 /,(8.4 \times 7.6)$ stereo occlusal view; (6) Bar $197^{\prime} 02$, right $M^{*} /,(7.9 \times 6.5+)$ occlusal view.

lar margin. The labial surface of the crown is missing.

Bar 1999'02 is a damaged, lightly worn upper right canine (Figure 3-2, 3), lacking much of the lingual part of the root. It is relatively low crowned (possibly female, buccal height $8.3 \mathrm{~mm}$ for a mesiodistal length of $7.4 \mathrm{~mm}$ ) with a scooped out lingual surface bordered cervically by a prominent cingulum that even forms a small tubercle in the lingualmost position. The mesial groove is not well expressed, but damage in this area prevents the morphology from being reliably assessed. The buccal surface is convex with broad but not high wrinkling in the enamel. The root profile is slightly concave buccally.

Bar 197'02 (Figure 3-6) is a lightly worn upper molar lacking the paracone. The protocone is the largest of the cusps and is bordered mesially by a well-formed cingulum. The hypocone is well detached from the trigon by a deep cleft.

Bar 1180'99 is an unworn right upper molar, probably M2/ (Figure 3-4), with conical bunodont cusps with light wrinkling. The two buccal cusps of the trigon are virtually devoid of interconnecting crests, each cusp standing separately from its neighbour. The protocone has a weak mesial crest and a better developed, but subdued, crista obliqua. 
There is a prominent mesial cingulum with a central tubercle. The cingulum extends round the lingual surface of the protocone and terminates at the anterior corner of the hypocone. The trigon is comprised of sub-equal cusps, the protocone being slightly larger than the other two cusps, and the central basin deep and unencumbered by crests and ridges. The hypocone is well separated from the trigon by a deep cleft and it has a cingular extension descending its buccal side as far as the distobuccal corner of the metacone, and it encloses a tiny distal fovea.

Bar 92'99, an unworn, rootless, isolated right upper third molar (Figure 3-5) is similar to the preceding tooth save for the fact that the metacone is smaller and the occlusal outline of the tooth thus more triangular than rectangular. Another difference, related to the small size of the metacone, is the diminutive extent of the distal cingulum, which is little more than an enamel fold at the base of the valley between the hypocone and metacone.

\section{Discussion}

Morphologically the Kipsaraman nyanzapithecine specimens accord reasonably closely with Nyanzapithecus pickfordi but they are slightly larger than the Maboko fossils (see Figure 4 and Figure 5 for metrics of the latter). They diverge from $N$. harrisoni from Nachola, Kenya, which is appreciably smaller and displays some morphological differences (Kunimatsu, 1992b, 1997). They are markedly different from $N$. vancouveringorum from Rusinga and Mfwangano, Kenya, which is much smaller and which has different molar proportions and morphology (Andrews 1974, 1978; Kuni-

Lower P4
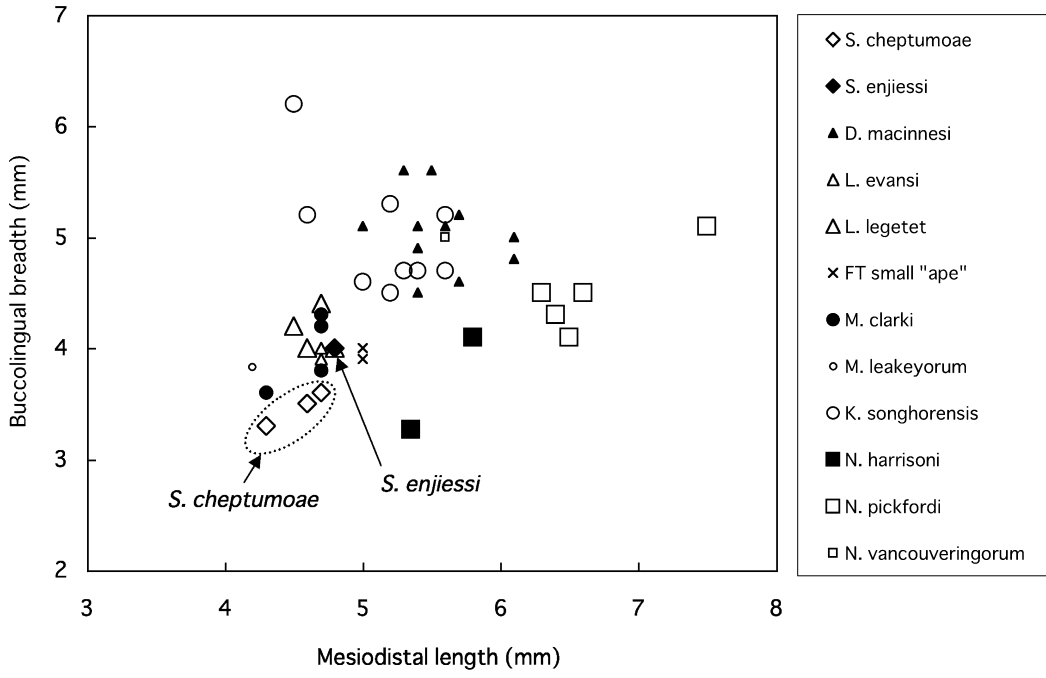

$\square \mathrm{N}$. vancouveringorum

Figure 4. Bivariate plot of lower $\mathrm{p} / 4 \mathrm{~s}$ of small 'apes' from East Africa.

Lower M1

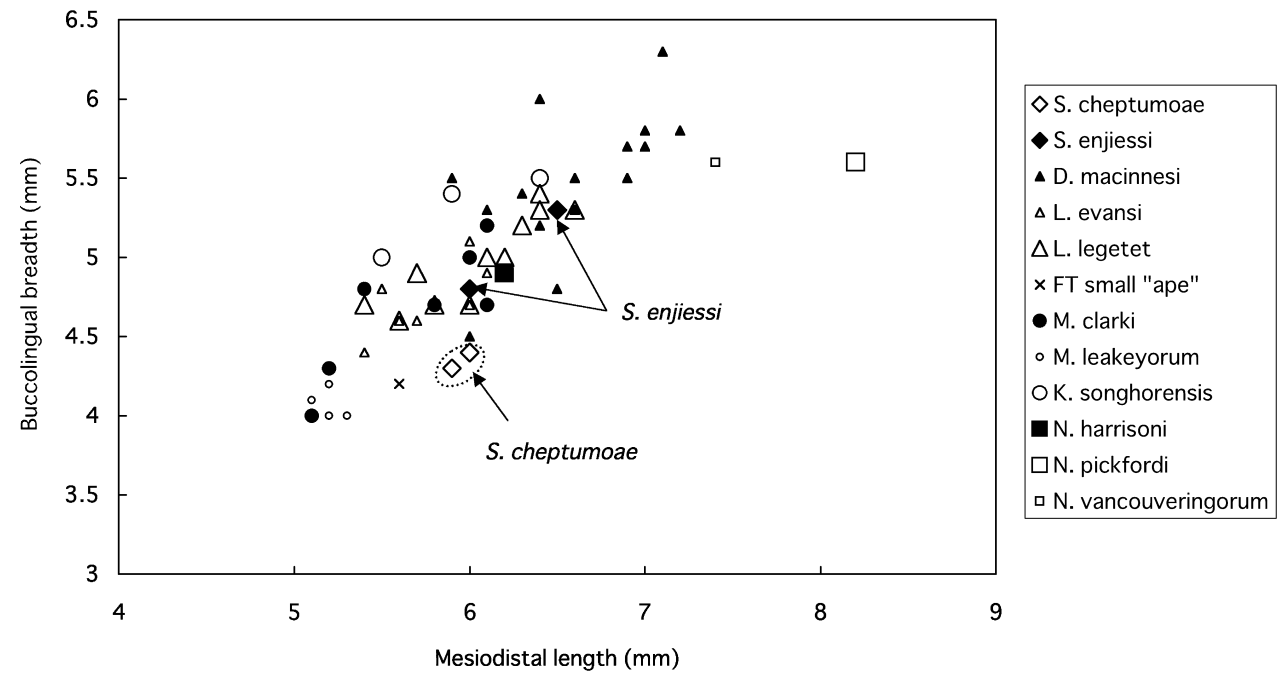

Figure 5. Bivariate plot of lower $\mathrm{m} / 1 \mathrm{~s}$ of small 'apes' from East Africa. 
matsu, 1992a)

Kelley et al. (2002) described and figured three specimens from Kipsaraman which they attributed to Nyanzapithecus sp. Morphologically and metrically their specimens are similar to the Maboko material, except KNM-TH 22913 $(\mathrm{MD}=9.6 \mathrm{~mm}, \mathrm{BL}=7.5 \mathrm{~mm})$ but only if it is identified as an $\mathrm{m} / 1$, which, if correct, would mean that it is much larger than the Maboko species. As an $\mathrm{m} / 2$ it falls closer to the range of variation of $N$. pickfordi, However, given that the Maboko sample of the species is quite small [only two specimens of $\mathrm{m} / 1$ (MD: $8.0-8.4 \mathrm{~mm}$, BL: $5.5-5.6 \mathrm{~mm}$ ) and $\mathrm{m} / 2$ (MD: $8.4-8.8 \mathrm{~mm}, \mathrm{BL}: 6.2-6.4 \mathrm{~mm}$ ) of $N$. pickfordi were listed by Harrison (1986)], the known range may be appreciably less than the real range of variation. The Kipsaraman specimens can be distinguished from both $N$. vancouveringorum and $N$. harrisoni by their more elongated upper molar crowns and more inflated molar cusps resulting in a more crowded appearance and more restricted occlusal foveae and basins, and in these aspects, they are most similar to N. pickfordi. Therefore, we prefer provisionally to refer the Kipsaraman sample to this species as $N$. cf. pickfordi.

The higher taxonomic status of Nyanzapithecus is problematic. The type species of this genus ( $N$. vancouveringorum) was once assigned to Rangwapithecus, together with a larger species $R$. gordoni. Harrison (1986) removed the former from Rangwapithecus and created a new generic name, Nyanzapithecus, for it and the material from Maboko, which he described as a new species ( $N$. pickfordi). Later, a third species ( $N$. harrisoni) was reported from Nachola (Kunimatsu, 1992b, 1997). N. vancouveringorum is known from Rusinga and Mfwangano Islands in Lake Victoria, western Kenya, and is older (ca. $18 \mathrm{Ma}$ ) than the other species of the genus. The two younger species $(N$. pickfordi and $N$. harrisoni) are approximately similar in age to each other (early Middle Miocene), although the latter might be slightly older than the former (ca. 16 Ma: Y. Sawada et al., unpublished data).

Because of its specialized dental morphology, Harrison (1986) considered that Nyanzapithecus belonged to the Oreopithecidae. Other researchers followed this interpretation (Kunimatsu, 1992b, 1997; McCrossin, 1992). However, while Oreopithecus bambolii from the Late Miocene of Europe shows a number of suspensory adaptations as do the extant hominoids (Harrison and Rook, 1997), there is very little evidence for suspensory locomotion among the East African Early/Middle Miocene catarrhines (Rose, 1993). The postcranial morphology of Nyanzapithecus is poorly known. McCrossin (1992) assigned a proximal humeral fragment to $N$. pickfordi, but its generalized morphology does not support suspensory locomotion for Nyanzapithecus. Moreover, recent studies of Oreopithecus (Harrison and Rook, 1997; Moyà-Solà and Köhler, 1997) suggest that it may be closely related to other European Miocene hominoids such as Dryopithecus, which was also adapted to suspensory locomotion (Moyà-Solà and Köhler, 1996) and that Oreopithecus may not be closely related to the East African Nyanzapithecus. Consequently, in his recent review, Harrison (2002) attributed Nyanzapithecus to a new subfamily Nyanzapithecinae together with some other East African genera (Mabokopithecus, Rangwapithecus, and Turkanap- ithecus), and placed the new subfamily in the family Proconsulidae within the superfamily Proconsuloidea. Such terms as Proconsuloidea and Proconsulidae are convenient for mentioning those primitive African Miocene catarrhines whose hominoid status is uncertain. However, we hesitate to use these terms in this article.

Although there is a debate about the presence or absence of a tail in Proconsul (Ward C.V. et al., 1991, 1999; Harrison, 1998), it is most probable that it had already lost it (Nakatsukasa et al., 2004). Loss of the tail pushes the balance toward the interpretation that Proconsul is a member of the Hominoidea. Nyanzapithecus and its relatives could also have passed over to the side of the Hominoidea, but the available material of this group is still poor and it is difficult to determine their phylogenetic position with certainty. Therefore, we retain them as superfamily indeterminate, and for convenience use the informal term 'nyanzapithecine' for this group.

Genus Limnopithecus Hopwood, 1933

Species Limnopithecus indeterminate

Synonymy. 1991-Kalepithecus cf. songhorensis Hill et al., 72 , Figure 3b.

Material. I1/ Bar 90'98 (left); P4/ Bar 1139'99 (left); M1/ Bar 294'02 (right); M2/ Bar 218'02 (right); M2/ Bar 2176'01 (right); M2/ Bar 192'02 (left); M2/ Bar 773'02 (left); M2/ Bar 2000'02 (left); M2/ Bar 775'02 (right); M3/ lacking distobuccal corner Bar 2095'01a (right); M3/ Bar 36'02 (left); M3/ Bar 772'02 (left); dP4/ Bar 1486'01 (right); dP4/ Bar 1009'99 (right); c/1 Bar 765'02 (left); p/4 Bar 189'02 (right); p/4 Bar 2001'02 (right); m/ 1 Bar 790'02 (left); mandible with $\mathrm{m} / 2-\mathrm{m} / 3$ Bar 216'02 (right); m/3 Bar 1115'99 (right); dc/1 Bar 1230'99 (left) plus KNM-TH 18689 M2/ (left) (Appendix 2).

Bar 1116'99 and Bar 1117'99, both of which are shown in Figure 6, may be upper deciduous canines of Limnopithecus sp. (Appendix 2).

\section{Description}

\section{Upper dentition}

Bar 90'98 is an isolated left upper central incisor (Figure 6-1) measuring $4.0 \mathrm{~mm}$ mesiodistally by $3.3 \mathrm{~mm}$ labiolingually and $4.3 \mathrm{~mm}$ high. It appears to be a permanent tooth judging by the robustness of the root. In lingual aspect the crown is spatulate with a barely perceptible basal swelling merging into the lingual cingulum. The latter structure is sharp-edged and is continuous with the mesial and distal ridges. The distal margin of the crown is curved mesially from the cervix to the cutting edge which is at right angles to the long axis of the root. The labial surface of the crown is smooth.

The left P4/ (Bar 1139'99) is short and broad (Figure 6-2), with a wide distal cingulum which fades out before reaching the lingual side of the protocone. There is a prominent crest joining the buccal and lingual cusps together, and a short mesial crest descending from the apex of the protocone obliquely towards the centre line of the tooth where it closes off a short mesial fovea. The distal fovea is much more extensive than the mesial one. At the mesiobuccal corner of 


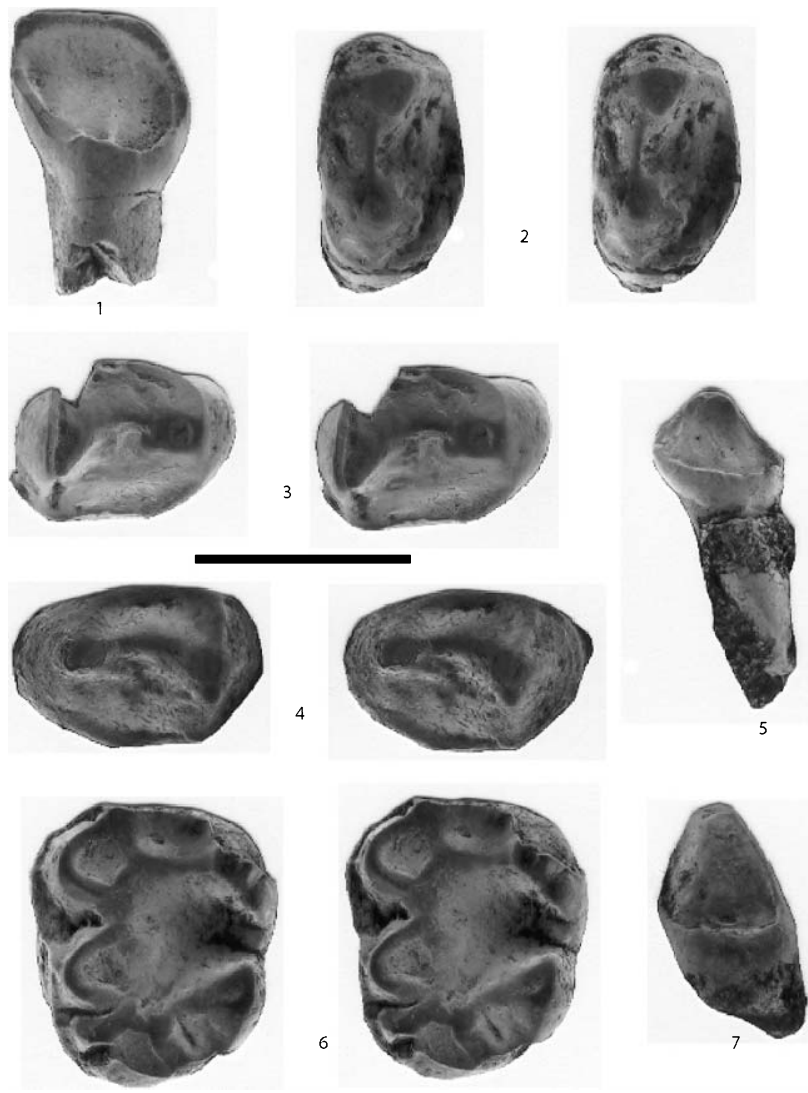

Figure 6. Limnopithecus sp. (1-2, 5-7) and Simiolus cheptumoae nov. sp. (3-4) from Kipsaraman, Tugen Hills, Kenya (SEM images) with length and breadth measurements (in $\mathrm{mm}$ ) (Scale bar $5 \mathrm{~mm}$ ). (1) Bar 90'98, left I1/, (4.1 × 3.3) lingual view; (2) Bar 1139'99, left P4/, $(3.6 \times 6.1)$ stereo occlusal view (mesial is to left and buccal is to top of image); (3) Bar 1004'99, right P4/, $(3.7 \times 5.8)$ stereo occlusal view; (4) Bar 1134'99, left P4/, $(3.8 \times 6.1)$ stereo occlusal view; (5) Bar 1116 '99, deciduous upper canine, (no measurements available) indeterminate small ape, lingual view; (6) Bar 1115'99, left $\mathrm{m} / 3$, $(6.8 \times 5.9)$ stereo occlusal view; (7) Bar 1117'99, deciduous upper canine, (no measurements available) indeterminate small ape, lingual view.

the tooth there is a small style.

The M1/ from Kipsaraman (Bar 294'02, Figure 7-9) is lightly worn with dentine showing at the tips of all four cusps. The protocone is joined to the paracone and metacone by continuous crests, but the two buccal cusps are not joined by crests. The hypocone is as large as the metacone, but is smaller than the protocone. The two buccal cusps are closer to each other than either is to the protocone, the trigon thereby enclosing a buccolingually wide, but mesiodistally short trigon basin. There is a strong lingual cingulum which extends from the mesial one as far distally as the hypocone where it almost reaches its apex. The cingulum is so broad that it places the protocone in a much more central position in the crown than it is in many hominoids, including other taxa with well-developed cingula such as Proconsul. There is a buccal cingulum on the paracone which extends to the metacone where it fades out. The mesial cingulum is well developed and there is a centrally positioned tubercle which is joined to the crest that runs mesially from the protocone. The distal cingulum is weak, but closes off a small, restricted fovea.

There are six new M2/s of Limnopithecus from Kipsaraman (Bar 218'02, Figure 7-1; Bar 2176'01, Figure 7-3; Bar 192'02, Figure 7-2; Bar 773'02, Figure 7-6; Bar 2000'02, Figure 7-5; Bar 775'02, Figure 7-4). Bar 2000'02 is the best preserved and serves for the description. The crown has a single lingual root and two buccal ones. In basic morphology the teeth are similar to the $\mathrm{M} 1 /$ described above but they are larger. The only significant difference consists of the presence of a lingually directed crest entering the distal fovea from the metacone which ends abruptly in the midline, which can be strong, as in Bar 2176'01, or weak, as in Bar 2000 '02. The buccal cingulum is weaker than in the M1/. In one specimen (Bar 2176'01) there is a small tubercle at the mesiolingual corner of the tooth growing out of the cingulum but other specimens lack this structure. The hypocone is not reduced, indeed it is almost as large as the protocone.

Two M3/s in the sample (Bar 36'02, Figure 7-8; Bar 772 '02, Figure 7-7) differ from the M2/s described above by being smaller and having greatly reduced metacones, as a consequence of which, the occlusal outline is almost triangular rather than quadrangular. In Bar 772'02 the metacone is so reduced that it forms a small tubercle rather than a separate cusp. The hypocone is as large as the paracone, but smaller than the protocone. The lingual cingulum is broad and reaches round the distal aspect of the hypocone and is confluent mesially with the wide mesial cingulum. There is a low buccal cingulum beneath the buccal notch between the paracone and metacone. The distal fovea in Bar 772'02 is quite large. There are three roots, a large lingual one and two slender buccal ones.

Two deciduous upper canines (Bar 1116'99 and Bar 1117'99) are tentatively attributed to Limnopithecus sp. The crowns are low and conical with a prominent lingual cingulum (Figure 6-5, 7). The lingual surface is concave and the root is elongated but smaller in diameter than the crown (Figure 6-5).

\section{Lower dentition}

A lower canine (Bar 765'02, Figure 8-2, 3, 4) is high with a sharp apex. The crown is longer and wider than the root indicating that it is probably from a male individual. The crown is slightly canted laterally on the root. From the apex of the crown there are two fine crests that descend towards cervix, one mesiolingually that terminates in a small, low tubercle, the other distally. The tooth has no cingula, although the lingual tubercle has two extremely fine but short crests running mesially and distally.

Two fragmentary $\mathrm{p} / 4 \mathrm{~s}$ from Kipsaraman are attributed to Limnopithecus (Bar 189'02 and Bar 2001'02). These teeth are buccolingually broader $(3.9 \mathrm{~mm}$ and $4.0 \mathrm{~mm}$ respectively) than the corresponding tooth of Simiolus cheptumoae (3.3-3.6 mm, $n=3$ ) (see Figure 4).

The first lower molar (Bar 790'02, Figure 8-1) is worn to the stage where there is continuous dentine exposed between the protoconid and hypoconid and small dentine lakes are present on the hypoconulid, entoconid, and metaconid. There is a continuous buccal cingulum extending from the 

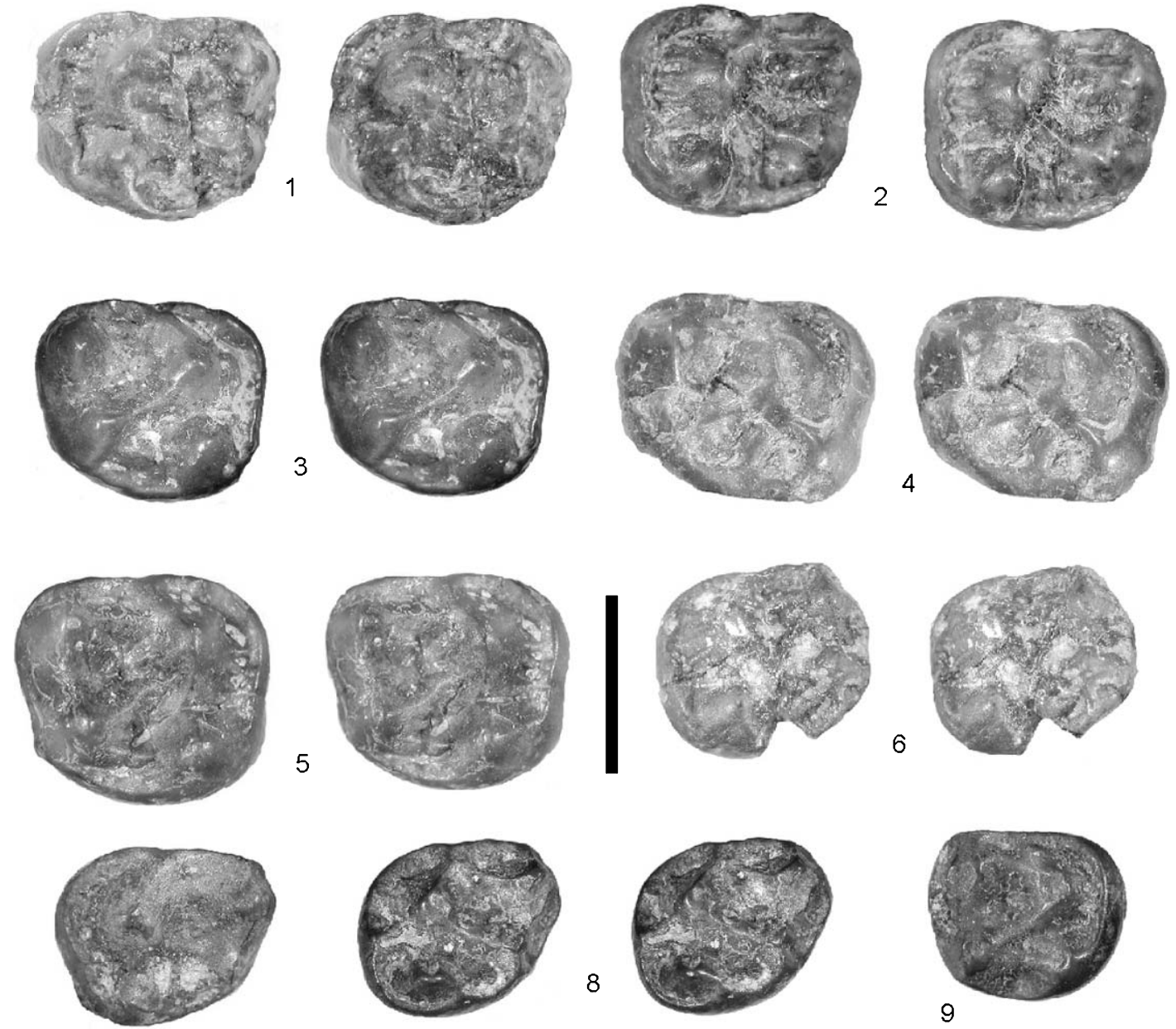

Figure 7. Limnopithecus sp. from Kipsaraman, Tugen Hills, Kenya with length/breadth measurements (in mm) (Scale bar $5 \mathrm{~mm})$. (1) Bar 218’02, left M2/, (5.4 × 6.4) stereo occlusal view; (2) Bar 192’02, left M2/, (5.8 × 6.7) stereo occlusal view; (3) Bar 2176’01, right M2/, (5.3 × 6.3) stereo occlusal view; (4) Bar 775'02, right M2/, (5.5 × 6.6) stereo occlusal view; (5) Bar 2000'02, right M2/, (6.2 $\times 6.9)$ stereo occlusal view; (6) Bar 773'02, left M2/, $(5.5 \times 6.4)$ stereo occlusal view; (7) Bar 772'02, left M3/, (4.9 × 6.2) occlusal view; (8) Bar 36'02, left M3/, (5.2 × 5.7) stereo occlusal view; (9) Bar 294'02, right M1/, $(4.8 \times 5.9)$ occlusal view.

mesial aspect of the protoconid to the distal end of the hypoconid where it fades into the lateral side of the hypoconulid. The main cusps are peripherally located so that the talonid basin dominates the occlusal surface. It opens lingually, low down between the metaconid and entoconid.

Bar 216'02 (Figure 8-5, 6, 7) is a mandible fragment with an acid-etched $\mathrm{m} / 2$ and $\mathrm{m} / 3$. A better preserved $\mathrm{m} / 3$ (Bar 1115'99, Figure 6-6) lacks some enamel distally. There are dentine lakes on the protoconid, hypoconid, and hypoconulid, but not on the two lingual cusps. The protoconid and metaconid are far apart which makes the mesial half of the tooth wider than its distal half. The three buccal cusps are almost in line with each other, the hypoconulid being in a more lateral position than it is in the $\mathrm{m} / 3$ of $S$. cheptumoae. The anterior fovea is restricted, whereas the talonid basin is large and dominates the occlusal surface of the crown. It opens lingually over a tiny marginal cusplet positioned low down between the metaconid and entoconid. The buccal cingulum is continuous from mesial to distal. There are two transversely oriented roots, the distal one somewhat triangular in section.

Bar 1230'99 is a left lower deciduous canine. The crown is low and the enamel appears to be thin. The mesial crest is short, extending from the apex of the crown to the mesial end of the lingual cingulum. The distal crest descends the crown towards a distal tubercle.

\section{Discussion}

The upper central incisor is one of the smallest anthropoid incisors recorded from the Miocene of Africa, being even smaller than the diminutive teeth of Dendropithecus macinnesi. The tooth is morphologically similar to that of Limnopithecus legetet from western Kenya, (Harrison, 1988) but is smaller.

The lower premolars from Kipsaraman attributed to Limnopithecus are broader than those of Simiolus cheptumoae (Figure 5). The lower molars differ from those of the latter species by having peripherally positioned main cusps sur- 


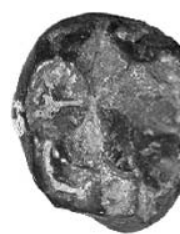

1

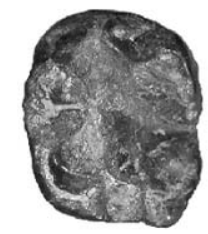

-

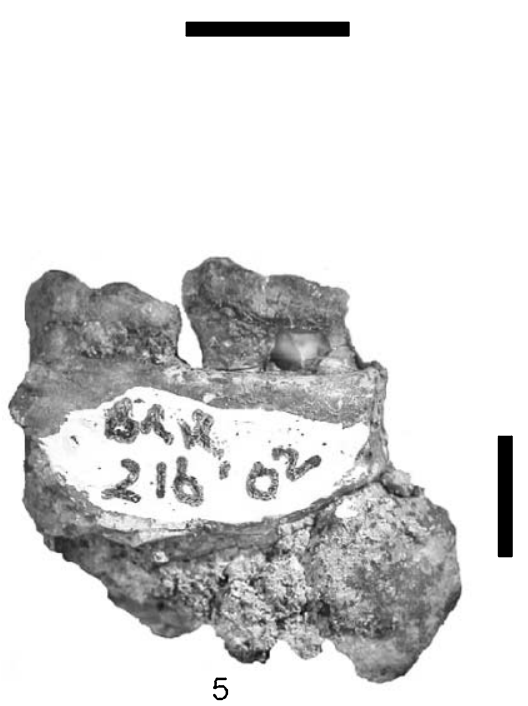

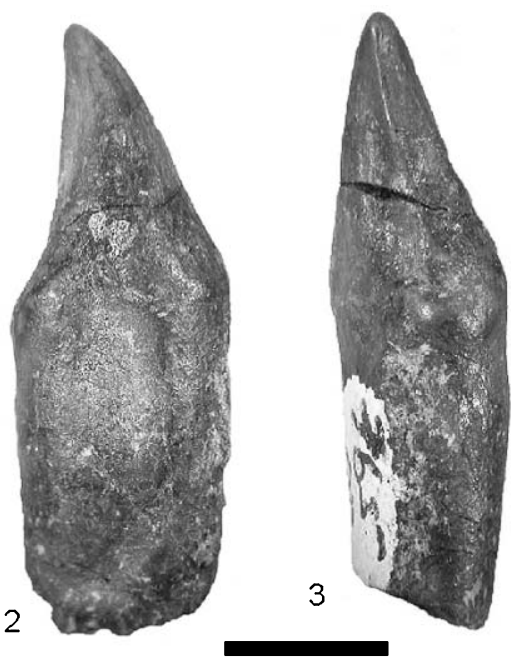
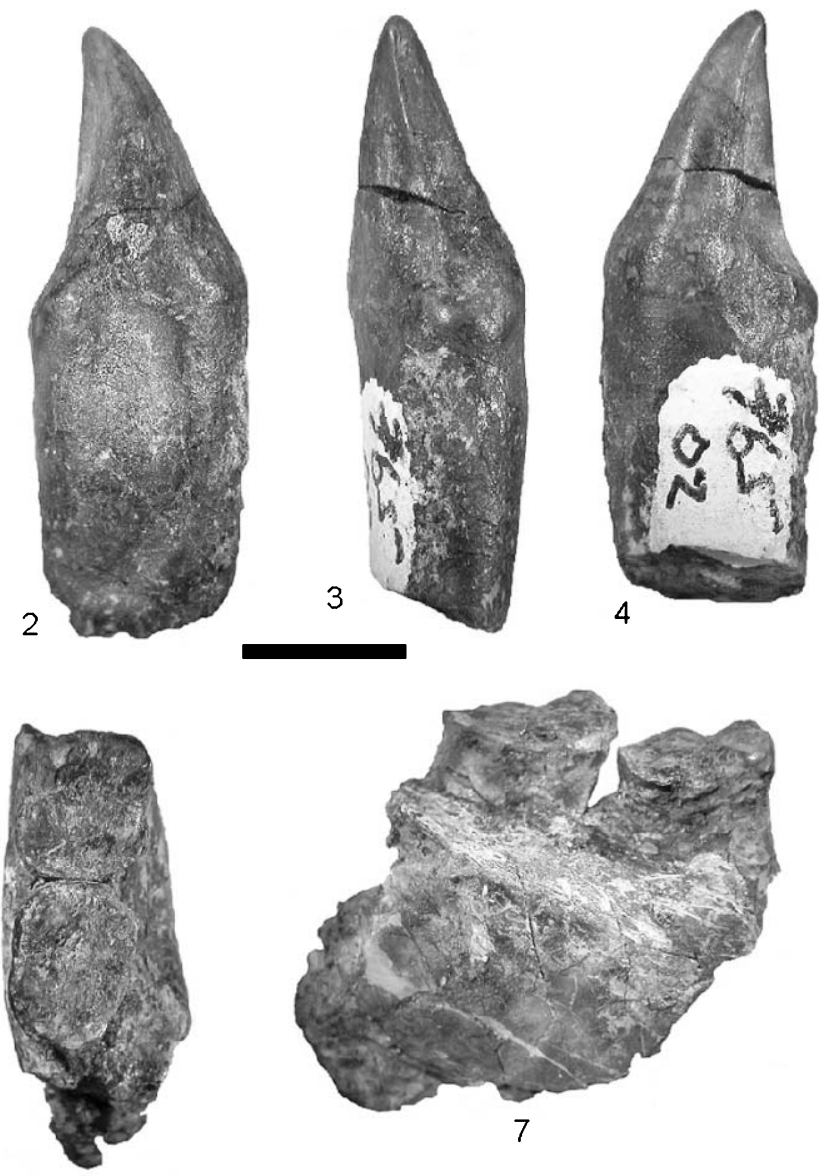

6

Figure 8. Limnopithecus sp. from Kipsaraman, Tugen Hills, Kenya with length/breadth measurements (in mm) (Scale bars $5 \mathrm{~mm})$. (1) Bar 790 '02, left $\mathrm{m} / 1,(5.7 \times 4.6)$ stereo occlusal view; (2-4) Bar 765'02, left c/1 $\mathrm{m},(7.1 \times 5.3)$ lingual, distal, and buccal views; (5-7) Bar 216'02, right mandible with $\mathrm{m} / 2-\mathrm{m} / 3(\mathrm{~m} / 3=6.8 \times 5.1)$, lingual, occlusal, and buccal views.

rounding a voluminous talonid basin, and the hypoconulid is laterally, rather than centrally, positioned.

Hill et al. (1991) described and figured an isolated, occlusally damaged, left upper molar of a small ape from Kipsaraman which they tentatively identified as an upper first molar of Kalepithecus cf. songhorensis, but comparison with the enlarged sample of small apes from the site indicates that the specimen is more likely to be an upper molar of Limnopithecus sp. The new material shows particular points of similarity to Limnopithecus from western Kenya including the relatively broad upper molars with strong development of the lingual cingulum which extends distally as far as the hypocone in some specimens, the buccally displaced lingual cusps of the upper molars especially the protocone, the restricted, fissure-like, mesial fovea in the upper molars, lower fourth premolar with two high main cusps and large distal basin, lower molars with buccal cingulum, and medially displaced protoconid and hypoconid (mesially displaced as well), among other characters. The lower fourth premolar differs markedly from that of Kalepithecus songhorensis which is broad and almost circular in occlusal outline, contrasting strongly with the much narrower and more rectangular outline of the Kipsaraman species.
The upper molars from Kipsaraman are shorter than those of Limnopithecus legetet but are about the same size as those of $L$. evansi. These teeth are very different morphologically and metrically from those of Turkanapithecus kalakolensis which is likely to be more closely related to Nyanzapithecus pickfordi than to any other Miocene East African hominoids (Harrison, 2002).

A persistent problem with Limnopithecus species is the correct determination of isolated teeth. Harrison (1988) identified material from the Koru suite of sites (Koru, Legetet, Chamtwara) as well as Rusinga and Napak as L. legetet and material from the Songhor area (Songhor, Mteitei Valley) as $L$. evansi. The differences in the upper molars are subtle, including the distal cusps of the M3/ being less well developed in $L$. evansi. The Kipsaraman M3/s also have reduced distal cusps in $\mathrm{M} 3 /$. There is significant overlap in the measurements of the teeth of the two species from western Kenya, which is one reason why the two species were considered synonymous for such a long time (Harrison, 1988). Until more complete material is found from Kipsaraman, including the premolars in association with the molars, it will remain difficult to identify to which species the above material belongs. In view of these difficulties we prefer to 
identify the Kipsaraman fossils as Limnopithecus sp. indeterminate.

Superfamily Dendropithecoidea Harrison, 2002 Family Dendropithecidae Harrison, 2002

Genus Simiolus Leakey and Leakey, 1988 (imprint 1987) Species Simiolus cheptumoae sp. nov.

Diagnosis. Simiolus species smaller than $S$. enjiessi; buccal cingulum in $\mathrm{p} / 4$ weak; mesial fovea of $\mathrm{p} / 4$ triangular; in lower molars, protoconid more mesially located than the metaconid with obliquely oriented protocristid and main cusps with poorly developed crests; metaconid apex in molars bifid; spout (lingual opening) of talonid basin lower than the rest of the basin; $\mathrm{m} / 3$ reduced.

Holotype. Bar 761'02, right mandible with $\mathrm{p} / 4-\mathrm{m} / 1$.

Type locality. Kipsaraman main site.

Location and age. Kipsaraman Main (GPS WGS 84 datum,
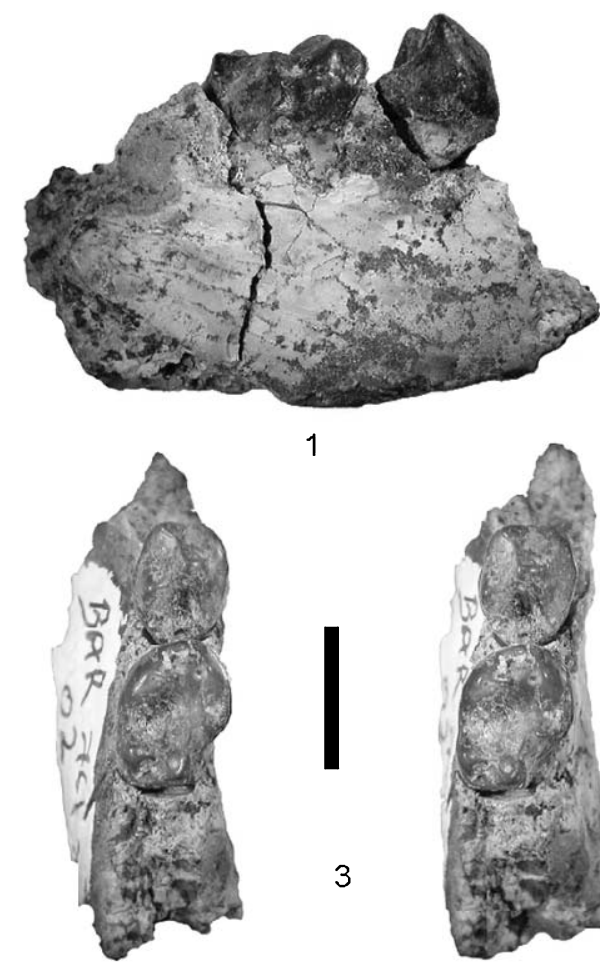

1

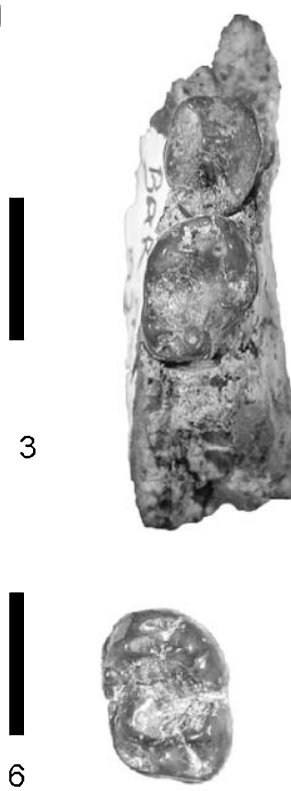

0044'53.7" N: 3549'33.6" E); Muruyur Formation, Middle Miocene, ca. 14.5 Ma, Faunal Set P IIIb.

Etymology. Named for Mrs Stella Cheptumo who found the holotype.

Referred material. dC1/ Bar 1488'01 (left); dC1/ Bar 230 '02 (right); dC1/ Bar 231'02 (left); dC1/ Bar 37'02 (left); P4/ Bar 1004'99 (right); P4/ Bar 1134'99 (left); p/4 Bar 23'98 (right); p/4 Bar 764'02 (left); m/1 Bar 2087'01 (left); m/3 Bar 824'02 (right) (Appendix 2).

\section{Description}

Deciduous upper dentition

There are four very small, low crowned upper canines from Kipsaraman (Bar 1488'01, Bar 230'02, Bar 231'02 which are represented by crowns only, and Bar 37'02 which has its root as well). They are similar to each other in crown morphology and the root in the specimen where it is completely preserved is small (Figure 9-8). We take these

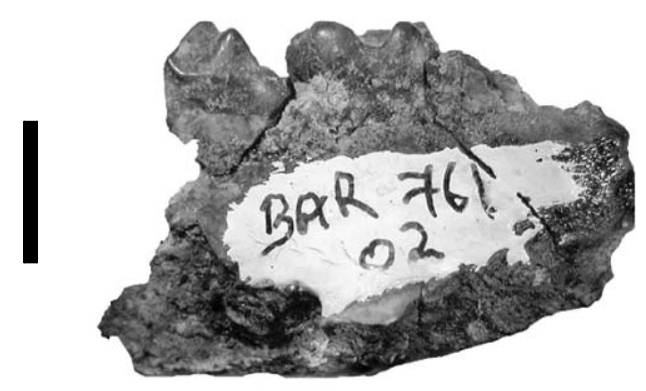

2

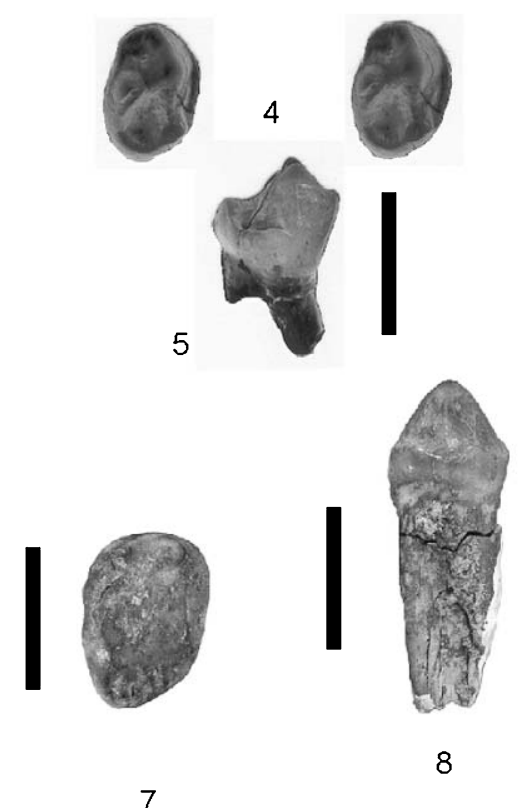

Figure 9. Simiolus cheptumoae sp. nov. from Kipsaraman, Tugen Hills, Kenya with length/breadth measurements (in mm) (4 and 5 are SEM images) (Scale bars $5 \mathrm{~mm})$. (1-3) Bar 761'02, holotype mandible $(\mathrm{p} / 4=4.6 \times 3.5 ; \mathrm{m} / 1=5.9 \times 4.3)$, buccal, lingual and stereo occlusal views; $(4$ and 5) Bar 23'98, right p/4, (4.3 × 3.3) stereo occlusal and buccal views; (6) Bar 2087'01, left $\mathrm{m} / 1,(6.0 \times 4.4)$ stereo occlusal view; (7) Bar $824^{\prime} 02$, right $\mathrm{m} / 3$ with enamel etched off, $(5.9 \times 4.4)$ occlusal view; $(8)$ Bar 37’02, upper deciduous canine, $(4.3 \times 3.6)$ lingual view. 
canines to represent deciduous teeth. The crowns are lower than the mesiodistal diameter. Lingually there is a weak cingulum and mesially there is a groove indicating that they are probably upper teeth. Buccally, the enamel extends slightly more rootwards than it does mesially or distally.

\section{Permanent upper dentition}

The P4/s (Bar 1004'99, Figure 6-3; Bar 1134'99, Figure 6-4) have widely spaced main cusps, with the lingual one lower than the buccal one and positioned closer to the midline of the crown than the buccal cusp which is close to the margin of the tooth. A transverse crest connects the buccal and lingual cusps, dividing the occlusal surface into mesial and distal foveae. From the apex of the lingual cusps a short crest reaches buccally and slightly distally, but does not extend beyond the midline. The mesial fovea is buccolingually wide, but mesiodistally short. The distal fovea is mesiodistally longer than the mesial one, and its surface is inclined distally until it comes up against the distal cingulum. The mesial and distal styles on the buccal cusp are low and weakly expressed.

\section{Permanent lower dentition}

Bar 761'02 is the holotype right mandible with $\mathrm{p} / 4-\mathrm{m} / 1$ (Figure 9-1, 2, 3). The mandible is fragmentary and does not preserve the ventral margin. The $\mathrm{p} / 4$ is unworn and is slightly below the level of the $\mathrm{m} / 1$. The buccal cusp dominates the crown, the lingual one being smaller than it but almost the same height. The mesial crest of the buccal cusp reaches the mesiolingual corner of the tooth where it ends in a small tubercle, from which a low, weak cingulum departs distally. The distal crest of the buccal cusp reaches the distobuccal corner of the crown. The lingual cusp has mesial and distal crests which are short, and it is joined to the buccal cusp transversely by a higher oblique crest directed mesiobuccally. The mesial fovea is small, triangular, and opens lingually, whereas the distal fovea is wide and located closer to the cervix level. Buccally the enamel extends further rootwards than it does mesially, lingually, or distally (Figure 10).

The first molar in the mandible lacks part of the hypoconid. It is in medium wear and the enamel is smooth. In occlusal view the lingual cusps are located close to the lingual margin of the crown, but the buccal cusps are posi-

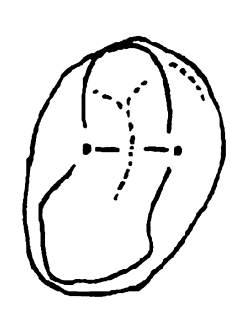

1
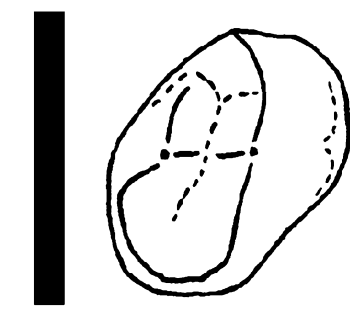

2
Figure 10. Comparison between $\mathrm{p} / 4 \mathrm{~s}$ of (1) Simiolus enjiessi and (2) $S$. cheptumoae sp. nov. The two main cusps of the teeth are aligned horizontally in both specimens ( $\mathrm{p} / 4$ of $S$. enjiessi is reversed for ease of comparison). Scale bar $5 \mathrm{~mm}$. tioned slightly more than half-way towards the midline from the buccal margin. They thus have a very interior location and flaring buccal walls. The protoconid is more mesially located than the metaconid while the hypoconid is more mesially positioned than the entoconid. The hypoconulid is almost in the centre line of the crown. There is a buccal cingulum between the protoconid and hypoconid. The mesial fovea is small, the talonid basin is large and opens lingually very low between the metaconid and entoconid. The distal fovea is small.

Bar 23'98 is an unworn, isolated right $\mathrm{p} / 4$ with part of the root (Figure 9-4, 5). The crown consists of two main cusps, the lingual one slightly offset to the rear of the labial one, but with the two cusps having almost the same height. The buccal cusp has a mesial crest that descends to join a cingular cusp in the midline of the tooth. It also has a distal crest that descends to join a distal cusplet on the distobuccal corner of the tooth, from which departs a low but generally sharp cingulum which terminates mesiobuccally at the point where an extremely diminutive cingulum descends from the mesial accessory cusplet towards the root. A better developed distal cingulum runs from the distal accessory cusplet towards the base of the lingual main cusp where it merges with the distal crest of this cusp, thereby closing off a distal fovea. There is no sign of a lingual cingulum. In occlusal view the mesial portion of the crown is appreciably narrower than the distal portion, but the crown is widest in the axis of the two main cusps. There are two roots which are fused for some distance below cervix. The mesiodistal length is $4.3 \mathrm{~mm}$ and its buccolingual breadth is $3.3 \mathrm{~mm}$. The height of the main cusp measured on the buccal side is $4.1 \mathrm{~mm}$. This is an exceedingly small catarrhine $\mathrm{p} / 4$, being only slightly larger than those of the diminutive colobine Microcolobus tugenensis Benefit and Pickford (1986) from the Late Miocene deposits at Ngerngerwa, Tugen Hills, Kenya. The crown is about the same length as $\mathrm{p} / 4 \mathrm{~s}$ of $M$. clarki (Fleagle and Simons, 1978) and M. leakeyorum (Harrison, 1989) but it is narrower than the premolars of either of these two species.

Bar 764'02 is a left $\mathrm{p} / 4$ that is similar in morphology to Bar 23'98 but is marginally larger $(4.7 \times 3.6)$ and the buccal cingulum is slightly weaker.

Bar 2087'01 is a lightly worn left $\mathrm{m} / 1$ (Figure 9-6). There are small wear facets on all the main cusps, but they are not deeply worn, forming small flat surfaces sloping at various angles to each other. There is a small mesial interstitial facet where the tooth contacted the $\mathrm{p} / 4$ and a larger one distally where it abraded against the $\mathrm{m} / 2$. The main cusps are disposed in the same pattern as that observed in Bar 761' 02. There are two transversely oriented roots. A notable feature is the presence of bifurcation of the apex of the metaconid almost as in Kogolepithecus morotoensis (Pickford et al., 2003), but unlike Kogolepithecus the entoconid of Simiolus lower molars shows no sign of subdivision.

Bar 824'02 is a worn right $\mathrm{m} / 3$ (Figure 9-7) in which the enamel has been etched away in places. The talonid basin is extensive. There are two roots.

\section{Discussion}

Simiolus cheptumoae differs from $S$. enjiessi (Leakey and Leakey, 1987) in a number of features. In its lower $\mathrm{p} / 4 \mathrm{~s}$, the 
mesial fovea is more triangular and opens more lingually, with the metaconid being smaller and positioned more distally relative to the protoconid (Figure 10). In S. enjiessi, the mesial fovea of the lower $\mathrm{p} / 4$ is more square and opens superiorly, and the protoconid and metaconid are more transversely aligned to each other. The crowns of $\mathrm{p} / 4 \mathrm{~s}$ are narrower in $S$. cheptumoae (BL/MD ratio: 76.5\%; range $76.1-76.7 \% ; n=3)$ than in S. enjiessi $(83.3 \%, n=1)$ (Figure 4). The lower molars of $S$. cheptumoae are similar to those of $S$. enjiessi in having elongated crowns, sharp cusps, narrow but marked occlusal crests, and the metaconid more distally positioned than the protoconid. In addition, the $\mathrm{m} / 1$ crowns of $S$. cheptumoae are relatively more elongated than in $S$. enjiessi (Figure 5) as is the case for $\mathrm{p} / 4 \mathrm{~s}$. Its teeth are generally smaller than those of $S$. enjiessi although in some measurements there is overlap in the range of variation of the two species. We think that these differences are not so great as to warrant separation of the two samples at the generic level. Hence, we assign the Kipsaraman specimens to a new species within the genus Simiolus.

In Kogolepithecus morotoensis, the apex of the metaconid in the lower molars is subdivided into two cusplets, as in Simiolus cheptumoae, and some individuals of Limnopithecus legetet possess incipient subdivision of this cusp.

Harrison $(1986,1988,1989)$ provided details which differentiate the various species of small apes from the Early and Middle Miocene of East Africa. The features serve to distinguish the new species of Simiolus from these other small 'apes'. S. cheptumoae can be distinguished from the majority of these small 'apes' in having elongated (narrow) lower $\mathrm{p} / 4 \mathrm{~s}$ and $\mathrm{m} / 1 \mathrm{~s}$ (Figure 4, Figure 5). Nyanzapithecus is also characterized by the elongation of the premolars and molars, but this genus is distinguished by its inflated, rounded and conical cusps, poorly developed occlusal crests, and strongly restricted occlusal foveae and basins (Harrison, 1982, 1986, 2002; Kunimatsu, 1992a, 1997). S. cheptumoae is generally larger than the two species of Micropithecus (M. clarki and $M$. leakeyorum) even though there is some overlap in a few of the dental measurements. The lower molars of $S$. cheptumoae are narrower relative to their length than those of $M$. clarki and M. leakeyorum and the offset between the buccal and lingual cusps is greater than it is in Micropithecus. S. cheptumoae is appreciably smaller than Dendropithecus macinnesi and $K$. morotoensis from which it differs in a number of morphological details, in particular the more restricted talonid basin (wide and long in Dendropithecus and Kogolepithecus) and the more peripheralized buccal cusps in Dendropithecus. It addition it differs from Kogolepithecus (Pickford et al., 2003) by having simple entoconids with no sign of the bifurcation that typifies the entoconid of the latter genus. Its molars are smaller than those of Limnopithecus legetet but are about the same size as those of $L$. evansi. The $\mathrm{p} / 4$, in particular is more ovoid in occlusal outline than the almost circular outline in L. evansi. It differs markedly morphologically and metrically from Turkanapithecus kalakolensis, especially in the obliquity of the cusp pairs.

Fort Ternan material attributed to Simiolus sp. by Harrison is probably not this genus, judging from the new material available from Kipsaraman. The lower canine, $p / 3$, and $p / 4$ in the two samples are different in shape and proportions, and the detailed morphology of the lower molar crowns is divergent. Harrison (1992) did not illustrate the fossils but judging from his descriptions the premolars differ from those of $S$. enjiessi by being more elongated and narrower. He considered that the Fort Ternan specimen was a female, whereas the type specimen from Kalodirr may represent a male and this may account for some of the morphological and metric differences. The $\mathrm{p} / 3$ in the type specimen is described as being high crowned and sectorial with enamel extending onto the mesial root (Leakey and Leakey, 1987). The Fort Ternan specimen has some similarities to $M$. leakeyorum from Maboko, except for the morphology of the $\mathrm{p} / 3$ which differs from it by the lesser development of the honing facet (the mesiobuccal part of the tooth). Because of the possible presence of sexual dimorphism in the $\mathrm{p} / 3 \mathrm{~s}$ of these small 'apes' they are dificult to interpret when the samples are so small.

\section{Superfamily Hominoidea Gray, 1825 \\ Family incertae sedis}

Subfamily Kenyapithecinae Andrews, 1992

Genus Kenyapithecus Leakey, 1962 (imprint 1961)

Species Kenyapithecus africanus (Le Gros Clark and Leakey, 1951)

Suprageneric nomenclature. Kelley et al. (2002), Begun (2002), and Ward and Duren (2002) credited the subfamily Kenyapithecinae to Leakey (1961). This is erroneous. The earliest use of a suprageneric name that we are aware of, for a group with Kenyapithecus as the type genus, was published by Andrews (1992) who erected the tribe Kenyapithecini.

Synonymy. 1995-Kenyapithecus Brown et al., 69. 1999Equatorius africanus Ward et al., 1382-1386, Figures 25. 2000_Griphopithecus Begun, 2375a. 2000—Kenyapithecus Benefit and McCrossin, 2375a. 2000-Equatorius Kelley et al., 2375a. 2000-Equatorius Nakatsukasa et al., 92. 2002-Equatorius africanus Kelley et al., 39-62, Figures 2-7.

Stratigraphy and age of referred material. Muruyur Formation, Middle Miocene, ca. 14.5 Ma, Faunal Set P IIIb. Specimen Bar 212'99 is from the type area of the Muruyur Formation at Cheparawa, the other material is from Kipsaraman.

Material. ?M1/ Bar 1237'99 (left); ?M2/ Bar 214'02 (left); c/1 Bar 212'99 (right); plus the fossils described by Kelley et al. (2002) (Appendix 3).

\section{Description \\ Upper dentition}

Bar $1237^{\prime} 99$ is a left upper molar, probably M1/, in light wear with the two lingual cusps showing dentine. The trigon is an equilateral triangle and the trigon basin is reduced by the voluminous nature of the main cusps. The hypocone is as large as the protocone. The mesial cingulum is wide and wraps round the mesial edge of the protocone. The distal cingulum is broad where it joins the crest that descends from 
the apex of the metacone. The buccal notch is not deep which makes the base of the crown quite substantial (from cervix to base of the notch measures $3.3 \mathrm{~mm}$ ). Beneath the buccal notch there is a deep but narrow groove bordered mesially by a low enamel fold. The mesial style of the paracone and the distal style of the metacone are clearly formed but small.

A lightly worn upper molar (Bar 214'02) is probably an M2/ (Figure 11-8). The crown is almost square in occlusal outline. The four cusps are voluminous, the occlusal enamel coarsely wrinkled and the lingual cingulum is small mesially and fades out before reaching the hypocone. The swollen appearance of the main cusps (Figure 12) has the effect of reducing the size of the trigon basin. The protocone is the largest cusp and its apex is located closer to the midline of the tooth than are the other cusps. The protocone, paracone and metacone form an equilateral triangle, whereas the hypocone is separated from the trigon by a continuous groove. It is slightly more lingually positioned than the protocone. The mesial crest of the protocone is rounded and ends high up where a tubercle projects upwards from the mesial cingulum. The distal crest of the protocone is lower and curves sharply towards the metacone from which it is separated by a narrow groove. The distal cingulum is sharpedged and closes off a distal fovea. The buccal notch is reduced in height, making for a deep base for the crown (cervix to base of notch is $4.7 \mathrm{~mm}$ ).

\section{Lower dentition}

A right lower canine from Cheparawa, in the type area of the Muruyur Formation, $10 \mathrm{~km}$ north of Kipsaraman, is similar in size to the canines of Proconsul nyanzae/heseloni in specimen KNM-RU 7290. The crown leans slightly outwards from the axis of the root. The apex is pointed and possesses two crests, one directed mesially where it joins the buccal end of the lingual cingulum. The second crest descends from the apex distolingually and is rounded rather than sharp. Just to the buccal side of the ridge there is a vertical groove in the surface of the enamel which faces distally. Below this groove there is a prominent distal tubercle which has a wear facet that curves from vertical mesially to horizontal distally. The enamel extends rootwards further on the buccal side than it does elsewhere on the tooth. Mesially the cervix is V-shaped immediately beneath the mesial tubercle.

\section{Discussion}

The upper molar Bar 214'02 and the lower canine from Cheparawa are compatible in size and morphology with other fossils assigned to Kenyapithecus africanus, not only from Kipsaraman, but also from Maboko and Majiwa (Pickford, 1982).

Ward S. et al. (1999) erected the genus Equatorius for the species $K$. africanus, but in doing so they incorrectly attributed the species africanus to Leakey (1961); it was named by Le Gros Clark and Leakey (1951). Kelley et al. (2002) provided additional details about the dentognathic remains and Sherwood et al. (2002) published preliminary descriptions of the postcranial fossils attributed to the species. The creation of the genus Equatorius was criticized by Begun (2000) and Benefit and McCrossin (2000), as well as by
Nakatsukasa et al. (2000) and Ishida et al. (2000) who consider that its creators used a mélange of fossils from Maboko, Kipsaraman, and Nachola in the diagnosis and description. The Nachola material was named Nacholapithecus kerioi by Ishida et al. (1999) in a publication that predated the erection of Equatorius.

\section{Subfamily incertae sedis \\ Genus Ugandapithecus Senut, Pickford, Gommery, and Kunimatsu, 2000 \\ Species Ugandapithecus gitongai sp. nov.}

Synonymy. 1988 - Large ape Pickford, 389. 1991—Proconsul cf. major Hill et al., 71-72, Figure 3a.

Diagnosis. Species of Ugandapithecus plotting within the upper part and beyond the range of metric variation of $U$. major but with higher cusp relief than in this species, cusps more blocky in appearance, lingual cingulum in upper molars extremely broad, having the tendency to form an accessory cusplet at the mesiolingual corner of the crown and to extend onto the mesial half of the hypocone; protocone more buccally positioned than in $U$. major; buccal cingulum present in upper molars, even if sometimes weak; trigon basin of upper molars deeper and more voluminous than in U. major; enamel more coarsely wrinkled and thus fewer wrinkles on occlusal surface than in $U$. major (visible mainly in unworn or slightly worn specimens); distal fovea of upper molars deeper than in $U$. major; M1/ slightly larger than in $U$. major; $\mathrm{m} / 3$ with metaconid subdivided into two cusplets, separated from entoconid by an additional small cusplet; accessory cusplet between entoconid and hypoconulid; hypoconulid has tendency to form accessory cusplets lingually and mesially; cingulum on buccal and distal aspects of hypoconulid, mesial fovea reduced in buccolingual breadth.

Holotype. Bar 737'02, left M1/ + Bar 210'02, left M2/, representing the same individual on the basis of the form and size of the interstitial contact facets between the two teeth and their close proximity at the time of discovery (Appen$\operatorname{dix} 4)$.

Type locality. Kipsaraman Main (GPS WGS 84 datum, 0044'53.7" N: 3549'33.6" E).

Stratigraphy and age. Muruyur Formation, Middle Miocene, ca. 14.5 Ma, Faunal Set P IIIb.

Etymology. Named in honour of Mr Eustace Gitonga, Founding Director of the Community Museums of Kenya.

Referred material. C1/f Bar 1473'01 (left); M1/ Bar 215'02 (left); M2/ Bar 35'02 (right); dc/1 Bar 282'02 (left); c/1 Bar 2201'01 (right); m/2 KNM TH 18690 (right); m/3 Bar 213'02 (right) (Appendix 4).

\section{Description}

\section{Permanent upper dentition}

Bar 1473'01 is a left upper canine of a large hominoid (Figure 11-1). It is low crowned considering the dimensions of the root, the diameter of which is greater than that of the crown. In overall aspect this tooth appears to belong to a 

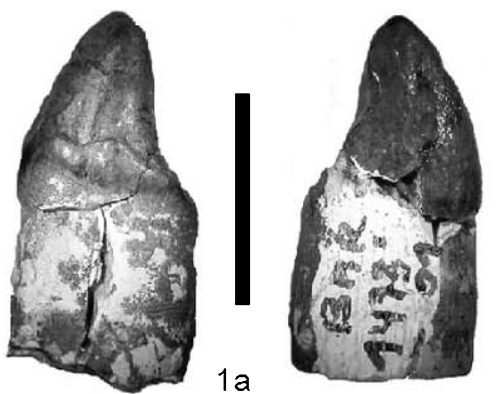

$1 b$

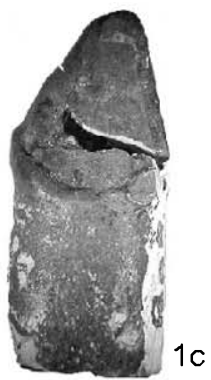

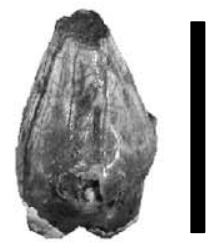

$2 a$

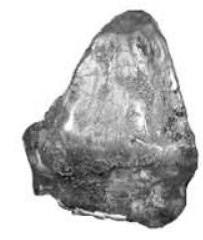

$2 b$

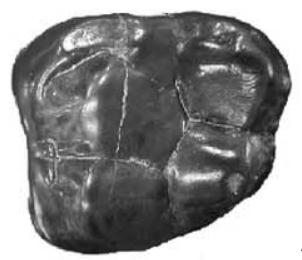

$3 a$
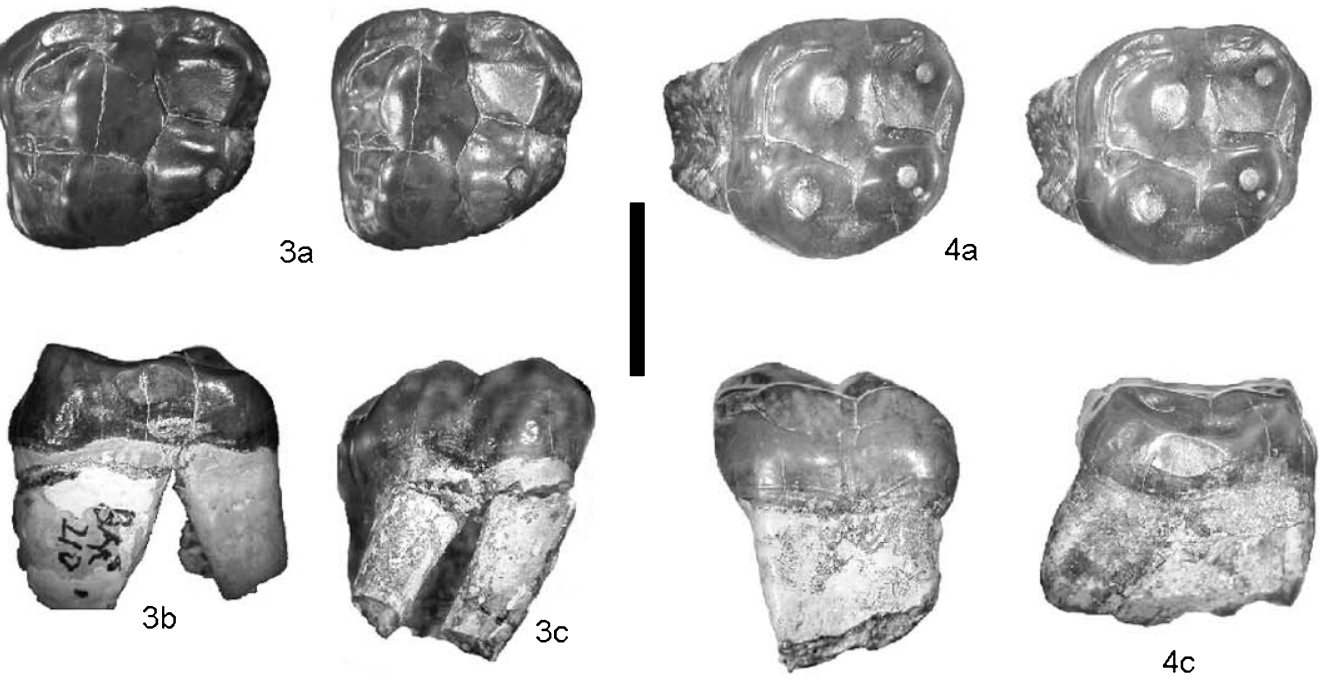

$4 \mathrm{~b}$
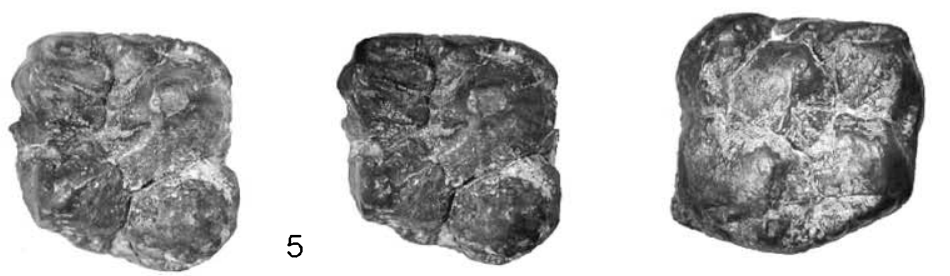

6
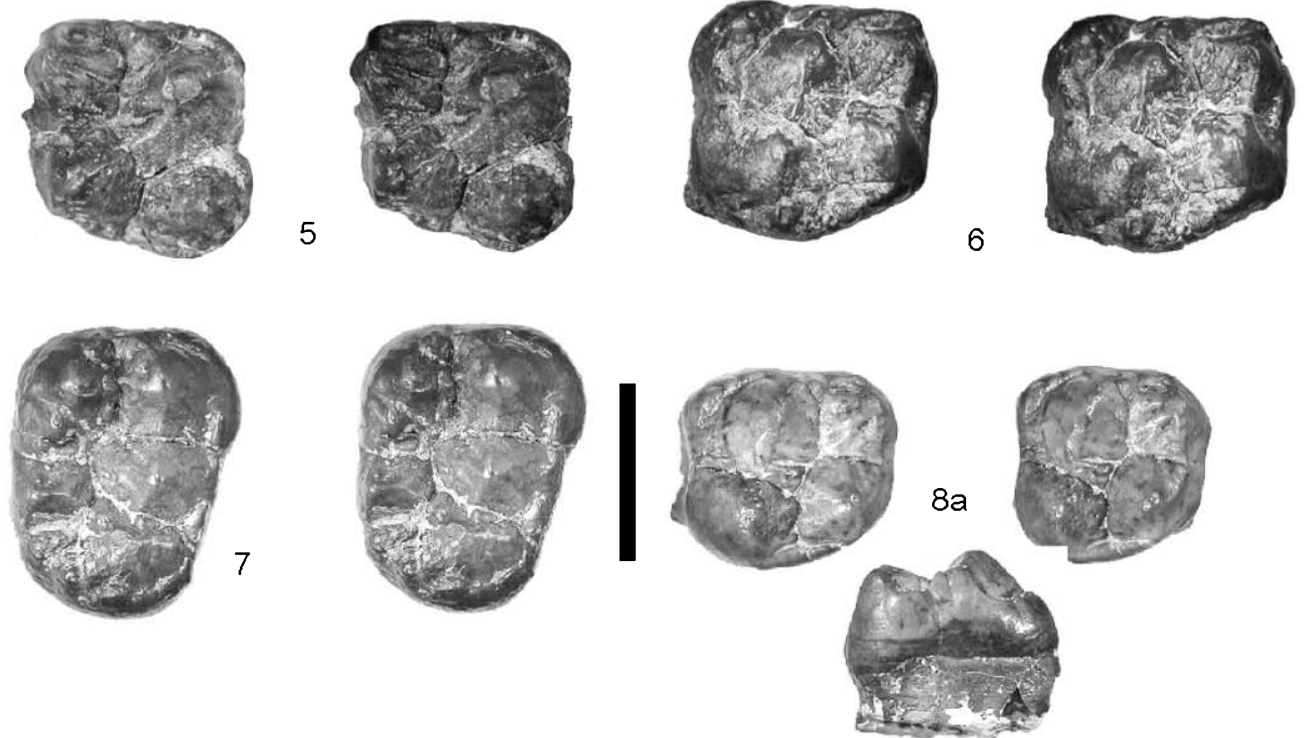

$8 \mathrm{~b}$

Figure 11. Ugandapithecus gitongai (1-7) and Kenyapithecus africanus (8) from Kipsaraman, Tugen Hills, Kenya with length/breadth measurements (in $\mathrm{mm}$ ) (Scale bars $10 \mathrm{~mm})$. (1) Bar 1473'01, left C1/f, $(9.2 \times 7.6)$ (a) mesiolingual, (b) distolabial, (c) distolingual views; (2) Bar 282'02, deciduous left lower canine, $(8 \times 7.1)$ (a) distal, (b) lingual views; (3) Bar 210'02, left M2/, part of holotype, $(14.2 \times 16.7)($ a) stereo occlusal, (b) mesial, (c) buccal views; (4) Bar 737'02, left M1/, part of holotype, (12.1 × 14.3) (a) stereo occlusal, (b) lingual, (c) distal views; (5) Bar 35'02, right M2/, (13.3 × 12.4) stereo occlusal view; (6) Bar 215'02, left M1/, (12.6 × 13.2) stereo occlusal view; (7) Bar 213'02, right m/3, $(16.1 \times 12.7)$ stereo occlusal view; (8) Bar 214'02, left M2/, $(11.7 \times 12.1)$ (a) stereo occlusal, (b) mesial views. 


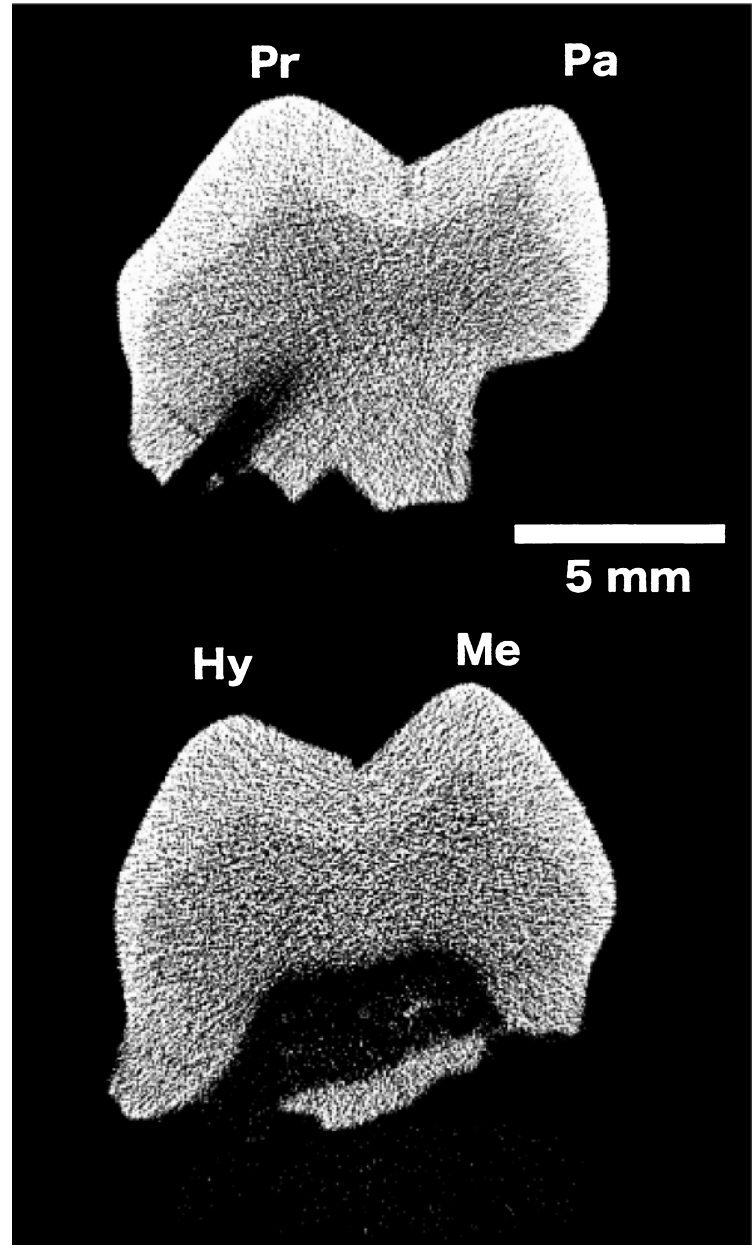

Figure 12. Sections based on micro-scans through the upper molar of Kenyapithecus africanus (Bar 214'02) to show enamel thickness (Pr: protocone, Pa: paracone, Me: metacone, Hy: hypocone).

female individual. There is a small apical wear facet confluent with a large linguodistal wear facet which extends to the lingual cingulum, and the tooth would have been somewhat higher when unworn, but not a great deal of height has been lost. The long, quite wide and cervically deep mesial groove dominates the mesial surface of the crown. It is bordered by swollen ridges and the lingual cingulum is well developed. The buccal enamel extends slightly further rootwards than it does elsewhere on the tooth, but it is not exaggerated in this respect. The mesial part of the cervix is open V-shaped below the mesial tubercle. There is no sign of a distal tubercle, but this could be due to the wear stage of the tooth, which is also slightly damaged in this position. There is an elongated vertical enamel defect on the buccal surface which descends from a horizontal one near the apex of the crown. The root is circular except mesially where it is flattened, and in this respect it differs markedly from the Fort Ternan upper female canine of Kenyapithecus wickeri which is more compressed, almost triangular in section. It is much closer in morphology and crown shape to the Moroto II female upper canine assigned to U. major (Pickford et al., 1999).

Bar 215'02 is an unworn left M1/ (Figure 11-6). The trigon is an equilateral triangle and the cusps are less 'puffy' than those of Kenyapithecus africanus, so the trigon basin is deeper and more voluminous (Figure 13). The lingual cingulum is huge, and even forms a distinct cusplet at the mesiolingual corner of the crown. The groove between the protocone and the cingulum is deep. The mesial cusplet at the end of the mesial crest of the protocone is enlarged and is continuous with the mesial cingulum which is separated from the cusps behind it by a deep groove. There is a weak buccal cingulum on the paracone which terminates well below the buccal notch. The base of this notch is nearly $5 \mathrm{~mm}$ above the cervix and the cingulum is about $2.7 \mathrm{~mm}$ above cervix. The hypocone is as large as the paracone, but slightly smaller than the protocone and metacone. The distal cingulum is swollen and ends buccally at the distal style of the metacone. There is a distinct cusplet at the lingual end of the distal cingulum behind the hypocone. The enamel is lightly wrinkled. In general aspect this tooth has a very 'blocky' occlusal surface, with large cusps separated by deep grooves, and highly inflated cingular structures to the point where accessory cusplets are formed.

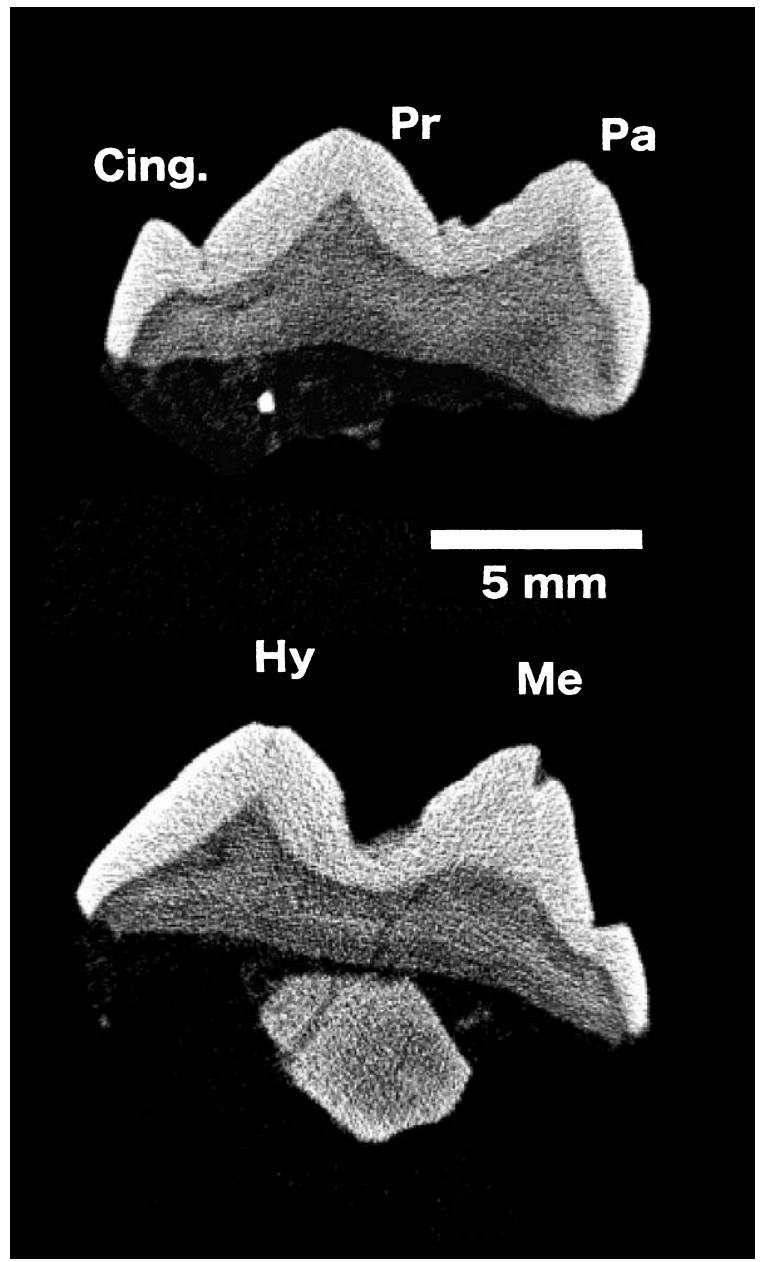

Figure 13. Sections based on micro-scans through the upper M1/ of Ugandapithecus gitongai sp. nov. (Bar 215'02) (Pr: protocone, Pa: paracone, Me: metacone, Hy: hypocone). 
Bar 737'02, a worn left M1/ (Figure 11-4), is part of the holotype, along with Bar 210'02. Dentine is exposed on all four main cusps, the lake on the paracone being the smallest. There are clear mesial and distal interstitial contact facets for the neighbouring teeth. The basic morphology of this tooth is the same as in Bar 215'02 described above, but much of the relief has been worn down and the enamel wrinkles eradicated by wear. Despite the heavy degree of wear the grooves separating the main cusps from each other and from the lingual cingulum are still clearly defined, indicating that they were originally deep. The lingual cingulum is broad, and the buccal one is prominent, being $4 \mathrm{~mm}$ above the cervix. The depths of the trigon basin are still unworn, indicating that it is deep, as in Bar 215'02. There are three large roots which are ovoid in section, a mesiodistally oriented lingual one, and two labiolingually oriented buccal ones.

Bar 210'02 is a worn left M2/ (Figure 11-3). The mesial interstitial facet for the $\mathrm{M} 1 /$ has a sharp but distinct, almost vertical crack in its centre. The facet is oval in outline and slopes slightly distally as it reaches the occlusal surface. The distal contact facet in M1/, Bar 737'02, described immediately above has a similar ovoid outline of comparable dimensions. It has a sharp but low relief vertical ridge in its middle and the facet inclines distally as it approaches the occlusal surface. The coincidence in shape, size and central groove-ridge structure of these interstitial facets indicate that we are dealing with two teeth from the same individual. Bar 210 '02 has a distal contact facet, which proves that the two teeth are M1/-M2/ and not M2/-M3/. The degree of wear in the $\mathrm{M} 2$ / is less than in the M1/ with no dentine exposed occlusally. In general terms the crown is an enlarged version of the M1/, with broad lingual cingulum separated from the protocone by a deep groove, voluminous main cusps of which the protocone is the largest and the hypocone and paracone the smallest. The buccal cingulum is weakly developed and lies $3.7 \mathrm{~mm}$ above cervix. There are three roots. The lingual one is 8 -shaped with the long axis of the 8 oriented mesiodistally. The other two roots are oval in outline with the long axis of the oval buccolingually oriented and they lean gently to the rear.

Bar 737'02 and Bar 210'02 were found in situ in close proximity to each other, and their interstitial facets are a perfect fit, indicating that the two teeth represent a single individual.

Bar 35'02 is an unworn and slightly damaged right M2/ (Figure 11-5). It was probably unerupted at the time of death. The lingual cingulum has broken away, but part of it that extends onto the mesial aspect of the protocone is preserved. The mesiobuccal corner of the paracone is broken off. The protocone is the largest cusp with the other three cusps being subequal in size. The mesial cingulum is strong with a large central cusplet which touches the protocone. The enamel is wrinkled. In most aspects, this tooth looks like a larger version of Bar 215'01 described above and given its unerupted status, it could well represent the same individual.

\section{Deciduous lower dentition}

Bar 282'02 is a deciduous left lower canine (Figure 11-2). It has a horizontal wear facet at its tip. The mesial tubercle is well developed but the lingual cingulum fades rapidly dis- tally. The distal crest is sharp and stands out in relief from the main cusp and it even bifurcates towards the cervix. The enamel is extremely thin where its dimensions can be seen on the apical wear facet. There is a prominent enamel defect on the mesial aspect of the crown but no sign of a mesial groove, which reveals that the tooth is a lower rather than an upper canine. The size of the specimen indicates that it belongs to a large-bodied hominoid. Comparison with the upper milk dentition of Ugandapithecus major from Songhor (KNM-SO 542) and Napak (Nap IV 1'99) reveals that it is likely to represent this genus on the basis of size.

\section{Permanent lower dentition}

Bar 2201'01 is the tip of a right lower canine. The form of the cervical part reveals that it is an incompletely formed germ. It is most similar to male lower canines of Ugandapithecus major, for example KNM-SO 396. It has the slight chisel-like ridge at the tip that blends downwards into the distal crest. Lingual to this there is a low angulation in the enamel that runs from the distal end of the 'chisel' towards cervix but fading out about half the height of the crown in the Songhor specimen. The mesial crest is sharper and leans slightly lingually, as in the Songhor specimen. There is a further angulation buccodistally, so that a cross section of the tip of the tooth gives a triangular section with relatively flat distal and mesial sides and a slightly rounded convex buccal side. There can be little doubt that this tooth belongs to $U$. gitongai despite its incomplete formation.

Bar 213'02 is a lightly worn right lower $\mathrm{m} / 3$ (Figure 11-7) with a tiny interstitial facet caused by contact with the $\mathrm{m} / 2$. The main cusps are large, 'blocky' looking and clearly separated from each other by deep grooves, just as in the upper molars. The protoconid is the largest cusp, followed in size by the metaconid, hypoconid, hypoconulid, and entoconid in decreasing order. The metaconid is subdivided distally into a small cusplet, and there are two cusplets between the hypoconulid and the entoconid, forming a distal cingulum. The buccal cingulum is narrow with gaps on the buccal surface of the protoconid and hypoconid. Anteriorly it blends into the mesial cingulum. The mesial fovea is quite small, but the talonid basin is vast, while the distal fovea is moderate in size. The base of the lingual notch between the metaconid and entoconid is $4.2 \mathrm{~mm}$ above cervix. This is the lower third molar of a very large hominoid, compatible in size and morphology with the upper molars described above.

\section{Discussion}

The fossils assigned to this new species of Ugandapithecus are of a very large hominoid, as large or larger than $U$. major (Bosler, 1981; Martin, 1981; Gommery et al., 1998; Senut et al., 2000). In Figure 14 the two upper first molars of $U$. gitongai are slightly over the upper limit of the size range of U. major. The better preserved M2/ (Bar 210'02) is within the range of $U$. major but is plotted near its upper limit (Figure 14). The other M2/ (Bar 35'02) is damaged so that precise measurement is impossible. However, if complete, it would have plotted within the larger half of the size range of U. major.

Hill et al. (1991) described and figured an isolated lower molar (right m/2) of this species as Proconsul cf. major but 


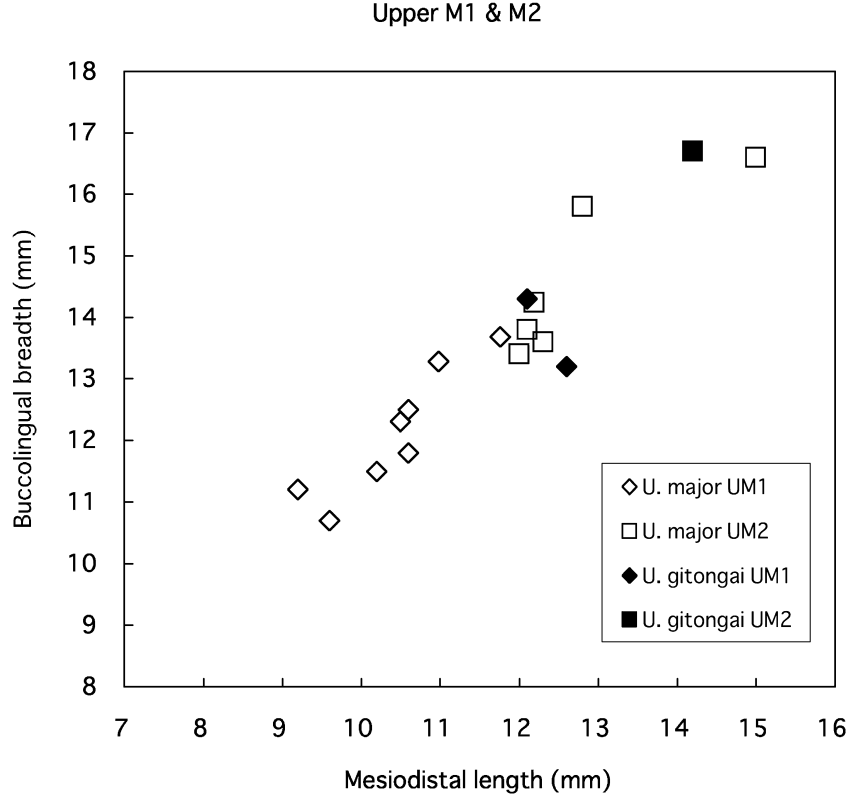

Figure 14. Bivariate plot of upper molars of Ugandapithecus major and $U$. gitongai sp. nov.

noted some differences from classic members of the species. In particular their specimen has expanded breadth dimensions, especially of the talonid, when compared with $U$. major, and the trigonid is broader than the talonid due to basal swellings on the cervical margins of the protoconid and metaconid. The differences noted by Hill et al. (1991), are precisely the kind of features that typify the $\mathrm{m} / 3$ and the upper molars from Kipsaraman described above. Even if this specimen is included, there are still only two lower cheek teeth in the hypodigm, a lower $\mathrm{m} / 2$ (KNM-TH 18690) and a lower $\mathrm{m} / 3$ (Bar 213'02). The $\mathrm{m} / 2$ is similar in size to the largest $\mathrm{m} / 2$ of $U$. major (Figure 15 ). However, the $\mathrm{m} / 3$ is slightly smaller than the three $\mathrm{m} / 3 \mathrm{~s}$ of $U$. major plotted in Figure 15 . This suggests that the $\mathrm{m} / 3$ might be slightly reduced relative to other molars in $U$. gitongai than in $U$. major, although the number of available specimens is still too small for this to be considered a firm conclusion.

\section{Superfamily Cercopithecoidea Gray, 1821}

Family Cercopithecidae Gray, 1821

Genus Prohylobates Fourtau, 1918

Species Prohylobates kipsaramanensis sp. nov.

Synonymy. 1991 - Small hominoid or Cercopithecidae Hill et al., 73. 2002-Victoriapithecus Kelley et al., 41.

Diagnosis. A species morphologically close to Prohylobates macinnesi but with relatively broad upper molars; male and female $\mathrm{p} / 3 \mathrm{~s}$ relatively narrower than in the Maboko species (length/breadth ratio of female specimens at Kipsaraman 1.76 and 1.61 , mean of female specimens at Maboko 1.32; length/breadth ratio of male specimen from Kipsaraman 2.05, male mean at Maboko 1.64); mesial cingulum well developed on protocone in upper molars; mandible and cheek teeth smaller than those of Prohylo-

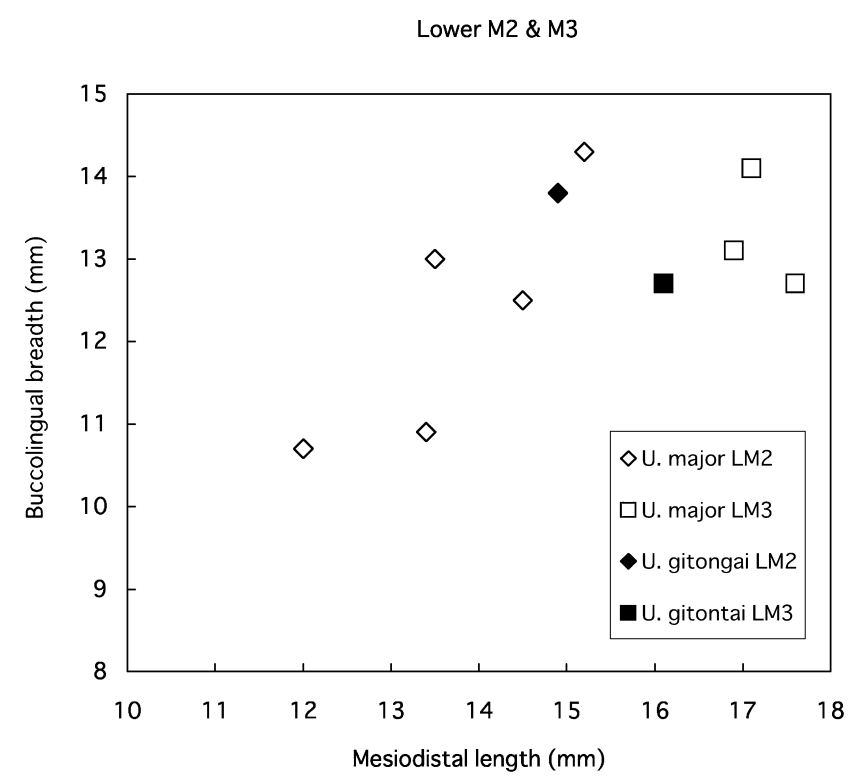

Figure 15. Bivariate plot of lower molars of Ugandapithecus major and $U$. gitongai sp. nov.

bates sp. from Buluk and $P$. simonsi from Libya; $\mathrm{m} / 3$ larger than those of $P$. tandyi from Egypt; ventral termination of the symphysis is below the $\mathrm{p} / 3$ (below $\mathrm{p} / 4$ in Buluk specimens).

Holotype. Bar 219'02, mandible with part of right ramus, symphysis, left ramus and left $\mathrm{m} / 2$.

Type locality. Kipsaraman Main (GPS WGS 84 datum, 0044'53.7" N: 3549'33.6" E).

Stratigraphy and age. Muruyur Formation, Middle Miocene, ca. 14.5 Ma, Faunal Set P IIIb.

Etymology. Named for the village of Kipsaraman ('the place of twins' in Tugen) which is near the type locality. Hill et al. (1991), Ward S. et al. (1999), and Sherwood et al. (2002) spelled the town as Kipsaramon, but this is incorrect, even though it has been used in the past.

Referred material. Holotype and 88 specimens listed in the descriptions and Appendix 5.

\section{Description}

\section{Permanent upper dentition}

Bar $1478^{\prime} 01$ is a well-preserved upper right central incisor (Figure 16-2, 3). The buccal surface is strongly convex, while lingually it is markedly concave. The orientation of the interstitial facet for the opposing $\mathrm{I} 1$ / reveals that the roots of the two central incisors were separated by a gap and that thereafter they diverged from each other. Lingually there is a prominent crest running from the mesial edge of the apex, which descends centrally before curving across and then apically near the distal margin where it blends into the distal crest of the apex. This forms a low but sharp lingual cingulum which closes off a large central basin. The central lingual rib is reduced to a fine crest which is much smaller than the mesial crest which is inflated and encroaches into the lin- 


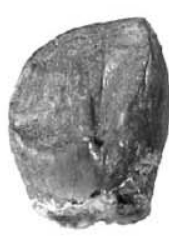

1

2
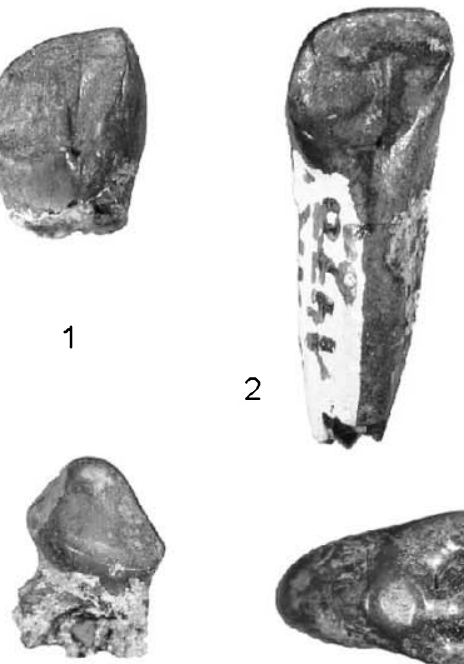

6

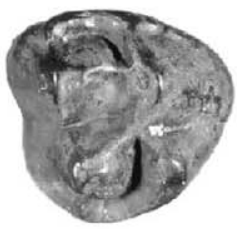

10

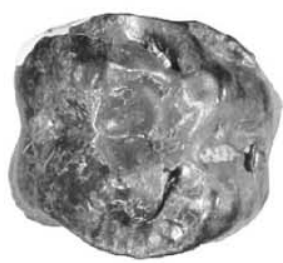

14

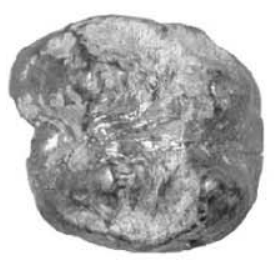

18

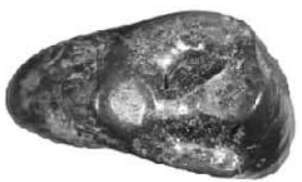

7

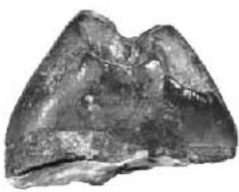

11

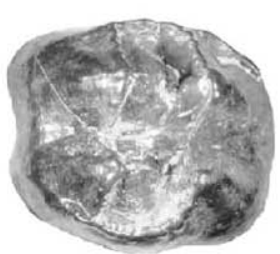

15

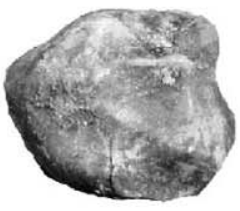

19

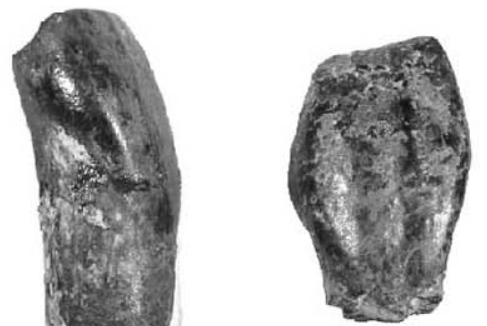

4

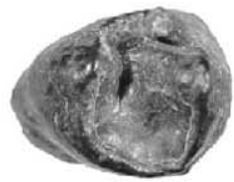

8

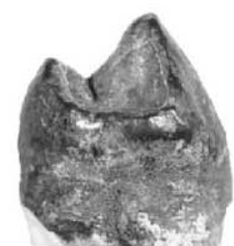

12

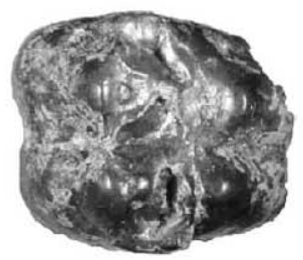

16

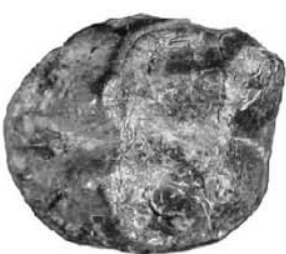

20

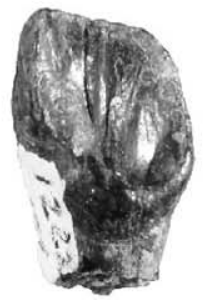

5

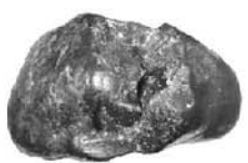

9

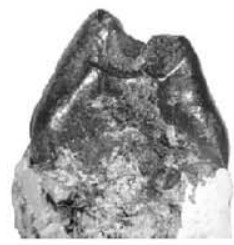

13

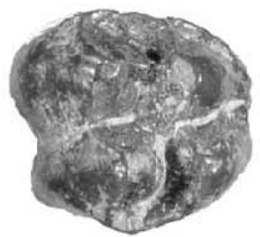

17

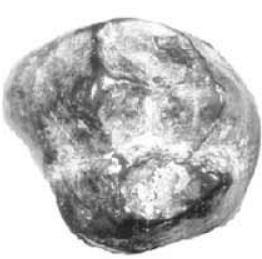

21

Figure 16. Prohylobates kipsaramanensis sp. nov. from Kipsaraman, Tugen Hills, Kenya with length/breadth measurements (in mm) (Scale bar $5 \mathrm{~mm}$ ). (1) Bar 779'02, right I1/, (5.5 × 4.0) lingual view; (2 and 3) Bar 1478'01, right I1/, $(5.1 \times 4.3)$ lingual and mesial views; (4 and 5) Bar 1222 '99, left I1/, $(5 \times 3.7)$ labial and lingual views; (6) Bar 1487'01a, left dC1/, $(3.8 \times 3.4)$ lingual view; (7) Bar 774'02, right P4/, $(4.6 \times 7.5)$ occlusal view; $(8,12)$ Bar 770'02, left P3/, $(4.5 \times 5.5)$ occlusal and distal views; $(9,13)$ Bar 768'02, left P4/, $(3.9 \times 6.7)$ occlusal and mesial views; (10) Bar 610'01, right dP4/, (5.2 × 5.4), occlusal view; (11) Bar 767'02, left M1 or 2/, (6.2 × 7.6), mesial view (see occlusal view in Figure 17-1); (14) Bar 1221'99, right M1 or 2/, (6.2 × 6.9) occlusal view; (15) Bar 185'02, right M1 or 2/, $(6.2 \times 7.2)$ occlusal view; (16) Bar 226’02, right M1 or 2/, $(7.0 \times 8.2)$ occlusal view; (17) Bar 44'02, right M1 or 2/, $(6.4 \times 6.7)$ occlusal view; (18) Bar 2178'01, right M1 or 2/, (6.5 $\times 7.0)$ occlusal view; (19) Bar 2089'01, left dP4/, (4.9 × 5.5) lacking enamel, occlusal view; (20) Bar 2179'01, left M1 or 2/, (6.6 × 7.2) occlusal view; (21) Bar $609^{\prime} 01$, right M3/, $(6.0 \times 6.8)$ occlusal view. 
gual basin.

Bar 779'02 right I1/ (Figure 16-1), Bar 1222'99 left I1/ (Figure 16-4, 5), and Bar 1475'01 left I1/ are structurally similar to Bar 1478'01 but are at different stages of wear.

Bar 763'02, a right upper I2/ is damaged lingually but the labial side is well preserved. The crown is convex labially and concave lingually, and the root is strongly curved. The asymmetry of the tooth indicates that it is a lateral rather than a central incisor. The I2/ of Prohylobates kipsaramanensis is appreciably smaller than its I1/s.

Bar 1003'99 is a left upper canine (Figure 17-12), probably of a female individual judging by the crown height and the size of the root relative to the crown. The lingual cingulum is fine and sharp, ending abruptly distally at the point where it meets the distal crest descending from the apex of the tooth. Anteriorly, the cingulum sweeps upwards towards the base of the mesial groove. The groove itself is small and extends almost to the apex of the crown, narrowing as it does so. Its lingual border is smooth and low and its buccal one is slightly more prominent, but in any case is not large. The cervix rises sharply apically on the mesial aspect of the crown, forming a deep $\mathrm{V}$ shape in its outline. This means that the mesial shoulder of the tooth is considerably higher than the distal tubercle. The enamel on the buccal surface extends much further rootwards than it does either mesially or distally. There is a single wear facet running down the lingual side of the distal crest. The mesial aspect of the root sports a groove below the mesial groove in the crown, indicating that it is likely to represent a cercopithecid tooth. If this is the case then it can be assigned to P. kipsaramanensis on the basis of size and morphology.

Bar 1238'99 is a left upper canine crown (Figure 18-3), evidently representing a male as it is extremely high crowned with a long and deep mesial groove that extends as far as the cervix. This groove probably passed onto the root, but since the root is missing in this specimen we cannot be sure. The crown is slightly concave lingually, as is usual in cercopithecoids.

Bar 770'02 is an unworn left P3/ (Figure 16-8, 12) probably of a male individual on the basis of the great extension of the enamel on the mesial buccal root. The mesial fovea is considerably shorter than the distal basin. The buccal cusp is larger and higher than the lingual one. It has crests directed mesially, centrally, and distally. Externally there are low styles mesially and distally. The lingual cusp has mesial and distal crests that join the mesial and distal cingula respectively. The central crest of the buccal cusp decends into the central valley, but does not cross it, thereby making an incomplete loph. Bar 1192'99 a right P3/ (Figure 18-4) is similar to Bar 770'02.

Bar 774'02 is a lightly worn right P4/ (Figure 16-7) with the roots and part of the maxilla. The small bit of bone attached to the specimen flares strongly away from the alveolar margin, just as in material from Maboko and Buluk. This flare accommodates the large mesial root of the first molar which is more laterally positioned than the buccal root of the P4/. The crown is composed of two main cusps linked mesially and distally by broad cingula. The buccal cusp is bigger and taller than the lingual one. The mesial fovea is smaller than the distal one. There are clear styles at the base of the buccal surface, one mesially the other distally. The enamel extends further rootwards on the mesiobuccal root than elsewhere. The lingual root is large and recurves below the crown at its tip. There appear to be two closely appressed buccal roots. Bar 3'00 left P4/, Bar 768'02 left P4/ (Figure $16-9,13)$, and Bar 1509'00 right $\mathrm{P} 4 /$ are similar to Bar 774 '02.

There are 13 complete cercopithecid upper first and second molars from Kipsaraman (Appendix 5). Bar 1221'99, a lightly worn right upper molar (Figure 16-14), is probably an $\mathrm{M} 1 /$ judging from its size relative to other upper molars from the site. It has four main cusps, a wide mesial cingulum and a narrow distal one. The protocone is the largest cusp, with the paracone, metacone, and hypocone being slightly smaller and sub-equal in stature. The main cusps form two lophs in which the apices of the cusps are close together, and their external bases far apart. There is thus considerable flare on the buccal and lingual surfaces of the tooth. The protocone has two well formed crests which lead mesiocentrally and distocentrally respectively. The mesial one fuses with the mesial cingulum, whereas the distal one touches a smaller crest emanating from the tip of the hypocone, and another one that descends mesiocentrally from the metacone. Tiny crests descend from the tips of the protocone and paracone towards each other, forming a transverse loph and closing off the rear of the mesial fovea. The paracone and metacone both have mesial and distal crests which are almost mesiodistally oriented. The distal crest of the paracone meets the mesial crest of the metacone quite high above the buccal notch. There is a tiny tubercle at the base of the lingual notch. The distal crest of the hypocone swings down and across towards the back of the metacone, forming a clear distal cingulum and closing off a distal fovea. The flare of the lingual walls is greater than that of the buccal ones.

Apart from the M3/s, the remainder of the upper molars are similar to Bar 1221'99, although they are at different wear stages. They are Bar 1203'99 (right), Bar 295'02 (right molar with roots), Bar 766'02 (left molar with roots), Bar 44'02 (right), Bar 185'02 (right), Bar 777'02 (left), Bar 2178'01 (right), Bar 767'02 (left), Bar 186'02 (right), Bar 226'02 (right), Bar 2179'01 (left), and Bar 1005'99 (left) (Figure 16, Figure 17, Figure 18).

Cercopithecid upper molars from Kipsaraman are quite similar to each other, except for two which stand out by their greater size, deeper buccal notch, broader cingula, and more exaggerated flare on the buccal cusps. The two specimens are Bar 226'02 (right) and Bar 1005'99 (left). Bar 2179'01 could belong to this type, but the surface of the enamel has been etched, possibly by stomach acids. These are all probably upper second molars. Upper molars have the apices of the main cusps close to each other and the external walls of the cusps flare markedly towards cervix. The cervix is slightly lower on the lingual than the buccal side, whereas in lower molars, the cervix is decidedly lower buccally than lingually. It is thus easy to distinguish upper from lower molars.

Bar 226'02 is a medium-worn right upper molar (Figure 16-16) with dentine showing at the tips of the protocone and paracone. The base of the protocone and hypocone is missing, and with it the low lingual cingulum. The protocone is 

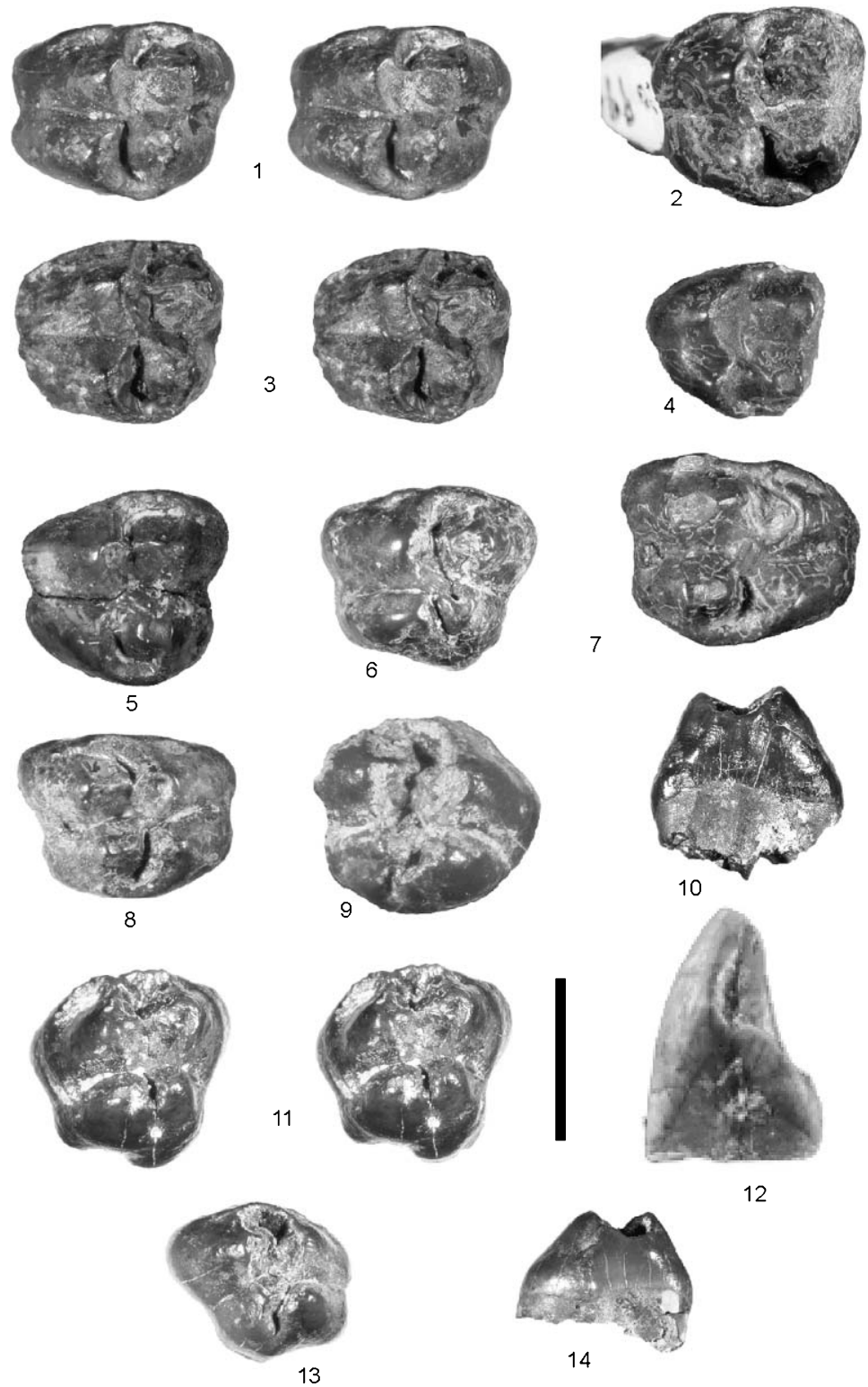

12

Figure 17. Prohylobates kipsaramanensis sp. nov. from Kipsaraman, Tugen Hills, Kenya with length/breadth measurements (in mm) (Scale bar $5 \mathrm{~mm}$ ). (1) Bar 767'02, left M1 or 2/, (6.2 × 7.6) stereo occlusal view (see mesial view in Figure 16-11); (2) Bar 766'02, left M1 or 2/, $(6.3 \times 7.6)$ occlusal view; (3) Bar 777'02, left M1 or 2/, $(6.0 \times 6.9)$ stereo occlusal view; (4) Bar 785'02, left dP4/, $(5.1 \times 5.6)$ occlusal view; (5) Bar 221'02, left dP4/, (6.1 × 7.4) occlusal view; (6) Bar 783'02, left M3/, $(6.3 \times 7.5)$ occlusal view; (7) Bar 295'02, right M1 or $2 /,(6.2 \times 7.7)$ occlusal view; (8) Bar 186'02, right M1 or 2/, $(6.1 \times 7.2)$ occlusal view; (9) Bar 298'02, right M3/, $(5.8 \times 7.5)$ occlusal view; (10 and 11$)$ Bar 823 '01, left M3/, (5.6 × 6.3) mesial and stereo occlusal views; (12) Bar 1003'99, left C1/f, (5.6 × 5.6) mesial view; (13 and 14) Bar 223'02, right $\mathrm{M} 3 /,(5.9 \times 7.4)$ occlusal and mesial views.

almost the same size as the paracone and it has a broad mesial crest that reaches the mesial cingulum in the midline of the crown, forming a substantial ridge that closes off the mesial fovea anteriorly. It has a strong distal crest that is directed obliquely backwards to join not only the hypocone, but also the metacone, which itself sends an oblique crest mesiocentrally from its tip forming a high wall between the trigon basin and the distal fovea. The connection between the protocone and the paracone is, in contrast, much weaker, even though present. The paracone has mesial and distal crests that are short and sharp, the mesial one ending closer to the midline of the crown than to its buccal side. This makes the mesial style very internal in position. The distal cusp pair is somewhat smaller than the mesial one. The hypocone has a distal crest that curves buccally to join the distal crest of the metacone thereby closing off the distal fovea. The mesial crest of the metacone is weak but sharp and touches the distal crest of the paracone somewhat internally, so that the buccal notch is deeply indented. There is no sign of any cingular fold at the buccal end of the median 


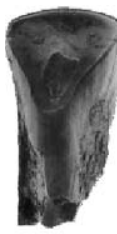

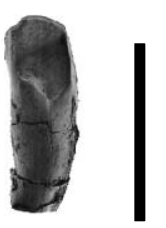

2
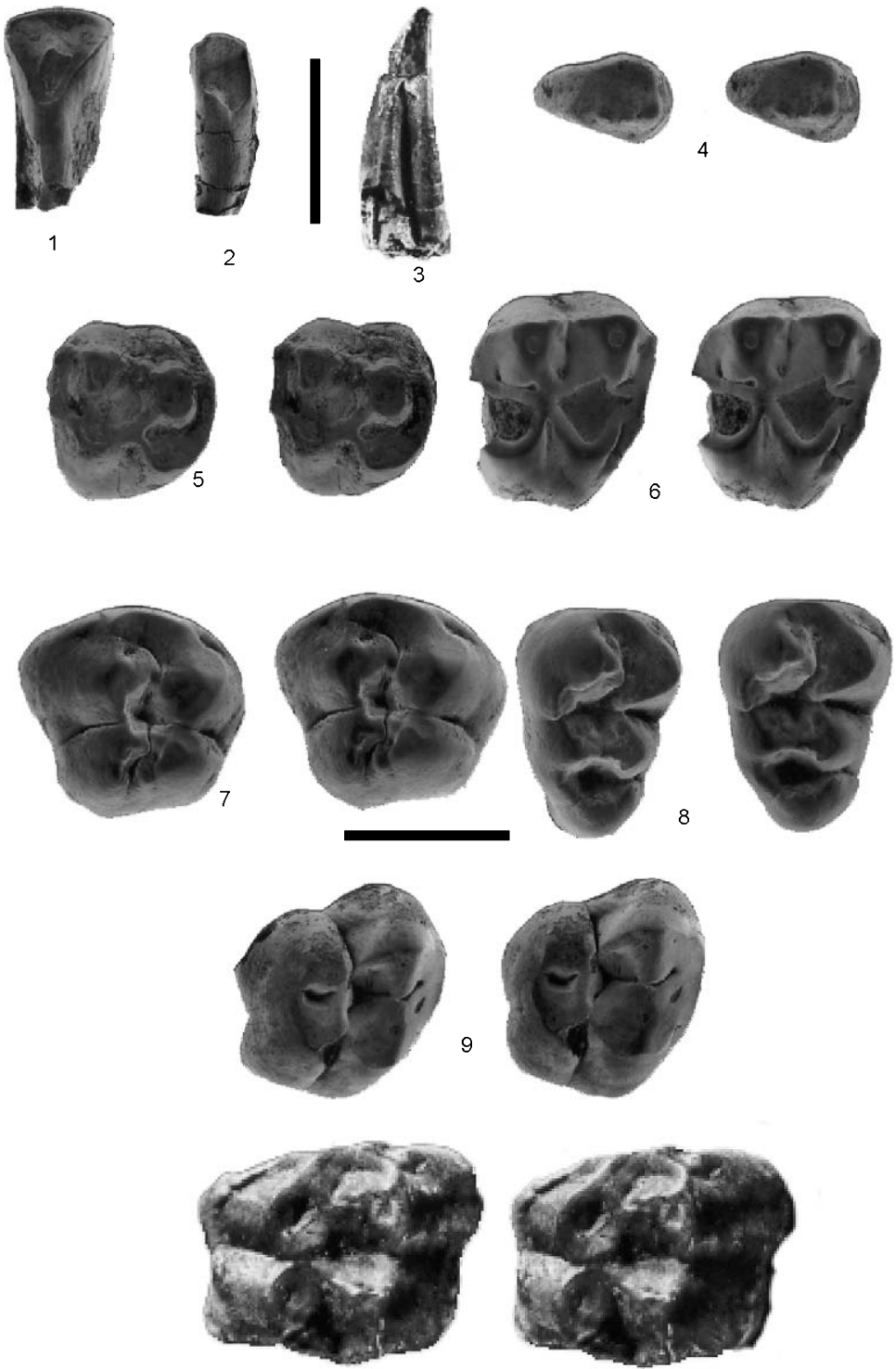

10

Figure 18. Prohylobates kipsaramanensis sp. nov. from Kipsaraman, Tugen Hills, Kenya with length/breadth measurements (in mm) (1 and 2 , 4-9 are SEM images) (Scale bars $5 \mathrm{~mm})$. (1) Bar 1010'99, lower i/1, $(3.8 \times 4.4)$ lingual view; (2) Bar 1239'99, right i/2, lingual view; (3) Bar 1238'99, left C1/, mesial view; (4) Bar 1192'99, right P3/, stereo occlusal view; (5) Bar 1185'99, left dP4/, (5.2 × 5.4) stereo occlusal view (mesial is to the left); (6) Bar 1203'99, right M1 or 2/, stereo occlusal view (mesial is to the right); (7) Bar 1007'99, right M3/, (6.1 × 7.2) stereo occlusal view; (8) Bar 917'99, right $\mathrm{m} / 3,(7.3 \times 5.7)$ stereo occlusal view; (9) Bar 86'99, right M3/, $(6.1 \times 7.1)$ stereo occlusal view (mesial is to the right); (10) Bar $1005 ' 99$, left M1 or 2/, $(7.1 \times 9.0)$ stereo occlusal view.

transverse valley. Flare on the buccal cusps is almost as great as on the lingual ones, which imparts an almost symmetrical profile to the tooth in distal and mesial views. The relatively internal position of the four main cusps means that the various basins and fovea are quite restricted in size.

Bar 1005'99 is a moderately worn left upper molar which is comparable morphologically to Bar 226'02. Being more complete cervically it preserves a clear lingual cingulum near the base of the protocone and hypocone, which is missing from the other part of the tooth due to damage. Dentine lakes are visible on both mesial cusps as well as on the hypocone. The fovea and basins are restricted, ridges are broad and the buccal and lingual notches deeply indented. This tooth possesses a distal interstitial facet for the tooth behind, showing that it is not likely to be a third upper molar.

From the Muruyur Formation there are eight upper third molars (seven from Kipsaraman and one from Keturo), recognizable as such because of the greatly reduced distal loph. They are all similar to each other and can be described together. The specimens are as follows: Bar 1508'00 (right), Bar 1007'99 (right), Bar 86'99 (right), Bar 783'02 (left), Bar 223'02 (right), Bar 609'01 (right), Bar 823'01 (left), Bar 298 '02 (right) (Figure 16, Figure 17, Figure 18). Bar 609'01 is the least worn (Figure 16-21). The protocone and para- 
cone are large but the metacone and hypocone are greatly reduced. The hypocone is separated from the trigon cusps by a groove. There is no distal cingulum, but the mesial one is strong and closes off a mesial fovea. The buccal notch is pinched in, as is the lingual one. The two mesial cusps have strong mesial and distal crests, but their central ones are weak and descend into the trough of the trigon basin without forming a cross loph. In overall aspects the third upper molars from Kipsaraman are close to those from Maboko attributed to Victoriapithecus by Benefit (1993) but most of them plot out above the regression line for the latter species (Figure 26). In other words, the crown tends to be relatively broader in Kipsaraman than in Maboko. On the other hand, the distal loph of the M3/s in Kipsaraman shows a tendency to be more narrowed buccolingually relative to the mesial loph than in Maboko (Figure 23). On average, the distal loph breadth/mesial loph breadth ratio is $75.0 \%$ for Kipsaraman and $79.4 \%$ for Maboko. Although the ranges of this index in the two samples overlap, the mean values are significantly different (Table 1).

Bar 86'99, from Keturo, is an isolated, rootless, right upper third molar in light wear with a dentine lake exposed on the tip of the protocone (Figure 18-9). The four main cusps are arranged in two loph-like pairs as in Prohylobates macinnesi from Maboko (von Koenigswald, 1969; Benefit, 1993). The protocone has two prominent crests, one of which leads mesiolabially to join the mesial cingulum in the midline of the crown where it produces a tiny cusplet which in this specimen shows a dentine lake due to the light wear that it has experienced. The other crest leads distally towards the hypocone, from which it is separated by a narrow but high groove. With slight further wear the protocone and hypocone would become confluent. The paracone also has two crests, one leading mesially to join the mesial cingulum, thereby closing off a mesial fovea. The distal crest descends into the buccal notch, but does not join the metacone. The metacone has a crest that leads mesiolingually to join a similar crest from the hypocone, thereby forming the mesial wall of a distal fovea that exists between these two cusps. Distally it has a crest that likewise joins the hypocone to form the distal wall of the same fovea. The labial and lingual notches are shallow and do not widely separate the main cusps as in colobine monkeys. The crown is $6.1 \mathrm{~mm}$ long mesiodistally by $7.1 \mathrm{~mm}$ broad buccolingually measured at the mesial cusp pair and $5.9 \mathrm{~mm}$ broad measured at the distal cusp pair. This makes the tooth appreciably smaller than the M3/ of Prohylobates sp. from Buluk, Kenya (Leakey, 1985).

Table 1. Relative distal loph size index

\begin{tabular}{lcc}
\hline & Maboko & Kipsaraman \\
\hline$n$ & 90 & 8 \\
Mean* & 79.4 & 75.0 \\
SD & 5.6 & 4.5 \\
Range & $69.1-94.6$ & $68.9-83.1$ \\
\hline
\end{tabular}

DB/MB [\%]: DB and MB are buccolingual breadths of the distal and mesial moieties, respectively.

$*, P<0.05$ in $t$-test.

\section{Deciduous upper dentition}

There are two upper deciduous canines in the Kipsaraman sample, numbered Bar 1487'01 a (Figure 16-6) and b, probably different individuals. They are simple conical pegs, not very pointed with a wear facet distally, a slight depression on the mesial face, and they have thin enamel. They are attributed to this species with some hesitation, mainly on the basis of size.

Bar 221'02 is a left upper dP4/ (Figure 17-5) on the basis of its trapezoidal occlusal outline due partly to the slightly reduced hypocone and partly to the somewhat distal positioning of the protocone relative to the paracone (Benefit, 1994). The mesial and distal crests of the protocone are broad, the mesial one joining the mesial cingulum and swinging buccally to join the mesial crest of the paracone, forming a substantial mesial wall for the mesial fovea. The distal crest of the protocone is obliquely oriented and joins the obliquely oriented mesial crest of the metacone, forming a strong ridge that walls off the distal side of the trigon basin. The trigon is partly filled by a swelling in the buccal surface of the protocone which reaches across the crown to join a thin central ridge on the paracone. The mesial crest of the hypocone joins this wall at right angles to it. The distal ridge of the hypocone swings backwards and then lingually across the rear of the tooth to join the distal style of the metacone, thereby closing off the distal fovea. The flare is greater on the protocone than on the paracone. The lingual and buccal notches are deep, but not as well marked as in the permanent molars. There is a substantial mesial facet, and a tiny distal interstitial facet caused by contact with the neighbouring teeth. Bar 610'01(Figure 16-10), Bar 1412'02, Bar 785'02 (Figure 17-4), Bar 2089'01 (Figure 16-19), Bar 1510'00, and Bar 1185'99 are similar to Bar 221'02 and are presumed to be $\mathrm{dP} 4 / \mathrm{s}$.

\section{Mandible}

Bar 219'02 is the holotype mandible with $\mathrm{m} / 2$ (Figure 19, Figure 20-1). The symphysis is preserved, as is a part of the right ramus as far back as the roots of the $p / 3$ and the left ramus back to $\mathrm{m} / 2$. The ventral part of the symphysis slopes steeply distoventrally. The planum slopes steeply and is concave where it enters the genioglossal fossa, which is large. There is no sign of a 'simian' shelf, the inferior transverse torus being short and rounded and positioned only slightly posterior to the superior transverse torus. The ventral extremity of the symphysis is below the $\mathrm{p} / 3$, whereas in the Buluk species it ends slightly further back below the $\mathrm{p} / 4$ (Leakey, 1985). The symphysis measures $21.6 \mathrm{~mm}$ from the alveolar margin to the ventral margin and it is $9.3 \mathrm{~mm}$ thick antero-posteriorly. The two branches of the mandible diverge rapidly towards the rear forming a V-shaped jaw with a rounded tip to the $\mathrm{V}$. The left branch is straight from $\mathrm{c} / 1-\mathrm{m} / 2$. It is deeper and more robust than Maboko specimens (KNM-MB 1, for example) (Figure 21), but shallower than the Buluk specimens. The mental foramen is low down beneath the $\mathrm{p} / 4$, as in Buluk and Maboko specimens.

The incisor alveoli are narrow and lie in the arc of a circle. The distance between the mesial edges of the two canines is about $7 \mathrm{~mm}$, meaning that the lower incisors were small teeth. The canine alveoli are damaged but measure about 

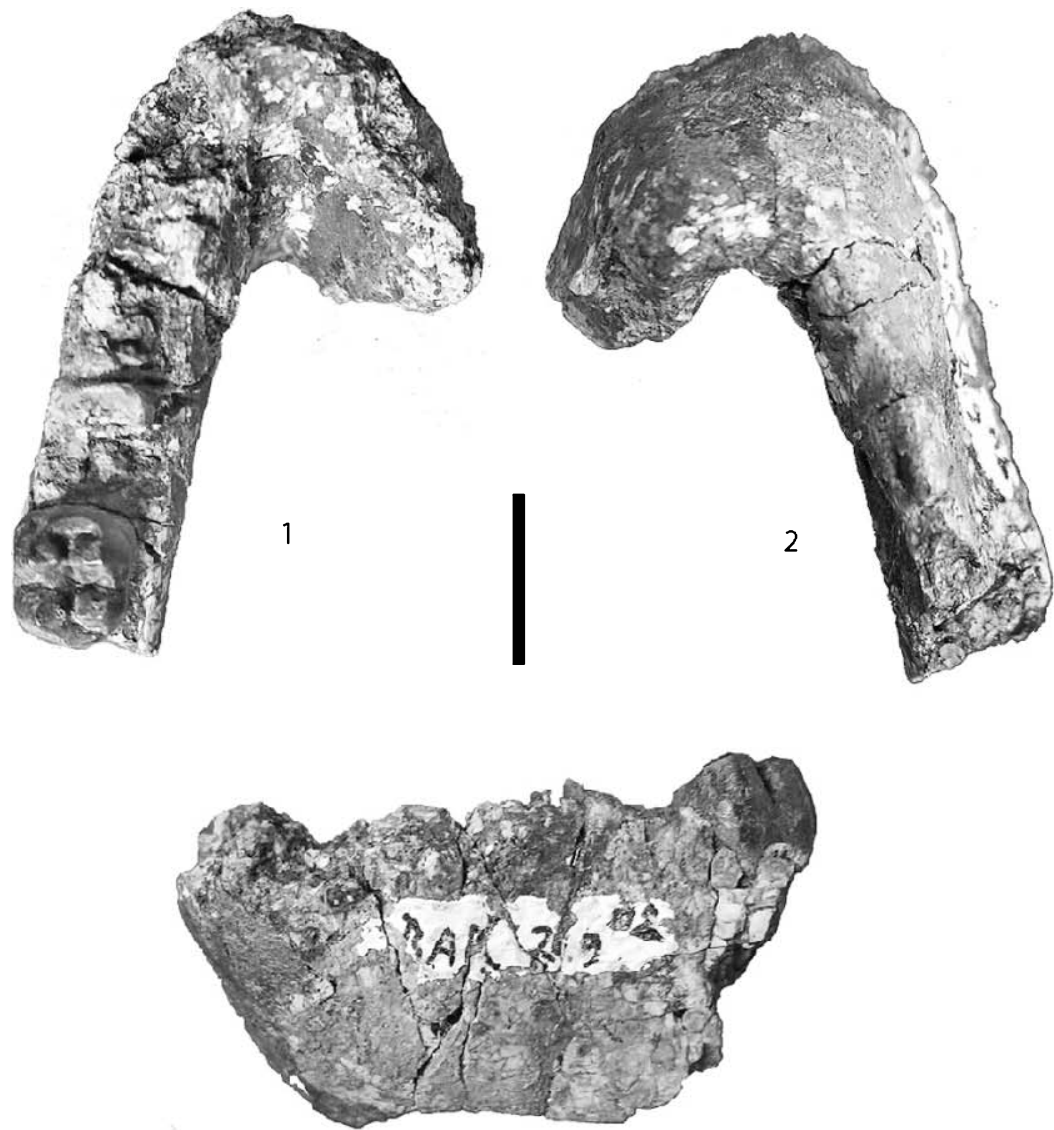

3

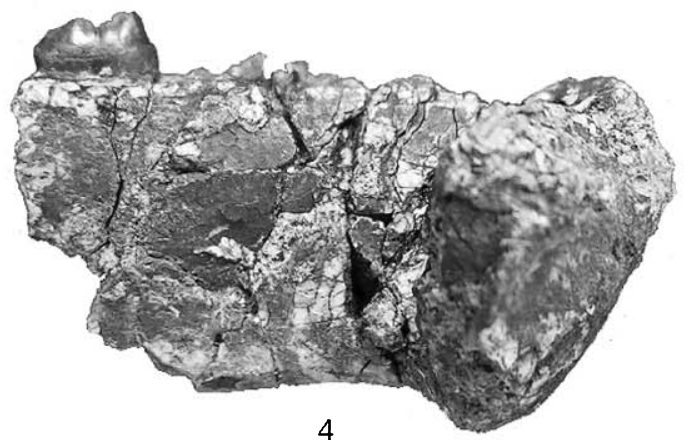

Figure 19. Prohylobates kipsaramanensis sp. nov. holotype mandible (Bar 219'02) from Kipsaraman, Tugen Hills, Kenya (Scale bar $10 \mathrm{~mm}$ ). (1) Occlusal view (see also Figure 20-1); (2) ventral view; (3) lateral view; (4) lingual view.

$5 \times 5 \mathrm{~mm}$. The roots of $\mathrm{m} / 1$ are preserved and measure $6.5 \times 5.5 \mathrm{~mm}$. The depth of the mandible at the front of $\mathrm{m} / 2$ is $18 \mathrm{~mm}$ and its breadth is $8.3 \mathrm{~mm}$. The $\mathrm{m} / 2$ is described in detail below.

\section{Permanent lower dentition}

Bar 1484'01 is the crown of a left $\mathrm{i} / 1$, lacking the root (Figure 22-5). It is unworn and slightly damaged at the apex distally. The labial surface is wide and convex, whereas the lingual surface is concave with prominent marginal crests. The central basin narrows rootwards and it has a very weak but elongated central rib. The enamel extends much further rootwards on the labial side than it does lingually. Bar 1010 '99 is a worn central lower incisor (Figure 18-1). It has a broad, slightly convex labial surface, and a much narrower lingual one. The labiolingual diameter of the tooth is greater than the mesiodistal diameter and the enamel extends much further rootwards labially than lingually. Most of the lingual surface morphology has been eradicated by wear, but at the base of the crown there is a small remnant of the lingual basin, showing that it was concave with well-developed lateral and mesial crests. Bar 780'02 (Figure 22-1, 2), is similar 

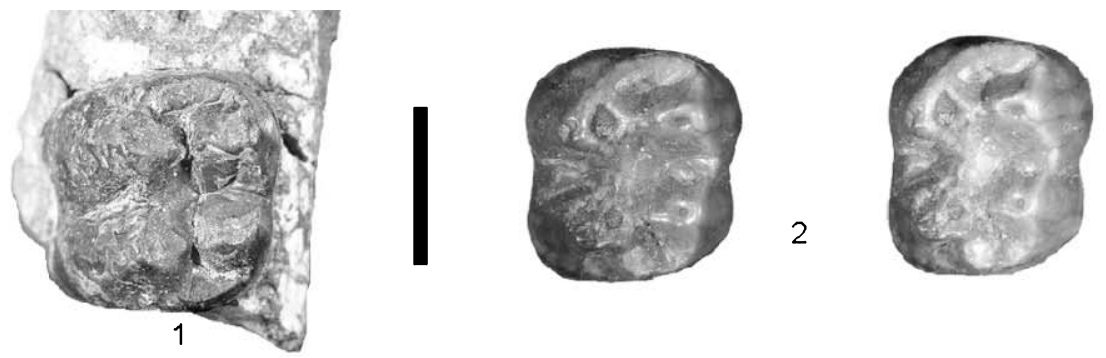

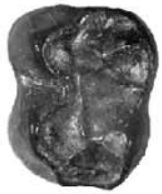

3

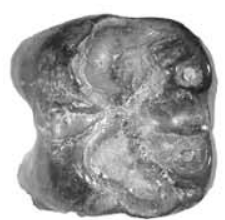

4

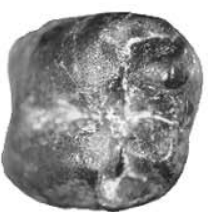

7

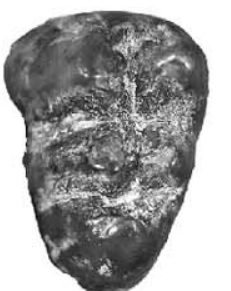

11

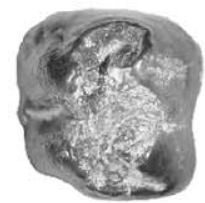

8
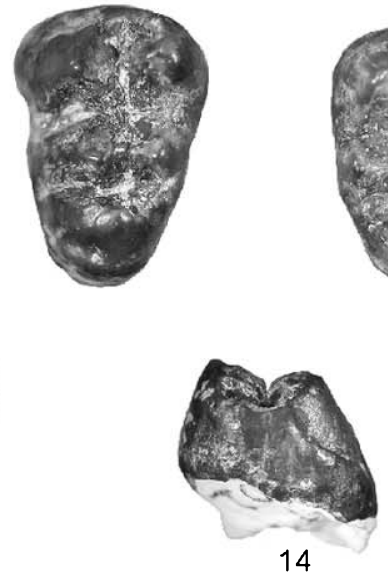

13

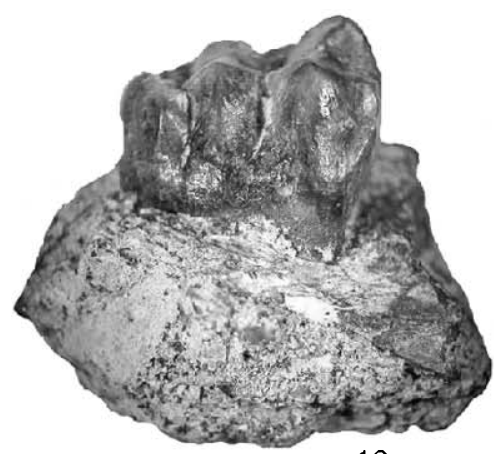

16

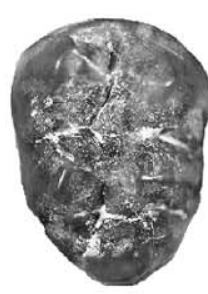

17

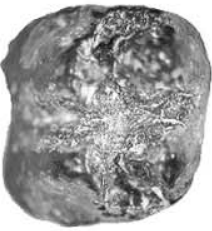

5
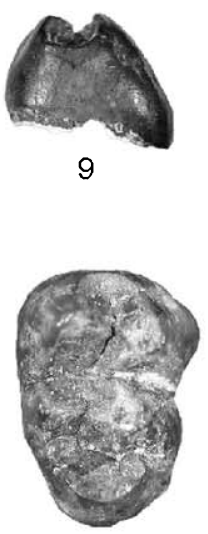

12

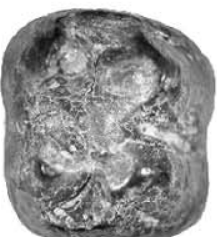

6

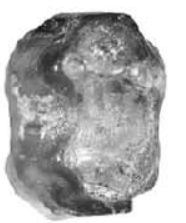

10

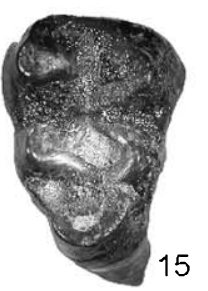

15

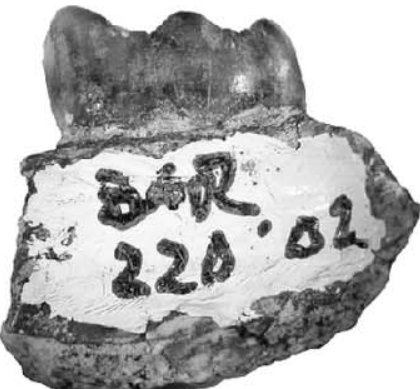

18

Figure 20. Prohylobates kipsaramanensis sp. nov. from Kipsaraman, Tugen Hills, Kenya with length/breadth measurements (in mm) (Scale bar $5 \mathrm{~mm})$. (1) Bar 219'02, left m/2, (7.3 × 6.8) occlusal view; (2) Bar 1474'01, left $\mathrm{m} / 1$ or 2, $(7.6 \times 6.8)$ stereo occlusal view; (3) Bar 1413'02, right dp/4, $(5.6 \times 4.4)$ occlusal view; (4) Bar $228^{\prime} 02$, left $\mathrm{m} / 1$ or $2,(6.1 \times 5.6)$ occlusal view; (5) Bar 225 '02, left $\mathrm{m} / 1$ or 2 , (6.8 $\left.\times 6.4\right)$ occlusal view; (6) Bar 224'02, right $\mathrm{m} / 1$ or 2, (7.0 × 6.6) occlusal view; (7) Bar 39’02, left m/1 or 2, (6.5 × 6.1) occlusal view; (8 and 9) Bar 222'02, left $\mathrm{m} /$ 1 or $2,(6.6 \times 7.0)$ occlusal and mesial views; $(10)$ Bar 789'02, left $\mathrm{m} / 1$ or $2,(6.1 \times 5.0)$ occlusal view; (11) Bar 1411'02, left m/3, (8.7 $\times 6.1) \mathrm{stereo}$ occlusal view; (12) Bar 38'02, right $\mathrm{m} / 3,(8.0 \times 5.7)$ stereo occlusal view; $(13$ and 14$)$ Bar 771 ' 02 , left $\mathrm{m} / 3,(8.0 \times 6.4)$ occlusal and mesial view; (15) Bar 1476'01, right $\mathrm{m} / 3,(8.8 \times 6.6)$ occlusal view; (16-18) Bar 220 '02, right mandible with $\mathrm{m} / 3(7.7 \times 6.0)$, buccal, occlusal, and lingual views. 


\section{Mandible}

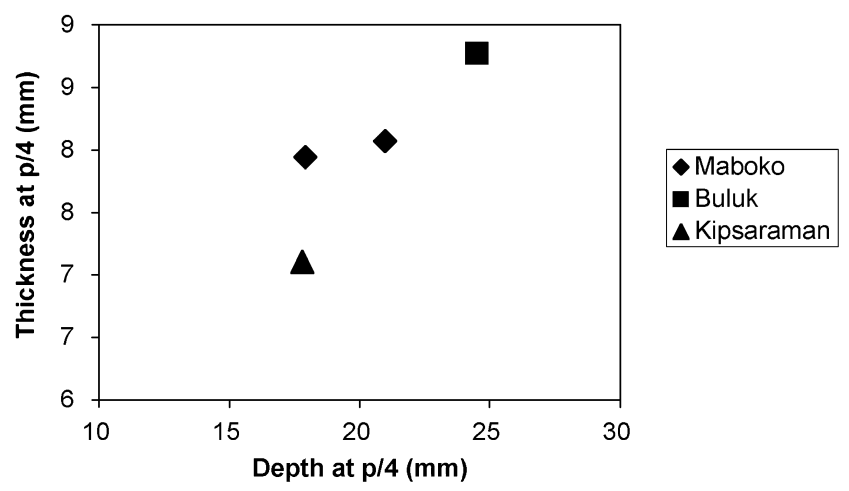

Mandible

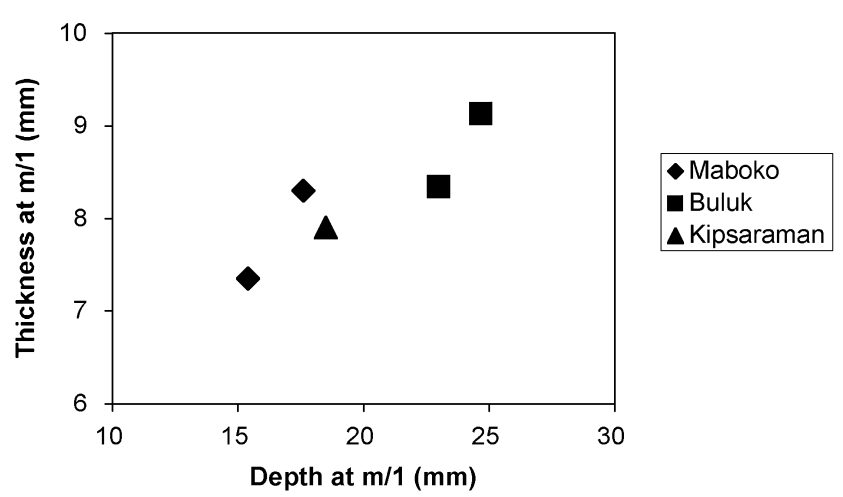

Figure 21. Bivariate plot of mandibular breadth against mandibular depth in Prohylobates sp. from Buluk, P. macinnesi from Maboko and $P$. kipsaramanensis sp. nov. from Kipsaraman.

in its preserved parts to Bar 1484'01.

Bar 41'02, a lightly worn right $\mathrm{i} / 2$ (Figure 22-3, 4), consists of a single cusp which is convex labially and concave lingually, and the cutting edge of the crown is concave lingually. In anterior view the distal edge is convexly curved and the enamel extends further distally than it does mesially. The asymmetry of the tooth reveals that it is a second, rather than a first incisor. Lingually there is a weak central rib and a tiny distal tubercle. Bar 1239'99 (right) (Figure 18-2) and Bar 1485'01 (left) are i/2s, more deeply worn than Bar 41'02 described above, but similar to it in morphology.

Bar 606'01 (Figure 22-6, 7, 8) and Bar 762'02 are right lower canines consisting of a prominent main cusp and a well-developed distal tubercle about $1 / 3$ the mesiodistal length of the tooth. In the former specimen, there is a small apical wear facet, another down the distal crest, and a third, more deeply worn one on the distal tubercle. The crown is slightly canted laterally with respect to the root. The mesial shoulder, marked by a small mesial tubercle, is high. From this tubercle there is a lingual cingulum which descends to the distal tubercle, and a prominent steep mesial crest which reaches the apex of the tooth. On the buccal surface, there is not a marked rootward extension of the enamel, which indicates that this tooth is probably from a female individual.

There are three lower $\mathrm{p} / 3 \mathrm{~s}$ in the sample, one (Bar 1482'01) (Figure 22-10, 11, 12) appreciably larger than the other two (Bar 607'01 and Bar 42'02) (Figure 22-9, 13, 14). All three of them lack the rootward extremity of the 'honing' surface due to damage. Bar 1482'01, which we take to represent a male individual, has a more mesiodistally elongated aspect than the other specimens, which we consider to be female. All three teeth consist of a single main cusp with three crests running from the apex towards the cervix. In Bar $607^{\prime} 01$ and Bar 42'02, the mesial crest runs obliquely from the tip of the main cusp towards the mesiolingual corner of the crown forming the occlusal edge of the 'honing' surface of the tooth. The central crest descends from the cusp tip distolingually where it joins the lingual cingulum. It is more voluminous than the other two crests and forms a small tubercle near cervix. The distal crest runs from the apex of the cusp towards the distal cingulum which thereby closes off a small distal fovea between it and the central crest. In Bar $607^{\prime} 01$ there is a tiny distal contact facet for the $\mathrm{p} / 4$. The lingual cingulum is clear between the ends of the mesial and central crests. There is a depression on the buccal surface of the crown between the main cusp and the distal cingulum, which forms a small tubercle distally. Bar 1482'01 is similar in construction to the previous tooth save for its more elongated appearance and the greater extent of its 'honing' surface. In addition, the depression on the buccal surface of the crown is better defined.

Bar 776' 02 is the best preserved of the lower $\mathrm{p} / 4 \mathrm{~s}$ (Figure $22-17,18)$. It is from the left side, and is composed of two main cusps, a prominent mesial fovea and a large distal basin. Enamel extends appreciably further rootwards on the mesiobuccal aspect than it does elsewhere on the crown. The two main cusps are equal in height and the mesial fovea is slightly higher than the distal basin. Bar 2088'01 (right) (Figure 22-19, 20), and Bar 229'02 (left) (Figure 22-15, 16) $\mathrm{p} / 4 \mathrm{~s}$ are similar to Bar 776'02. Bar 299'02 is a broken $\mathrm{p} / 4$ similar to the above specimens.

Lower first and second molars from Kipsaraman are as follows: Bar 39'02 (left), Bar 222'02 (left germ), Bar 784'02 (left in mandible fragment, worn down to base of buccal notch), Bar 789'02 (left with roots, but with enamel etched off the crown), Bar 224'02 (right), Bar 769'02 (right), Bar 787'02 (deeply worn), Bar 225'02 (left), Bar 40'02 (right), Bar 228'02 (left, deeply worn), Bar 43'02 (left), Bar 781'02 (right deeply worn), Bar 2177'01 (buccal half of right $\mathrm{m} / 1$ ) (Figure 20), and there are some fragments of lower molars (see Appendix 5).

In the lower molars the enamel extends rootwards much further buccally than lingually. The apices of the main cusps are close together, and buccal flare is moderate, not as marked as in the upper molars. The lingual walls of the lower molars are more vertical. In none of the Kipsaraman specimens is there a separate hypoconulid, but all the specimens have a well-formed distal cingulum which is beaded in unworn material.

Bar 827'02, a left lower molar, has the enamel completely dissolved from its occlusal surface, although some remains in the buccal side. The dentinal horns and crests associated 


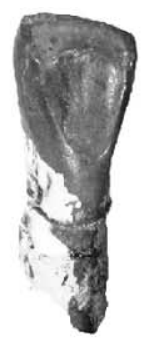

1

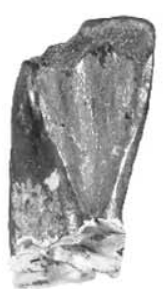

5

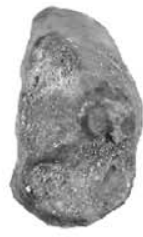

9

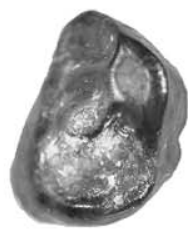

13

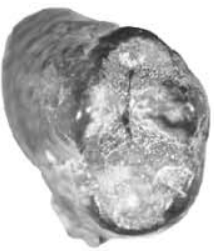

17

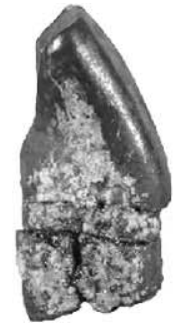

2
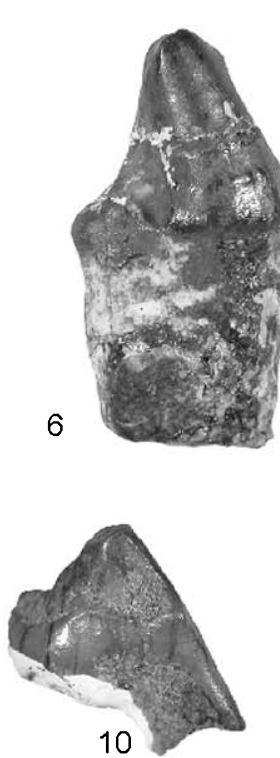

10

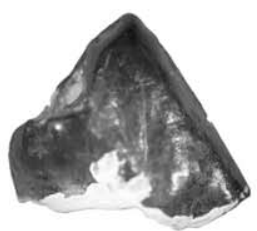

14

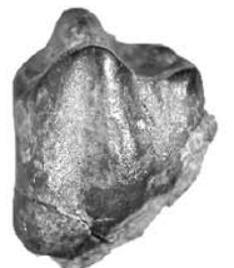

18
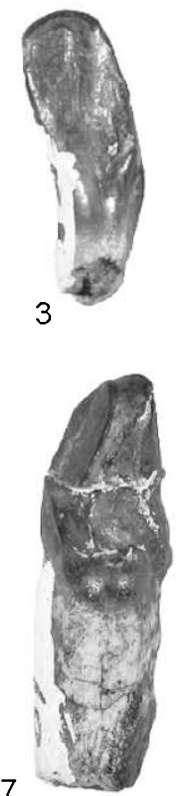

8

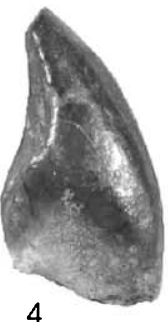

4
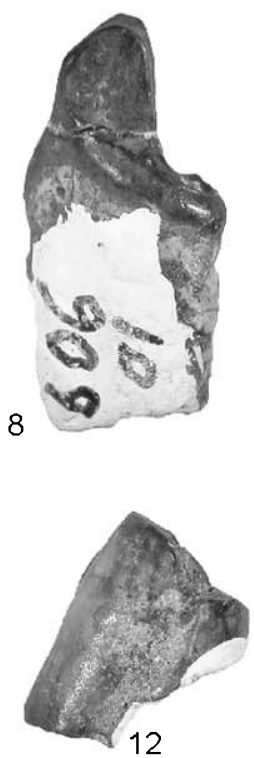

11

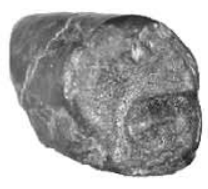

15

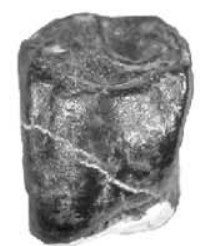

16

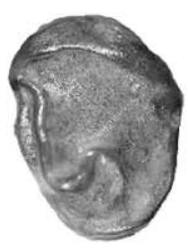

19

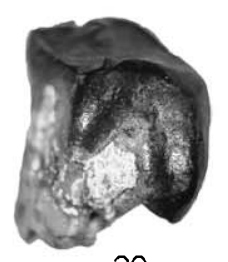

20

Figure 22. Prohylobates kipsaramanensis sp. nov. from Kipsaraman, Tugen Hills, Kenya with length/breadth measurements (in mm) (Scale bar $5 \mathrm{~mm})$. (1 and 2) Bar 780'02, right i/1, (3.4 × 4.2), lingual and mesial views; ( 3 and 4) Bar 41'02, right $\mathrm{i} / 2,(2.7 \times 4.0)$ lingual and distal views; (5) Bar 1484'01, left i/1, (3.6 × 3.5) lingual view; (6-8) Bar 606'01, right c/1, $(5.9 \times 3.6)$ buccal, distal, and lingual views; (9) Bar 42’02, right p/3, $(6.0 \times 3.4)$ occlusal view; $(10-12)$ Bar 1482'01, left p/3, $(7.2 \times 3.5)$ lingual, occlusal, and buccal views; $(13$ and 14) Bar 607’01, right p/3, $(5.8 \times 3.6)$ occlusal and buccal views; $(15$ and 16$)$ Bar 229'02, left p/4, $(4.7 \times 4.7)$ occlusal and buccal views; $(17$ and 18$)$ Bar 776'02, left p/4, $(6.2 \times 5.1)$ occlusal and buccal views; $(19$ and 20$)$ Bar 2088'01, right p/4, $(4.5 \times 5.4)$ occlusal and buccal views. 
with them are preserved and show the typical cercopithecid lophodont pattern. The lingual horns are peripherally located, whereas the buccal ones are almost in the centre of the tooth. This indicates that there was significant buccal flare in this tooth. The mesial and distal roots are compressed mesiodistally. Of the above material, the smaller specimens are likely to be first molars and the larger ones second, but the serial position of some teeth cannot be determined with confidence [cf. Benefit (1993) for the same difficulty at Maboko].

The only tooth preserved in the holotype mandible (Bar $219^{\prime} 02$ ) is the $\mathrm{m} / 2$ (Figure 19, Figure 20-1), which is bilophodont, with well-developed mesial and distal cingula. There are four main cusps, two lingual ones near the lingual margin of the crown, and two buccal ones which have marked buccal flare, such that their apices are about $1 / 3$ of the way across the crown. The two buccal cusps are linked by crests which descend from their apices towards the medial transverse valley, thereby forming a low wall within the valley. Lingually, the crests from the tips of the two lingual cusps are weak and descend towards the lingual notch, but without forming a barrier at its end. The mesial and distal fovea are well developed, but are small compared with the trigonid basin. The protoconid and hypoconid are slightly larger than the metaconid and entoconid. There are three crests leading from the apex of the protoconid, a mesial one that contacts a cusplet on the mesial cingulum, a central one that leads across the tooth towards the metaconid, thereby forming a loph, and a distal one which extends backwards into the median transverse valley where it joins a mesial crest from the hypoconid. The hypoconid has a distal crest that leads distocentrally where it contacts a cusplet in the distal cingulum. It also has a slight centrally directed crest which descends into the central valley, but without crossing it towards the entoconid. The metaconid has mesial and distal crests, as does the entoconid, although in the latter cusp the distal crest is weakly developed. The buccal notch is deeply indented, but the lingual one is not.

Bar $1474^{\prime} 01$ is a mandible fragment with moderately worn left lower molar (Figure 20-2). There are small dentine lakes on all four main cusps. The mesial fovea is large, as is the broadness of the mesial cingulum, all of which makes the mesial shelf broad. The protoconid and hypoconid have well-developed mesial and distal crests which descend obliquely towards the mid-line of the tooth. The lingual aspects of these two cusps are swollen and form a contact across the crown towards the metaconid and entoconid respectively. The distal cingulum runs from the rear of the entoconid to join the distal crest of the hypoconid quite close to the midline of the tooth. This leaves a deep cleft on the distobuccal aspect of the hypoconid. The buccal notch is deeply indented, with a thin fold of enamel in its base. The mesial and distal crests of the metaconid and entoconid are sharp and lingually located. There is a very slight enamel fold on the mesiobuccal aspect of the protoconid, descending from the midline of the tooth towards cervix buccally. Bar $608^{\prime} 01$, a left lower $\mathrm{m} / 1$ or $\mathrm{m} / 2$ is similar to Bar 1474 '01.

Seven complete lower third molars from the Muruyur Formation yield a good idea of the range of variation at the site (Figure 18, Figure 20). Bar 917'99 (right), Bar 38'02 (right), Bar 771'02 (left), Bar 1477'01 (left), Bar 1476'01 (right, worn), Bar 1411'02 (left), and Bar 220'02 (right) are all constructed on the same basic pattern, but Bar 1477'01 narrows considerably more distally, due to damage to the buccal side. Bar 2096'01, another $\mathrm{m} / 3$, is too eroded for measurements to be taken.

The lower third molars are comprised of five main cusps. In general, the two mesial lophids of the $\mathrm{m} / 3$ look similar to second molars, except that the second lophid is narrower than the first. In strong contrast, the hypoconulid is elongated in comparison with those in the second molars. It is developed into a third lobe comprising a main cusp in line with the protoconid and hypoconid, with a large crest running round towards the back of the entoconid. Bar 220'02 (Figure 20-16, 17, 18) is typical and serves as the basis for description. The protoconid is the largest cusp. It has two strong crests, a mesial one directed towards the centre line of the tooth where it joins the mesial cingulum. The distal one descends obliquely into the centre of the median transverse valley, where it meets the mesial crest on the hypoconid roughly in the centre of the valley. Because of its position, there is a deeply indented buccal notch at the end of the transverse valley. The central crest of the protoconid is short, more like a swelling on the lingual side of the cusp, which touches the centrally directed crest of the metaconid, thereby imparting a loph-like morphology to the mesial cusp pair and enclosing a small mesial fovea. The mesial crest of the metaconid is short and oblique, descending towards the centre line, thereby forming a mesial cingulum. This cingulum descends at a steep angle from the tip of the metaconid lingually, to the base of the protoconid on the buccal side of the crown. The distal crest of the metaconid is directed straight

Relative size of distal loph in M3/

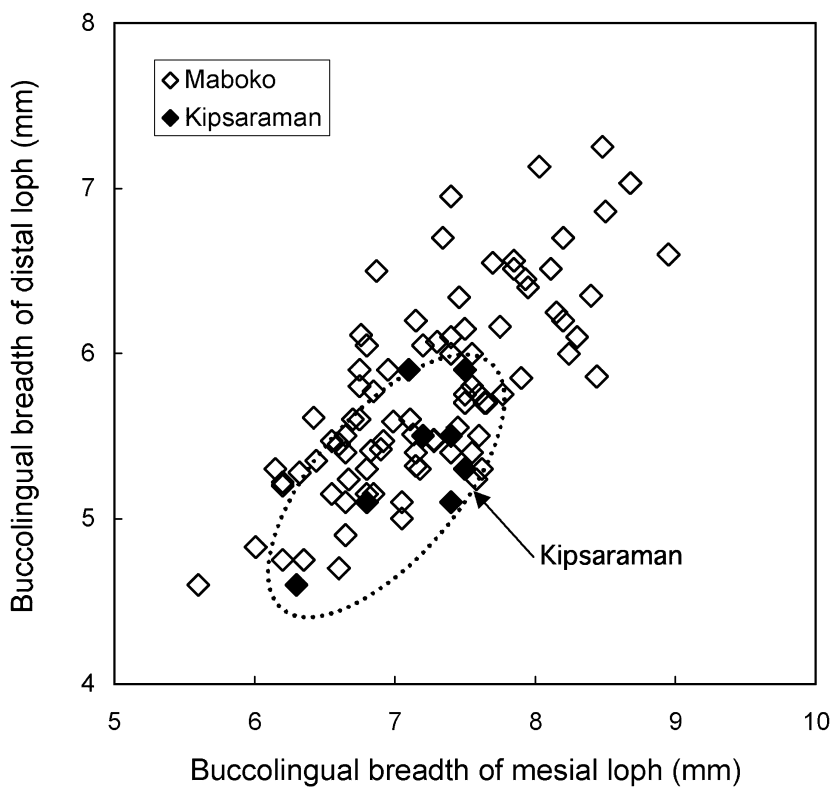

Figure 23. Relative size of distal loph of M3/ in Prohylobates macinnesi and Prohylobates kipsaramanensis sp. nov. (Maboko data from Benefit, personal files). 
backwards where it meets the mesial crest of the entoconid, thus closing off the median transverse valley on its lingual end. The entoconid is swollen buccally and touches the hypoconid in the centre of the tooth, forming a loph-like cusp pair. The distal crest of the entoconid swings obliquely backwards towards the centre line of the tooth where it joins the hypoconulid, enclosing a distal fovea. The distal crest of the hypoconid is directed straight backwards but it ends before reaching the groove that separates the hypoconid from the hypoconulid, and as a result there is a deeply indented buccal notch between the two cusps. In some individuals the hypoconulid is short (Bar 220'02, Figure 20-17) and in others it is longer (Bar 38'02, Figure 20-12). This expresses itself in the size of the distal fovea, which is either pinched in or somewhat more voluminous. The hypoconulid sits on a root that is inclined distally but which is fused throughout its length to the root below the second loph. Most of the teeth are relatively straight to slightly concave on the buccal side, but Bar 917'99 is more markedly concave due to damage. The $\mathrm{m} / 3$ hypoconulid is smaller than it is in Maboko specimens that we have been able to examine, in accordance with the reduced distal cusp pair in the upper third molars. Unfortunately, there are no published data regarding hypoconulid size in $P$. macinnesi and the Buluk cercopithecoids.

\section{Deciduous lower dentition}

Bar 1413'02 is a right dp/4 in moderate wear (Figure 20$3)$. The cusp layout is similar to that of permanent lower molars but the enamel is thinner and the crown not so high. Bar 786'02 is the distal half of a left lower dp/4 and Bar 1032 '99 is a slightly damaged left $\mathrm{dp} / 4$.

\section{Discussion}

Six cercopithecid specimens differ from the remainder of the Kipsaraman monkey fossils by the greater degree of flare on the main cusps, the greater thickness of the enamel, increased broadness of cingula, and their slightly larger size. Given the variation that exists in the Cercopithecidae at Maboko, which are assigned to a single species by Benefit (1993), it is possible that these six specimens are part of the normal variation found within assemblages of victoriapithecines. Provisionally the entire Kipsaraman assemblage is attributed to a single species but it differs from the Maboko species in several details, such as the more buccolingually compressed $\mathrm{p} / 3 \mathrm{~s}$ (see diagnosis). In bivariate plots (Figure 24, Figure 25, Figure 26, Figure 27) the molars of Prohylobates kipsaramanensis almost invariably plot above the regression line of Maboko specimens and some individuals fall outside the range of variation of $P$. macinnesi. The length/breadth ratios for the Maboko and Kipsaraman upper molars are given in Table 2. The mean values in M1/ and M3/of the Kipsaraman sample are significantly smaller than those of the Maboko sample, indicating relatively broader crowns in the former. Although the difference between the mean values of $\mathrm{M} 2$ / in the two samples is not significant statistically, most likely due to the low number of the Kipsaraman specimens (only two), the mean length/breadth ratio of the Kipsaraman M2/ is considerably smaller than that of Maboko (82.1\% vs $91.5 \%$, respectively). In the figures and

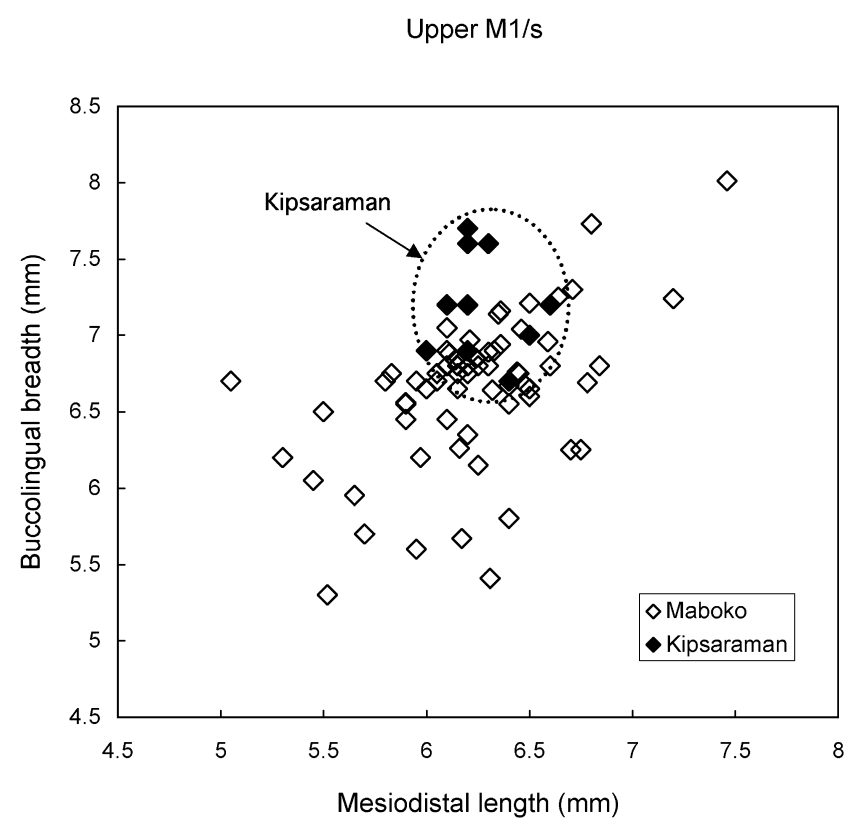

Figure 24. Bivariate plot of upper M1/s of Prohylobates macinnesi and teeth considered to be M1/s of Prohylobates kipsaramanensis sp. nov. on the basis of size, although some doubt remains about their serial position (Appendix 5). (Maboko data from Benefit, personal files).

\section{Upper M2/s}

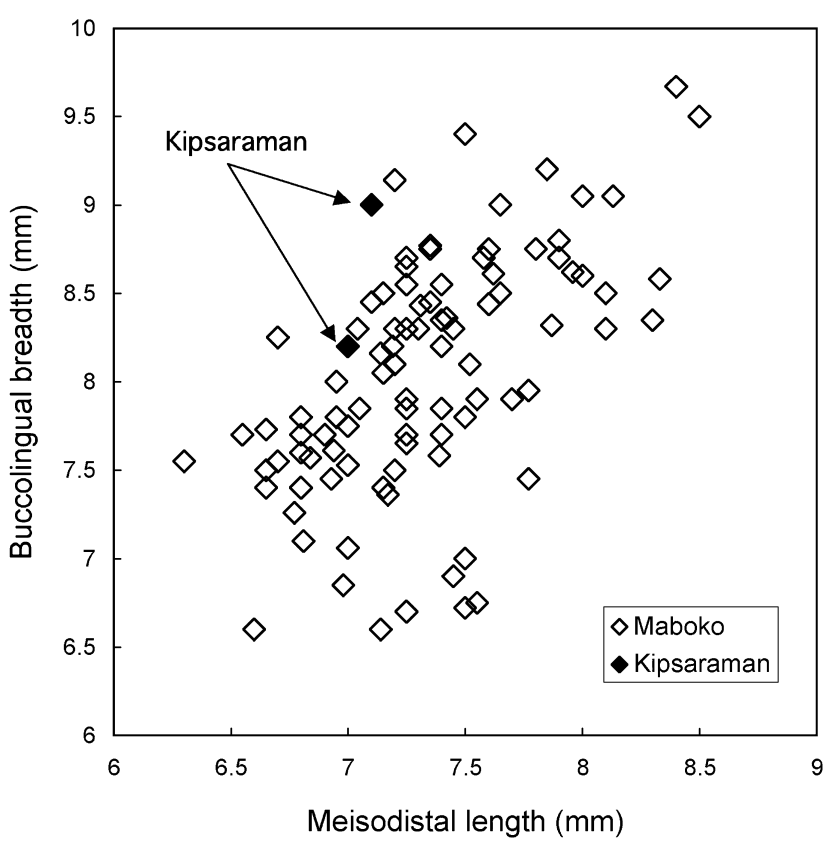

Figure 25. Bivariate plot of upper M2/s of Prohylobates macin$n e s i$ and teeth considered to be M2/s of $P$. kipsaramanensis sp. nov. on the basis of size, although some doubt remains about their serial position (Appendix 5). (Maboko data from Benefit, personal files).

table, the serial position of first and second molars has been estimated on the basis of size, but it should be borne in mind that it is difficult to position these teeth unless they are in 


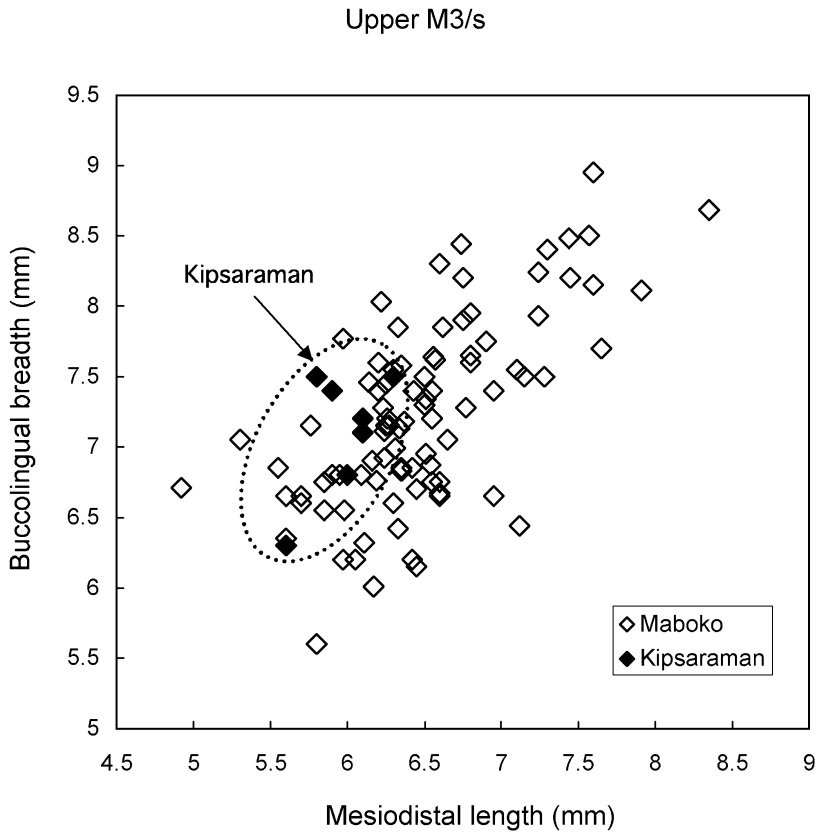

Figure 26. Bivariate plot of upper M3/s of Prohylobates macinnesi and Prohylobates kipsaramanensis sp. nov. (Maboko data from Benefit, personal files).

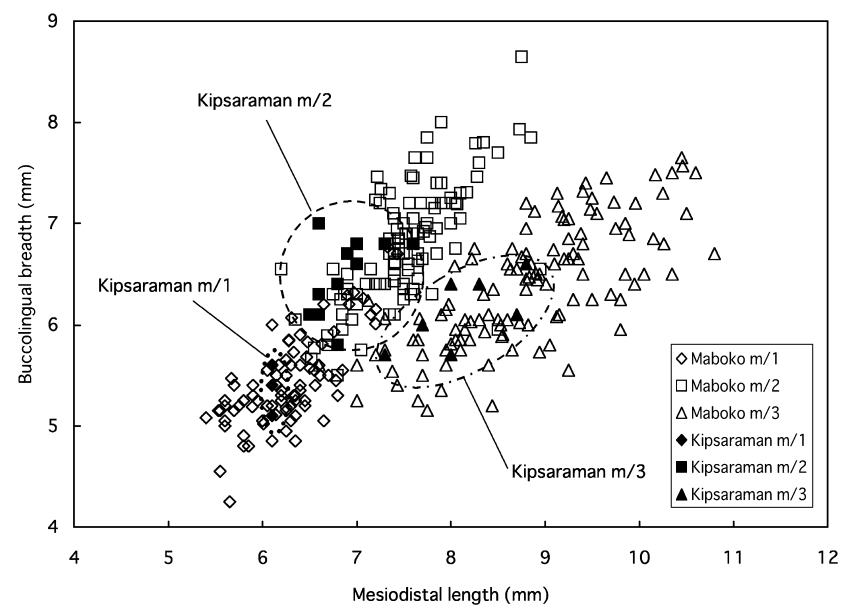

Figure 27. Bivariate plots of lower molars of Prohylobates macinnesi and Prohylobates kipsaramanensis sp. nov., showing the tendency for Kipsaraman molars to be slightly broader on average than those from Maboko. (Maboko data from Benefit, personal files).

maxillae or mandibles (Appendix 5). The different regressions of the upper and lower molars indicate that the Kipsaraman monkeys belong to a different species from that at Maboko (Benefit, 1993). An isolated cercopithecid upper molar from Napak, Uganda (Pilbeam and Walker, 1968) is similar in size to $\mathrm{M} 2 / \mathrm{s}$ of $P$. kipsaramanensis. The range of variation of $P$. kipsaramanensis is appreciably less than that of the Maboko sample attributed to $P$. macinnesi.

Examination of the question of synonymy between Victoriapithecus and Prohylobates leads us to conclude that they are likely to represent a single genus. Not only is that proba-
Table 2. Upper molar length/breadth ratio

\begin{tabular}{lcc} 
& Maboko & Kipsaraman \\
\hline Upper M1 & & \\
$n$ & 70 & 10 \\
Mean** & 94.0 & 87.3 \\
SD & 6.7 & 5.1 \\
Range & $75.4-116.6$ & $80.5-95.5$ \\
Upper M2 & & \\
$n$ & 94 & 2 \\
Mean & 91.5 & 82.1 \\
SD & 6.7 & 4.6 \\
Range & $78.8-111.9$ & $78.9-85.4$ \\
Upper M3 & & 8 \\
$n$ & 91 & 83.6 \\
Mean** & 89.9 & 4.2 \\
SD & 7.0 & $77.3-88.9$ \\
Range & $73.3-110.6$ &
\end{tabular}

L/MB [\%]: L, mesiodistal length; MB, buccolingual breadth of the mesial moiety.

**, $P<0.01$ in $t$-test.

ble, but the two species Prohylobates tandyi and Victoriapithecus macinnesi are closely related to each other as shown by similarities in morphology and dimensions. Leakey (1985) has already indicated that the two genera are probably synonymous, but Benefit (1993) kept them separate. However, close reading of Benefit's exhaustive paper reveals that she was not entirely convinced of this, with all the features she listed as separating the genus Prohylobates from Victoriapithecus falling within the range of variation of the latter. Even the most 'diagnostic' features do not differentiate the taxa: the length of the mesial shelf in lower molars (supposedly shorter in Victoriapithecus), the position of the hypoconulid in $\mathrm{m} / 3$ (said to be closer to the buccal wall in Victoriapithecus than in Prohylobates), metaconid height relative to crown length (indicated to be lower in Victoriapithecus), crown height below the median lingual notch (reported to be low in Victoriapithecus but higher in Prohylobates), completeness of the distal lophid in $\mathrm{m} / 2$ and $\mathrm{m} / 3$ (indicated to be complete in Victoriapithecus and incomplete in Prohylobates).

It is interesting to note that von Koenigswald (1969) did not know that Prohylobates was a cercopithecid, even if it is likely that he knew about the existence of the genus. As he stated in his introduction, the only pre-Pontian monkey fossils known to him at the time of his study were from Maboko Island, Kenya (MacInnes, 1943) and the Albertine Basin, Congo (Hooijer, 1963). Fourtau (1918) erected the genus Prohylobates for a mandible from Wadi Moghara, Egypt, from deposits almost the same age as Maboko, in the belief that it was a hominoid, and it was not until 1969 that Simons removed it from Hominoidea and attributed it to Cercopithecidae, in a paper that appears to have been unavailable to von Koenigswald until after his own paper had been published. It is possible, given the great similarities between the two genera, that von Koenigswald would not have erected the genus Victoriapithecus had he been aware of the cercopithecid status of the Wadi Moghara specimen. Be that as it may, Victoriapithecus was erected, but until recently no serious evidence has been put forward to show that it is any dif- 


\section{ferent from Prohylobates.}

Studies by Benefit (1993) and Leakey (1985) confirm that the two genera are similar to each other, even though neither of these authors took the formal step of declaring them synonymous. As Leakey (1985) pointed out, "On the present evidence there are no clearly defined characters separating the two genera Prohylobates and Victoriapithecus, and it is possible that the genera are synonymous." In her subsequent publication based on more than 2000 teeth and several mandibles from Maboko, Benefit (1993) retained two genera, but the diagnostic features that were taken to separate them are subtle and in fact occur in both, as pointed out above. What is required is a closer comparison of all the fossils, which is beyond the scope of this paper. As Simons (1969) noted, the Wadi Moghara species Dryopithecus mogharensis Fourtau is also a cercopithecid, and it is now generally accepted as part of the hypodigm of $P$. tandyi.

\section{Overview}

\section{Systematic overview}

Old World catarrhine systematics is currently in a state of flux. For example, four systematic schema published in 2002 by various authors in a single monograph are mutually contradictory (Begun, 2002; Harrison, 2002; Kelley et al., 2002; Ward and Duren, 2002). Not only do ranks within the four schema vary considerably, but the contents of the suprageneric units diverge greatly from author to author. For example, the genus Kenyapithecus is classed as Griphopithecidae by Begun (2002) and Hominidae by Ward and Duren (2002). The subfamily Afropithecinae is assigned to Proconsuloidea by Harrison (2002) and to Hominidae by Ward and Duren (2002). Griphopithecinae is a subfamily of Afropithecidae according to Kelley (2002) but is part of Griphopithecidae in Begun (2002). There are many other contradictions in the four schemes, but they are irrelevant to the present paper.

The following systematic arrangement of the Kipsaraman catarrhines represents somewhat of a compromise, taking into account the creation of new families and superfamilies by Harrison (2002).

\section{Catarrhines from Kipsaraman, Kenya}

Order Primates Linnaeus, 1758

Suborder Anthropoidea Mivart, 1864

Infraorder Catarrhini Geoffroy, 1812

Superfamily incertae sedis

Family incertae sedis

Genus Nyanzapithecus Harrison, 1986

Species Nyanzapithecus cf. pickfordi Harrison, 1986

Genus Limnopithecus Hopwood, 1933

Species Limnopithecus indeterminate

Superfamily Dendropithecoidea Harrison, 2002

Family Dendropithecidae Harrison, 2002

Genus Simiolus Leakey and Leakey, 1988 (imprint 1987)

Species Simiolus cheptumoae sp. nov.

Superfamily Hominoidea Gray, 1825

Family incertae sedis
Subfamily Kenyapithecinae Andrews 1992

Genus Kenyapithecus Leakey, 1962 (imprint 1961)

Species Kenyapithecus africanus

(Le Gros Clark and Leakey, 1951)

Family incertae sedis

Genus Ugandapithecus Senut, Pickford, Gommery and Kunimatsu, 2000

Species Ugandapithecus gitongai sp. nov.

Superfamily Cercopithecoidea Gray, 1821

Family Cercopithecidae Gray, 1821

Subfamily Victoriapithecinae von Koenigswald, 1969

Genus Prohylobates Fourtau, 1918

Species Prohylobates kipsaramanensis sp. nov.

\section{Palaeoenvironment at Kipsaraman}

Fossil plants from Kipsaraman consist of petrified wood and leaf impressions preserved in fine-grained tuffs. The only identified plants are Dracaena (the dragon tree) (Osmaston, in Pickford, 1975) represented by fossilized leaves. The presence of this tree indicates a heavily wooded to forested setting. The mammals from Kipsaraman accord with this suggestion. Among the suiformes, there are at least eight taxa, two diminutive folivores (Namachoerus moruoroti and Lopholistriodon pickfordi), three or more frugivores/omnivores (Diamantohyus nadirus, Kenyasus sp. (small), Kenyasus namaquensis, Kenyapotamus ternani) and a gigantic omnivore (Megalochoerus khinzikebirus). There are two tragulid species, a climacoceratid, a giraffoid (Palaeotragus sp.), brachyodont (browsing) bovids, bunodont gomphotheres (Afrochoerodon kisumuensis, Protanancus macinnesi), and deinotheres (Deinotherium hobleyi) (probably folivorous). Mammals adapted to open country and grazing habits are conspicuous by their absence. The overall aspect of the palaeoenvironment would thus be a forested to heavily wooded region.

It is already known that the Kipsaraman deposits accumulated in and around a shallow lacustrine basin, accompanied by the formation of palaeosols (of forest affinities) (Pickford, 1975). At Kipsaraman itself, the deposits were trampled while soft with the result that most of the fossils are fragmented and broken, but not very dispersed in the strata. The abundant presence of crocodile coprolites in the sediments suggests that the deposits were not reworked or transported after initial deposition, but were merely trampled in situ.

\section{Aspects of predation on Kipsaraman catarrhines}

There are several teeth from Kipsaraman which have had the enamel etched from the occlusal surface, but which remain with well-preserved dentine, and even sometimes roots. In other sites, this kind of damage has been attributed to the action of digestive acids, in particular of crocodiles, which dissolve enamel but not dentine. Out of 89 cercopithecid dental specimens, three show this kind of damage, whilst out of 42 small 'ape' specimens, five have it. None of the larger hominoids show this kind of chemical attack, but the sample is small. It is concluded that monkeys and small 
apes occasionally fell prey to crocodiles, which abound at Kipsaraman, being the commonest fossils at the site, represented by teeth, jaw fragments, scutes, limb bones, and coprolites.

\section{Summary of Kipsaraman catarrhines}

The primate fauna from the Muruyur Formation at Kipsaraman, Keturo, and Cheparawa, based on 199 teeth (54 collected between 1980 and 2000 by the BPRP, and 145 collected between 1999 and 2002 by the KPE), resembles that from Maboko more than those from any other sites in East Africa and is quite different from the Nachola assemblage which is almost the same age. Kipsaraman has yielded at least two species of small catarrhine (Simiolus cheptumoae sp. nov. and Limnopithecus sp.), a medium-sized species (Nyanzapithecus cf. pickfordi), a large hominoid (Kenyapithecus africanus), and a huge species (Ugandapithecus gitongai sp. nov.) In addition to these hominoids, Kipsaraman has yielded abundant dental remains of the cercopithecid Prohylobates kipsaramanensis sp. nov.

The taxonomic representation is uneven, P. kipsaramanensis being the most abundant species, followed by $K$. africanus and Limnopithecus sp. while the other three taxa are rarer (Table 3).

Maboko Island (and the neighbouring sites of Majiwa and Kaloma in the same formation) has yielded evidence of 6 or 7 catarrhine species (von Koenigswald, 1969; Pickford, 1985; Harrison, 1986, 1989; Benefit, 1993, 1994). Most abundant is the monkey $P$. macinnesi, known from more than 2000 specimens. K. africanus is quite common (69 teeth known) $N$. pickfordi is moderately common (nearly 90 dental specimens), as is Micropithecus leakeyorum (34 specimens) (referred to Simiolus leakeyorum by Retallack et al., 2002) and cf. Limnopithecus evansi (Retallack et al., 2002). The enigmatic Mabokopithecus clarki possibly represents another 'ape' at the site, but its status is still unclear (Harrison, 2002). Galagids are present at the two localities. Thus the overall structure of the primate fauna from Maboko is similar to that from Kipsaraman.

In contrast, Nachola in northern Kenya (16 Ma) has yielded three species of catarrhines: Nacholapithecus kerioi, which is very abundant (well over 200 specimens often comprising articulated skeletal remains); $N$. harrisoni, which is rarer (23 teeth described in the literature); and Prohylobates, which is as rare as Nyanzapithecus (Ishida et al., 1984, 1999;

Table 3. Catarrhine fauna of the Muruyur Formation at Kipsaraman ${ }^{a}$

\begin{tabular}{lc}
\hline \multicolumn{1}{c}{ Taxon } & Number of teeth $^{\mathrm{b}}$ \\
\hline Simiolus cheptumoae sp. nov. & $10^{\mathrm{c}}$ \\
Limnopithecus sp. & $25^{\mathrm{c}}(+2 ?)$ \\
Nyanzapithecus cf. pickfordi & 8 \\
Kenyapithecus africanus & $53^{\mathrm{d}}$ \\
Ugandapithecus gitongai sp. nov. & 9 \\
Prohylobates kipsaramanensis sp. nov. & 89
\end{tabular}

\footnotetext{
a Five indeterminate small 'ape' teeth are not listed.

b Specimens from Cheparawa and Keturo are included.

${ }^{\mathrm{c}}$ Most teeth are isolated but each of these species is represented by a mandible with two teeth.

${ }^{\mathrm{d}}$ Most of these teeth are in mandibles and maxillae.
}

Pickford et al., 1987; Kunimatsu, 1997). Thus the taxonomic content and structure of the catarrhine fauna from Nachola differs markedly from those of Maboko and Kipsaraman.

The Kipsaraman catarrhine fauna shares some taxa with Fort Ternan, in particular Kenyapithecus and possibly Limnopithecus sp. (Harrison, 1992), but not the second small 'ape' from Fort Ternan called Simiolus sp. by Harrison (1992), the status of which is uncertain. Fort Ternan has also yielded a nyanzapithecine (Harrison, 1992) but no cercopithecid fossils are known from there, nor has it yielded any Ugandapithecus material. The non-primate mammal fauna from Fort Ternan as well as the terrestrial gastropods (Pickford, 1995) and plants (grasses in particular) suggest that Fort Ternan was open woodland, and much less vegetated than Kipsaraman.

\section{Small 'apes' from Early and Middle Miocene of East Africa}

For many years the diversity of small 'apes' in East African Miocene deposits was underestimated, despite good samples from many localities. In effect until the 1970's there was a tendency to attribute specimens to one of two taxa depending on size (Limnopithecus legetet and L.macinnesi). Since the mid 1970's it has become clearer that material traditionally assigned to these two 'species' was morphologically diverse and as a consequence the fossils are now classified in at least six genera (Limnopithecus, Kogolepithecus, Dendropithecus, Micropithecus, Kalepithecus, Simiolus) (Harrison, 1981, 1988; Leakey and Leakey, 1987; Pickford et al., 2003) with some genera being represented by two species (L. legetet, L. evansi, Micropithecus clarki, M. leakeyorum). The present study increases the total by erecting a new species Simiolus cheptumoae. The Kipsaraman fossils, even though fragmentary, are sufficiently different from the type species of Simiolus to remove any doubt about the distinctiveness of the species and permits a clear diagnosis to be proposed.

The current situation is thus that there are nine named species of small 'apes' known from the Early and Middle Miocene deposits of East Africa, plus a few enigmatic specimens, such as an upper molar from Ngorora and several teeth from Fort Ternan, whose affinities are not clear. The distribution of these species is given in Table 4.

\section{Intermediate sized 'apes' (nyanzapithecine) from the Early and Middle Miocene of East Africa}

In addition to the 'small-bodied apes', there are other small 'apes' that have traditionally been excluded from the group, despite the fact that some of them are quite small. These are now identified as Rangwapithecus, Nyanzapithecus, Mabokopithecus, and Turkanapithecus. Even though the size grouping is artificial (they can be thought of as intermediate sized apes, being in general larger than Dendropithecus macinnesi but smaller than Proconsul species, although there is some overlap in dental dimensions), the four genera have been linked in various ways to Oreopithecus (Harrison, 1986; Kunimatsu, 1992a, b), which might indicate that the group may have a legitimate zoological basis. Harrison (2002), for example, classifies the four genera in the Nyanzapithecinae, in the Proconsuloidea. 
Table 4. Small 'apes' from Miocene deposits of East Africa

\begin{tabular}{|c|c|c|c|c|}
\hline Species & $\begin{array}{c}\text { Middle Early Miocene } \\
20-18.5 \mathrm{Ma}\end{array}$ & $\begin{array}{c}\text { Late Early Miocene } \\
18.5-17.5 \mathrm{Ma}\end{array}$ & $\begin{array}{c}\text { Latest Early Miocene } \\
17.5-16 \mathrm{Ma}\end{array}$ & $\begin{array}{l}\text { Middle Miocene } \\
16-12.5 \mathrm{Ma}\end{array}$ \\
\hline Micropithecus clarki & $\begin{array}{l}\text { Napak, Koru, Legetet, } \\
\text { Chamtwara }\end{array}$ & & & \\
\hline Micropithecus leakeyorum & & & & Maboko, Majiwa \\
\hline Micropithecus sp. ${ }^{1}$ & & & & Fort Ternan \\
\hline Limnopithecus legetet & $\begin{array}{l}\text { Koru, Legetet, } \\
\text { Chamtwara, Napak }\end{array}$ & $\begin{array}{l}\text { Rusinga, Bukwa, } \\
\text { William's Flat }\end{array}$ & & \\
\hline Limnopithecus evansi & Songhor, Mteitei Valley & & & $\begin{array}{l}\text { Maboko (cf.) } \\
\text { Kipsaraman (cf.) }\end{array}$ \\
\hline Kogolepithecus morotoensis & & & Moroto II & \\
\hline Kalepithecus songhorensis & $\begin{array}{l}\text { Songhor, Mteitei Valley, } \\
\text { Koru }\end{array}$ & & & \\
\hline Dendropithecus macinnesi & Songhor, Koru, Napak & $\begin{array}{l}\text { Rusinga, Angulo, } \\
\text { Karungu, Mfwangano }\end{array}$ & & \\
\hline Simiolus enjiessi & & & Kalodirr, Locherangan & \\
\hline Simiolus cheptumoae & & & & Kipsaraman \\
\hline Undetermined genus & & & & Fort Ternan, Ngorora \\
\hline
\end{tabular}

The stratigraphic distribution of these 'intermediate sized apes' is provided in Table 5. In East Africa the diversity of the 'intermediate sized apes' is always low, the only site with two taxa being Maboko, and even here there is doubt about the distinctiveness of Mabokopithecus clarki and Nyanzapithecus pickfordi (Harrison, 1986, 2002).

\section{Medium and large apes from the Early and Middle Miocene of East Africa}

There is a relatively high diversity of hominoids from the Early and Middle Miocene of East Africa (Table 6) that are generally larger than the 'intermediate sized apes' listed above, although there is considerable overlap in size between, for example, Rangwapithecus gordoni, which is attributed to the former group, and Proconsul africanus, which is listed in the latter. Kamoyapithecus hamiltoni is not included in this analysis, as it is reported to be of Late Oligocene age (Leakey et al., 1995).

The diversity of medium and large apes fluctuates through the period under examination, but is highest in the Middle Miocene, numerically compensating for the apparent diminution of diversity among the small 'apes'. Whereas there are four species known from the middle Early Miocene (20-
18.5 Ma) (of which two are extremely rare) and only one species from the late Early Miocene (18.5-17.5 Ma), there are two species known in the latest Early Miocene (17.5$16 \mathrm{Ma}$ ) and five in the Middle Miocene (16-12.5 Ma). It was thought for many years that there could only be one species of large ape at any one site, but two species are now known to occur together at some localities (Moroto II, Kipsaraman) (Pickford, 2002; Pickford et al., 2003). At these sites the apes are large (Kenyapithecus africanus, Ugandapithecus gitongai, Ugandapithecus major, Afropithecus turkanensis, depending on the site) and the faunas also contain cercopithecids, sometimes in large quantities.

\section{Cercopithecids from the Early and Middle Miocene of East Africa}

Monkey fossils are extremely rare in Early Miocene East African sites, the only specimens known are from Napak V, consisting of two teeth, a distal humerus, and an elbow joint. Moroto II has yielded three teeth from the southern gullies (Pickford et al., 2003). Nothing is known from the prolific Early Miocene sites in western Kenya where hundreds of catarrhine fossils have been collected (Andrews, 1978; Harrison, 1988). In strong contrast, cercopithecid fossils abound

Table 5. Intermediate sized 'apes' (nyanzapithecines) from the Early and Middle Miocene of East Africa

\begin{tabular}{lcccc}
\hline \multicolumn{1}{c}{ Species } & $\begin{array}{c}\text { Middle Early Miocene } \\
20-18.5 \mathrm{Ma}\end{array}$ & $\begin{array}{c}\text { Late Early Miocene } \\
18.5-17.5 \mathrm{Ma}\end{array}$ & $\begin{array}{c}\text { Latest Early Miocene } \\
17.5-16 \mathrm{Ma}\end{array}$ & $\begin{array}{c}\text { Middle Miocene } \\
16-12.5 \mathrm{Ma}\end{array}$ \\
\hline $\begin{array}{l}\text { Rangwapithecus gordoni } \\
\text { Nyanzapithecus vancouveringorum } \\
\text { Nyanzapithecus pickfordi }\end{array}$ & Songhor ${ }^{1}$ & Rusinga, Mfwangano & \\
Nyanzapithecus harrisoni & & & Maboko \\
Mabokopithecus clarki & & Kipsaraman (cf.) \\
Turkanapithecus kalakolensis & & Kalodirr & Mabola \\
Oreopithecidae? indet. & & & Fort Ternan \\
& & & Kapsibor \\
\hline
\end{tabular}

\footnotetext{
${ }^{1}$ Bosler (unpublished notes) listed an $\mathrm{i} / 2$ and an $\mathrm{m} / 3$ of $R$. gordoni from Legetet and a $\mathrm{p} / 4$ from Chamtwara, and Bosler (1981) listed the genus
} at Koru on the basis of the same three teeth. Pending confirmation of these identifications, we prefer to omit them from the table. 
Table 6. Medium and large apes from the Early and Middle Miocene of East Africa

\begin{tabular}{|c|c|c|c|c|}
\hline Species & $\begin{array}{c}\text { Middle Early Miocene } \\
20-18.5 \mathrm{Ma}\end{array}$ & $\begin{array}{c}\text { Late Early Miocene } \\
18.5-17.5 \mathrm{Ma}\end{array}$ & $\begin{array}{c}\text { Latest Early Miocene } \\
17.5-16 \mathrm{Ma}\end{array}$ & $\begin{array}{c}\text { Middle Miocene } \\
16-12.5 \mathrm{Ma}\end{array}$ \\
\hline Proconsul africanus & $\begin{array}{l}\text { Koru, Chamtwara, Legetet, Song- } \\
\text { hor, Mteitei Valley, Kapurtay }\end{array}$ & & & \\
\hline Proconsul nyanzae/heseloni & Napak & Rusinga, Mfwangano & & \\
\hline Ugandapithecus major & Songhor, Napak, Chamtwara & & & \\
\hline Ugandapithecus gitongai & & & Moroto II cf. ${ }^{2}$ & Kipsaraman \\
\hline $\begin{array}{l}\text { 'Xenopithecus koruensis }{ }^{1} \\
\text { Afropithecus turkanensis }\end{array}$ & Koru & & Kalodirr, Moroto $\mathrm{II}^{3}$ & \\
\hline & & & Locherangan & \\
\hline Kenyapithecus africanus & & & & $\begin{array}{l}\text { Maboko, Nyakach, Kipsaraman, } \\
\text { Cheparawa, Majiwa, Kaloma }\end{array}$ \\
\hline Kenyapithecus wickeri & & & & Fort Ternan \\
\hline Nacholapithecus kerioi & & & & Nachola \\
\hline Undetermined species & & & Moruorot, Buluk ${ }^{4}$ & Fort Ternan, Ngorora \\
\hline
\end{tabular}

${ }^{1}$ Xenopithecus koruensis was described as a separate genus from Proconsul africanus by Hopwood (1933), based on the material from Koru, Western Kenya. It was usually treated as a junior synonym of $P$. africanus in later articles (for example, Andrews, 1978). Madden (1980), however, revived Xenopithecus as a subgenus of Proconsul, while he classified other Proconsul species in a subgenus P. (Proconsul). Madden (1980) also assigned the material from Lothidok, northern Kenya, to P. (Xenopithecus) hamiltoni sp. nov. Later, Leakey et al. (1995) recognized the Lothidok material as a different genus from Proconsul, but retained the Koru material in $P$. africanus. Consequently, the name Xenopithecus could not be applied to the Lothidok material, for which they, therefore, created a new generic name Kamoyapithecus. Although the material described as ' $X$. koruensis' appears to have some differences from other Proconsul species, such as slightly smaller size, and unexpanded trigon with crowded trigon cusps (Madden, 1980), the taxonomy of ' $X$. koruensis' is made difficult due to the very poor nature of the material. In this article, we tentatively retain this taxon with the original name in quotation marks.

2 Four specimens of Ugandapithecus from Moroto II include an upper molar that is extremely large $(14.2 \times 14.5)$ (Pickford et al., 1999, 2003) which could belong to $U$. gitongai.

${ }^{3}$ The Moroto palate (UMP62-11) was assigned to Proconsul major (= Ugandapithecus major) (Pilbeam, 1969; Andrews, 1978). Later, its affinity to Afropithecus/Heliopithecus was pointed out (Andrews, 1992; Andrews and Martin, 1987; Leakey et al., 1988). Pickford (2002) provided a new reconstruction of the Moroto palate, which suggested a strong resemblance to the skull of Afropithecus turkanensis (KNM-WK 16900). Although there are a few minor differences between the Moroto palate and A. turkanensis from Kenya, those traits could be either exaggerated or obliterated due to the damage to the specimens. In this article, we refer the Moroto material to A. turkanensis rather than to Morotopithecus bishopi (Gebo et al., 1997).

${ }^{4}$ The large-bodied hominoid from Buluk is generally assigned to A. turkanensis, although it was originally identified as Sivapithecus (Leakey and Walker, 1983), but one of the authors (M.P.) has some doubts about its specific affinity to the Kalodirr material (Pickford et al., 2003) and considers that it is closer to U. gitongai. Pending revision of the specimens we leave them as undetermined in this article.

Table 7. Cercopithecids from the Early and Middle Miocene of East Africa

\begin{tabular}{lccc}
\hline \multicolumn{1}{c}{ Species } & $\begin{array}{c}\text { Middle Early Miocene } \\
20-18.5 \mathrm{Ma}\end{array}$ & $\begin{array}{c}\text { Late Early Miocene } \\
18.5-17.5 \mathrm{Ma}\end{array}$ & $\begin{array}{c}\text { Latest Early Miocene } \\
17.5-16 \mathrm{Ma}\end{array}$ \\
\hline $\begin{array}{l}\text { Prohylobates sp. } \text { indet. }^{1} \\
\text { Prohylobates macinnesi }\end{array}$ & Napak V & Buluk, Loperot & Nachola, Ngorora \\
Prohylobates kipsaramanensis & & Moroto II & Mabok, Majiwa, Ombo, Nyakach \\
\hline
\end{tabular}

${ }^{1}$ There are likely at least two species involved in this listing.

at some Middle Miocene sites, such as Maboko and Kipsaraman, where they greatly outnumber other catarrhines, even though their diversity at each site is low (one species in each site) (Benefit, 1993, 1994; this study) (Table 7). There is one Middle Miocene site, Fort Ternan, which has yielded a diverse catarrhine fauna comprising two 'small-bodied apes', a nyanzapithecine and two large hominoids, but no cercopithecids (Harrison, 1992), suggesting that Middle Miocene monkeys were still somewhat stenotopic, and had not adapted to many different habitats as they were to by Late Miocene times (Pickford and Senut, 1988).

\section{Conclusions}

Six taxa of catarrhines are described from three Middle Miocene localities in the Muruyur Formation (ca. 14.5 Ma),
Tugen Hills, Kenya. Three of the species are new to science. The catarrhines from the sites consist of Simiolus cheptumoae sp. nov., Limnopithecus sp., Nyanzapithecus cf. pickfordi, Kenyapithecus africanus, Ugandapithecus gitongai sp. nov., and Prohylobates kipsaramanensis sp. nov.

In terms of quantities of fossils, the Kipsaraman catarrhine fauna is dominated by a species of victoriapithecine monkey (89 specimens), but small 'apes' with some dental adaptations to folivory were also abundant [23 (+2?)] specimens attributed to Limnopithecus sp., and 12 specimens to Simiolus cheptumoae). An 'intermediate sized ape' species (Nyanzapithecus cf. pickfordi) is represented by 8 fossils, a large species of catarrhine, Kenyapithecus africanus, is well represented by teeth ( 53 specimens) belonging to a few individuals only, while the remaining species, a very large primate, Ugandapithecus gitongai, is rare (9 specimens). In 
addition there are 5 indeterminate small 'ape' teeth from the site.

The Kipsaraman discoveries represent a significant addition to our knowledge about Middle Miocene catarrhines of East Africa.

\section{Acknowledgments}

We thank members of the Kenya Palaeontology Expedition for their help in the field, in particular Dr Brigitte Senut and $\mathrm{Mr}$ Kiptalam Cheboi. Research permission was accorded by the Ministry of Education, Research and Technology, Kenya. Funds were provided by the Collège de France (Prof. Y. Coppens), the Département Histoire de la Terre (Prof. Ph. Taquet, S. Sen, C. de Muizon), the French Ministry of Foreign Affairs (Commission de Fouilles), and the CNRS (Projet PICS). We are particularly keen to thank the Community Museums of Kenya (Mr E. Gitonga) for their help and cooperation and Prof. H. Ishida for inviting M.P. to spend time in his laboratory as visiting professor at Kyoto University. We would also like to thank Dr Brenda Benefit for providing us with unpublished measurements of Maboko cercopithecids and Christiane Chancogne and Dennis Serette for some of the photographs.

\section{References}

Andrews P.J. (1974) New species of Dryopithecus from Kenya. Nature, 249: 188-196, 680.

Andrews P.J. (1978) A revision of the Miocene Hominoidea of East Africa. Bulletin of the British Museum of Natural History (Geology), 30: 85-224.

Andrews P.J. (1992) Evolution and environment in the Hominoidea. Nature, 360: 641-646.

Andrews P.J. and Martin L. (1987) The phyletic position of the Ad Dabtiyah hominoid. Bulletin of the British Museum of Natural History (Geology), 41: 383-393.

Begun D. (2000) Technical comments: Middle Miocene hominoid origins. Science, 287: 2375, www.sciencemag.org/cgi/content/full/287/5462/2375a.

Begun D. (2002) European hominoids. In: Hartwig W.C. (ed.), The Primate Fossil Record. Cambridge University Press, Cambridge, pp. 339-368.

Benefit B. (1993) The permanent dentition and phylogenetic position of Victoriapithecus from Maboko Island, Kenya. Journal of Human Evolution, 25: 83-172.

Benefit B. (1994) Phylogenetic, paleodemographic, and taphonomic implications of Victoriapithecus deciduous teeth from Maboko, Kenya. American Journal of Physical Anthropology, 95: 277-331.

Benefit B. and McCrossin M.L. (2000) Middle Miocene hominoid origins. Science, 387: 2375, www.sciencemag.org/cgi/content/full/287/5462/2375a.

Benefit B. and Pickford M. (1986) Miocene fossil cercopithecoids from Kenya. American Journal of Physical Anthropology, 69: 441-464.

Bosler W. (1981) Species groupings of early Miocene Dryopithecine teeth from East Africa. Journal of Human Evolution, 10: $151-158$

Brown B., Ward S., and Hill A. (1995) New Kenyapithecus partial skeleton from the Tugen Hills, Baringo District, Kenya. American Journal of Physical Anthropology, Supplement 20: 69.

Fleagle J. and Simons E.L. (1978) Micropithecus clarki, a small ape from the Miocene of Uganda. American Journal of Physi- cal Anthropology, 49: 427-440.

Fourtau R. (1918) Contributions à l'étude des Vertébrés Miocènes de l'Egypte. Geological Survey of Egypt, Cairo, pp. i-vii, 1121.

Gebo D.L., MacLatchy L., Kityo R., Deino A., Kingston J., and Pilbeam D. (1997) A hominoid genus from the Early Miocene of Uganda. Science, 276: 401-404.

Gommery D., Senut B., and Pickford M. (1998) New hominoid post-cranial remains from the early Miocene of Napak, Uganda. Annales de Paléontologie, 84: 287-306.

Harrison T. (1981) New finds of small fossil apes from the Miocene locality at Koru in Kenya. Journal of Human Evolution, 10: 129-137.

Harrison T. (1982) Small bodied apes from the Miocene of East Africa. Ph.D. dissertation, University of London, pp. 1-647.

Harrison T. (1986) New fossil anthropoids from the Middle Miocene of East Africa and their bearing on the origin of the Oreopithecidae. American Journal of Physical Anthropology, 71: 265-284.

Harrison T. (1988) A taxonomic revision of the small Catarrhine Primates from the early Miocene of East Africa. Folia Primatologica, 50: 59-108.

Harrison T. (1989) A new species of Micropithecus from the middle Miocene of Kenya. Journal of Human Evolution, 18: 537 557.

Harrison T. (1992) A reassessment of the taxonomic and phylogenetic affinities of the fossil Catarrhines from Fort Ternan, Kenya. Primates, 33: 501-522.

Harrison T. (1998) Evidence for a tail in Proconsul heseloni. American Journal of Physical Anthropology, Supplement 26: 93-94.

Harrison T. (2002) Late Oligocene to middle Miocene catarrhines from Afro-Arabia. In: Hartwig W.C. (ed.), The Primate Fossil Record. Cambridge University Press, Cambridge, pp. 311338.

Harrison T. and Rook L. (1997) Enigmatic anthropoid or misunderstood ape? The phylogenetic status of Oreopithecus bambolii reconsidered. In: Begun D.R., Ward C.V., and Rose M.D. (eds.), Function, Phylogeny, and Fossils: Miocene Hominoid Evolution and Adaptations. Plenum Press, New York, pp. 327-362.

Hill A., Behrensmeyer K., Brown B., Deino A., Rose M., Saunders J., Ward S., and Winkler A. (1991) Kipsaramon: a lower Miocene hominoid site in the Tugen Hills, Baringo District, Kenya. Journal of Human Evolution, 20: 67-75.

Hooijer D.A. (1963) Miocene mammals of Congo. Annales du Muséum Royal d'Afrique Centrale, Séries 8, Science géologique, 46: 1-77.

Hopwood A.T. (1933) Miocene primates from British East Africa. Annals and Magazine of Natural History, Series 10, 11: 9698.

Ishida H., Pickford M., Nakaya H., and Nakano Y. (1984) Fossil Anthropoids from Nachola and Samburu Hills, Samburu District, Northern Kenya. African Study Monographs, Supplementary Issue 2: 73-85.

Ishida H., Kunimatsu Y., Nakatsukasa M., and Nakano Y. (1999) New hominoid genus from the Middle Miocene of Nachola, Kenya. Anthropological Science, 107: 189-191.

Ishida H., Nakatsukasa M., Kunimatsu Y., and Nakano Y. (2000) Erection of a new genus and species: Nacholapithecus kerioi for a middle Miocene hominoid from Nachola area, northern Kenya. Anthropological Science, 108: 92.

Kelley J. (2002) The hominoid radiation in Asia. In: Hartwig W.C. (ed.), The Primate Fossil Record. Cambridge University Press, Cambridge, pp. 369-384.

Kelley J., Ward S., Brown B., Hill A., and Downs W. (2000) Middle Miocene hominoid origins. Science, 287: 2375a.

Kelley J., Ward S.C., Brown B., Hill A., and Duren D.L. (2002) Dental remains of Equatorius africanus from Kipsaramon, 
Tugen Hills, Baringo District, Kenya. Journal of Human Evolution, 42: 39-62.

Kunimatsu Y. (1992a) A revision of the hypodigm of Nyanzapithecus vancouveringi. African Study Monographs, 13: 231-235.

Kunimatsu Y. (1992b) New finds of a small anthropoid primate from Nachola, Northern Kenya. African Study Monographs, 13: 237-249

Kunimatsu Y. (1997) New species of Nyanzapithecus from Nachola, Northern Kenya. Anthropological Science, 105: $117-141$.

Leakey L.S.B. (1961) A new lower Pliocene fossil primate from Kenya. Annals and Magazine of Natural History, Series 13, 4: 689-697 (actually published in 1962).

Leakey M.G. (1985) Early Miocene cercopithecids from Buluk, Northern Kenya. Folia primatologica, 44: 1-14.

Leakey M.G., Ungar P.S., and Walker A. (1995) A new genus of large primate from the late Oligocene of Lothidok, Turkana District, Kenya. Journal of Human Evolution, 28: 519-531.

Leakey R.E. and Leakey M.G. (1987) A new Miocene small-bodied ape from Kenya. Journal of Human Evolution, 16: 369387.

Leakey R.E. and Walker A. (1983) New higher primates from the early Miocene of Buluk, Kenya. Nature, 318: 173-175.

Leakey R.E., Leakey, M.G., and Walker, A. (1988) Morphology of Afropithecus turkanensis from Kenya. American Journal of Physical Anthropology, 76: 289-307.

Le Gros Clark W.E. and Leakey L.S.B. (1951) The Miocene Hominoidea of East Africa. Fossil Mammals of Africa, 1: 1-117.

MacInnes D.G. (1943) Notes on the East African Miocene primates. Journal of the East Africa and Uganda Natural History Society, 17: 141-181

Madden C.T. (1980) New Proconsul (Xenopithecus) from the Miocene of Kenya. Primates, 21: 241-252.

Martin L. (1981) New specimens of Proconsul from Koru, Kenya. Journal of Human Evolution, 10: 139-150.

McCrossin M.L. (1992) An oreopithecid proximal humerus from the middle Miocene of Maboko Island, Kenya. International Journal of Primatology, 13: 659-677.

Moyà-Solà S. and Köhler M. (1996) A Dryopithecus skeleton and the origins of great-ape locomotion. Nature, 379: 156-159.

Moyà-Solà S. and Köhler M. (1997) The phylogenetic relationships of Oreopithecus bambolii Gervais, 1872. Comptes Rendus de l'Académie des Sciences, Series 2A, 324: 141-148.

Nakatsukasa M., Ishida H., Kunimatsu Y., and Nakano Y. (2000) Whole skeleton of the large hominoid from Nachola, northern Kenya. Anthropological Science, 108: 92.

Nakatsukasa M., Ward C.V., Walker A., Teaford M.F., Kunimatsu Y., and Ogihara N. (2004) Tail loss in Proconsul heseloni. Journal of Human Evolution, 46: 777-784.

Pickford M. (1975) Stratigraphy and palaeoecology of five Late Cenozoic Formations in the Kenya Rift Valley. Ph.D. dissertation, University of London, 219 pp.

Pickford M. (1981) Preliminary Miocene mammalian biostratigraphy for western Kenya. Journal of Human Evolution, 10: 73 97.

Pickford M. (1982) New higher primate fossils from the middle Miocene deposits at Majiwa and Kaloma, western Kenya. American Journal of Physical Anthropology, 58: 1-19.

Pickford M. (1985) A new look at Kenyapithecus based on recent discoveries in western Kenya. Journal of Human Evolution, 14: 113-143.

Pickford M. (1988) Geology and fauna of the Mid-Miocene Muruyur Beds, Baringo District, Kenya. Human Evolution, 3: 381-390.

Pickford M. (1995) Fossil land snails of East Africa and their palaeoecological significance. Journal of African Earth Sciences, 20: 167-226.

Pickford M. (2002) New reconstruction of the Moroto hominoid palate and a reassessment of its affinities to Afropithecus turkanensis. Human Evolution, 17: 1-19.

Pickford M. and Senut B. (1988) Habitat and locomotion in Miocene cercopithecoids. In: Gautier-Hion A., Bourlière F., Gautier J.-P., and Kingdon J. (eds.), A Primate Radiation. Cambridge University Press, Cambridge, pp. 35-53.

Pickford M., Ishida H., Nakano Y., and Yasui Y. (1987) The Middle Miocene Fauna from the Nachola and Aka Aiteputh Formations, Northern Kenya. African Study Monographs, Supplementary Issue 5: 141-154 (actually published in 1999).

Pickford M., Senut B., and Gommery D. (1999) Sexual dimorphism in Morotopithecus bishopi, and early Middle Miocene hominoid from Uganda, and a reassessment of its geological and biological contexts. In: Andrews P. and Banham P. (eds.), Late Cenozoic Environments and Hominid Evolution: A Tribute to Bill Bishop. Geological Society, London, pp. 27 38.

Pickford M., Senut B., Gommery D., and Musiime E. (2003) New Catarrhine fossils from Moroto II, Early Middle Miocene (ca. 17.5 Ma) Uganda. Comptes Rendus Palévol, 2: 649-662.

Pilbeam D.R. (1969) Tertiary Pongidae of East Africa: evolutionary relationships and taxonomy. Bulletin of the Peabody Museum of Natural History, Bulletin 31, Peabody Museum of Natural History, Yale University, New Haven, pp. 1-185.

Pilbeam D.R. and Walker A. (1968) Fossil monkeys from the Miocene of Napak, North-east Uganda. Nature, 220: 657660.

Retallack G.J., Wynn J.G., Benefit B., and McCrossin M.L. (2002) Paleosols and paleoenvironments of the middle Miocene Maboko Formation, Kenya. Journal of Human Evolution, 42: 659-703.

Rose M.D. (1993) Locomotor anatomy of Miocene Hominoids. In: Gebo D.L. (ed.), Postcranial Adaptation in Primates. Northern Illinois University Press, De Kalb, pp. 252-272.

Senut B., Pickford M., Gommery D., and Kunimatsu Y. (2000) A new genus of Early Miocene hominoid from East Africa: Ugandapithecus major (Le Gros Clark and Leakey, 1950). Comptes Rendus de l'Académie des Sciences, Series 2A, 331: 227-233.

Sherwood R.J., Ward S.C., Hill A., Duren D.L., Brown B., and Downs W. (2002) Preliminary description of the Equatorius africanus partial skeleton (KNM-TH 28860) from Kipsaramon, Tugen Hills, Baringo District, Kenya. Journal of Human Evolution, 42: 63-73.

Simons E.L. (1969) Miocene monkey (Prohylobates) from northern Egypt. Nature, 223: 687-689.

von Koenigswald R. (1969) Miocene Cercopithecoidea and Oreopithecoidea from the Miocene of East Africa. Fossil Vertebrates of Africa, 1: 39-52.

Ward C.V., Walker A., and Teaford M.F. (1991) Proconsul did not have a tail. Journal of Human Evolution, 21: 215-220.

Ward C.V., Walker A., and Teaford M. (1999) Still no evidence for a tail in Proconsul heseloni. American Journal of Physical Anthropology, Supplement 28: 273.

Ward S. and Duren D. (2002) Middle and Late Miocene African hominoids. In: Hartwig W.C. (ed.) The Primate Fossil Record. Cambridge University Press, Cambridge, pp. 385397.

Ward S., Brown B., Hill A., Kelley J., and Downs W. (1999) Equatorius: a new hominoid genus from the Middle Miocene of Kenya. Science, 285: 1382-1386. 
Appendix 1. Nyanzapithecus cf. pickfordi from Kipsaraman, Tugen Hills, Kenya, with length and breadth measurements (in $\mathrm{mm}$ )

\begin{tabular}{lllcc}
\hline Prefix & \multicolumn{1}{c}{ Number } & Tooth & Length & Breadth \\
\hline Bar & $217^{\prime} 02$ & I1/ & $7.0 \mathrm{e}$ & - \\
Bar & $1999^{\prime} 02$ & C1/ & 7.4 & 5.9 \\
Bar & $1180^{\prime} 99$ & ?M2/ & 8.5 & 7.6 \\
Bar & $197^{\prime} 02$ & $\mathrm{M}^{* /}$ & 7.9 & $6.5+$ \\
TH & $37368(=93-2)$ & M2/ & 8.7 & 7.8 \\
Bar & $92^{\prime} 99$ & M3/ & 8.4 & 7.6 \\
TH & 22905 & M3/ & 8.8 & 7.8 \\
TH & 22913 & m/2 & 9.6 & 7.5 \\
\hline
\end{tabular}

Measurements for specimens with the TH prefix from Kelley et al. (2002).

*, serial position uncertain; e, estimated measurement; + , tooth is broader than the value.

Appendix 2. Small 'apes' from Kipsaraman, Tugen Hills, Kenya, with length and breadth measurements (in mm)

\begin{tabular}{|c|c|c|c|c|c|c|}
\hline Prefix & Number & Tooth & Length & Breadth & $\begin{array}{c}\mathrm{L} \times \mathrm{B} \\
\text { (broken) }\end{array}$ & Species \\
\hline Bar & $1140 ’ 99$ & $\mathrm{dc} / 1$ & - & - & & Indet. \\
\hline Bar & $296 ’ 02$ & $\mathrm{dp} / 4$ & 4.3 & 3.6 & & Indet. \\
\hline Bar & $1032 ’ 99$ & frag & - & - & & Indet. \\
\hline Bar & $2095^{\prime} 01 \mathrm{~b}$ & frag & - & - & & Indet. \\
\hline Bar & $782 ’ 02$ & M2/ & $6.0 \mathrm{e}$ & $6.8 \mathrm{e}$ & $(5.6 \times 6.6)$ & Indet. \\
\hline Bar & $90 ’ 98$ & I1/ & 4.1 & 3.3 & & Limnopithecus sp. \\
\hline Bar & $11399^{\prime} 99$ & P4/ & 3.6 & 6.1 & & Limnopithecus sp. \\
\hline Bar & 294’02 & M1/ & 4.8 & 5.9 & & Limnopithecus sp. \\
\hline Bar & $192 ’ 02$ & M2/ & 5.8 & 6.7 & & Limnopithecus sp. \\
\hline Bar & $2000^{\prime} 02$ & M2/ & 6.2 & 6.9 & & Limnopithecus sp. \\
\hline Bar & $2176^{\prime} 01$ & M2/ & 5.3 & 6.3 & & Limnopithecus sp. \\
\hline Bar & $218^{\prime} 02$ & M2/ & 5.4 & 6.4 & & Limnopithecus sp. \\
\hline Bar & 773 '02 & M2/ & 5.5 & 6.4 & & Limnopithecus sp. \\
\hline Bar & $775^{\prime} 02$ & M2/ & 5.5 & 6.6 & & Limnopithecus sp. \\
\hline $\mathrm{TH}$ & 18689 & M2/ & 6.0 & 7.5 & & Limnopithecus sp. \\
\hline Bar & $2095^{\prime} 01 \mathrm{a}$ & M3/ frag. & - & 6.1 & & Limnopithecus sp. \\
\hline Bar & 36,02 & $\mathrm{M} 3 /$ & 5.2 & 5.7 & & Limnopithecus sp. \\
\hline Bar & $772^{\prime} 02$ & M3/ & 4.9 & 6.2 & & Limnopithecus sp. \\
\hline Bar & 1116 '99 & $\mathrm{dC} 1 /$ & - & - & & Indet. (Limnopithecus sp. ?) \\
\hline Bar & $1117 ’ 99$ & $\mathrm{dC} 1 /$ & - & - & & Indet. (Limnopithecus sp. ?) \\
\hline Bar & $1009 ' 99$ & $\mathrm{dP} 4 /$ & - & - & & Limnopithecus $\mathrm{sp}$. \\
\hline Bar & $1486 ’ 01$ & $\mathrm{dP} 4 /$ & $4.8 \mathrm{e}$ & $5.7 \mathrm{e}$ & $(4.6 \times 5.5)$ & Limnopithecus sp. \\
\hline Bar & $1899^{\prime} 02$ & $\mathrm{p} / 4$ & - & 3.9 & & Limnopithecus sp. \\
\hline Bar & $2001^{\prime} 02$ & $\mathrm{p} / 4$ & - & 4.0 & & Limnopithecus sp. \\
\hline Bar & $790 ’ 02$ & $\mathrm{~m} / 1$ & 5.7 & 4.6 & & Limnopithecus sp. \\
\hline Bar & 216,02 & $\mathrm{~m} / 2$ & 6.4 & 5.3 & & Limnopithecus sp. \\
\hline Bar & $1115^{\prime} 99$ & $\mathrm{~m} / 3$ & 6.8 & 5.9 & & Limnopithecus sp. \\
\hline Bar & $216^{\prime} 02$ & $\mathrm{~m} / 3$ & 6.8 & 5.1 & & Limnopithecus sp. \\
\hline Bar & $765^{\prime} 02$ & $\mathrm{c} / 1 \mathrm{~m}$ & 7.1 & 5.3 & & Limnopithecus sp. \\
\hline Bar & $1230 ’ 99$ & $\mathrm{dc} / 1$ & 4.9 & 4.3 & & Limnopithecus sp. \\
\hline Bar & $1488^{\prime} 01$ & $\mathrm{dC} 1 /$ & 4.2 & 3.1 & & Simiolus cheptumoae sp. nov. \\
\hline Bar & $230 ’ 02$ & $\mathrm{dC} 1 /$ & 4.4 & 3.2 & & Simiolus cheptumoae sp. nov. \\
\hline Bar & 231 '02 & $\mathrm{dC} 1 /$ & 4.0 & 3.2 & & Simiolus cheptumoae sp. nov. \\
\hline Bar & $37^{\prime} 02$ & $\mathrm{dC} 1 /$ & 4.3 & 3.6 & & Simiolus cheptumoae sp. nov. \\
\hline Bar & $1004 ’ 99$ & $\mathrm{P} 4 /$ & 3.7 & 5.8 & & Simiolus cheptumoae sp. nov. \\
\hline Bar & 1134 '99 & $\mathrm{P} 4 /$ & 3.8 & 6.1 & & Simiolus cheptumoae sp. nov. \\
\hline Bar & $23 ’ 98$ & $\mathrm{p} / 4$ & 4.3 & 3.3 & & Simiolus cheptumoae sp. nov. \\
\hline Bar & $761 ' 02$ & $\mathrm{p} / 4$ & 4.6 & 3.5 & & Simiolus cheptumoae sp. nov. \\
\hline Bar & $764 ’ 02$ & $\mathrm{p} / 4$ & 4.7 & 3.6 & & Simiolus cheptumoae sp. nov. \\
\hline Bar & $2087^{\prime} 01$ & $\mathrm{~m} / 1$ & 6.0 & 4.4 & & Simiolus cheptumoae sp. nov. \\
\hline Bar & $761{ }^{\prime} 02$ & $\mathrm{~m} / 1$ & 5.9 & 4.3 & & Simiolus cheptumoae sp. nov. \\
\hline Bar & $824^{\prime} 02$ & $\mathrm{~m} / 3$ & 5.9 & 4.4 & & Simiolus cheptumoae sp. nov. \\
\hline
\end{tabular}

Measurements for TH 18689 from Hill et al. (1991). Measurements in parentheses are of broken teeth.

e, estimated measurement. 

Appendix 3. Kenyapithecus africanus from Kipsaraman and Chep-
arawa, Tugen Hills, Kenya, with length and breadth measurements (in $\mathrm{mm}$ )

\begin{tabular}{|c|c|c|c|c|}
\hline Prefix & Number & Tooth & Length & Breadth \\
\hline $\mathrm{TH}$ & 22886 & $\mathrm{I} 1 /$ & 8.0 & 6.4 \\
\hline $\mathrm{TH}$ & 28860 & $\mathrm{I} 1 /$ & 10.2 & 7.5 \\
\hline $\mathrm{TH}$ & 22887 & $\mathrm{I} 2 /$ & 4.8 & 5.5 \\
\hline $\mathrm{TH}$ & 22888 & $\mathrm{I} 2 /$ & 4.8 & 6.3 \\
\hline $\mathrm{TH}$ & 28860 & $\mathrm{I} 2 /$ & 6.5 & 7.1 \\
\hline $\mathrm{TH}$ & 22893 & P3/ & 6.1 & 9.2 \\
\hline $\mathrm{TH}$ & $22896 / 22912$ & P3/ & 6.3 & 9.1 \\
\hline $\mathrm{TH}$ & 22892 & P4/ & 5.9 & 9.0 \\
\hline $\mathrm{TH}$ & 22894 & P4/ & 6.5 & 9.1 \\
\hline $\mathrm{TH}$ & $93-1$ & $\mathrm{P} 4 /$ & 6.2 & 8.8 \\
\hline TH & 22897 & M1/ & 8.9 & 9.7 \\
\hline $\mathrm{TH}$ & 22898 & M1/ & 8.7 & 9.6 \\
\hline TH & 22899 & M1/ & 8.5 & 9.8 \\
\hline $\mathrm{TH}$ & 22900 & M1/ & 9.8 & 10.3 \\
\hline $\mathrm{TH}$ & 23525 & M1/ & 8.8 & 9.8 \\
\hline $\mathrm{TH}$ & 23180 & M1/ & 8.8 & 9.6 \\
\hline Bar & $1237^{\prime} 99$ & ?M1/ & 9.8 & 11.3 \\
\hline Bar & $214^{\prime} 02$ & ?M2/ & 11.7 & 12.1 \\
\hline $\mathrm{TH}$ & $22901 / 23528$ & M2/ & 10.1 & 11.7 \\
\hline TH & 22902 & M2/ & 9.8 & 10.3 \\
\hline TH & 22903 & M2/ & 10.7 & 11.0 \\
\hline $\mathrm{TH}$ & 22916 & M2/ & 11.0 & 11.3 \\
\hline $\mathrm{TH}$ & 23180 & M2/ & 10.5 & 11.3 \\
\hline TH & 22904 & M3/ & 9.6 & 9.7 \\
\hline $\mathrm{TH}$ & 23527 & M3/ & 10.0 & 10.3 \\
\hline TH & $93-52$ & M3/ & 9.3 & 9.2 \\
\hline TH & 22889 & $\mathrm{C} 1 /$ & 10.1 & 8.6 \\
\hline TH & 22891 & $\mathrm{C} 1 /$ & 11.6 & 9.4 \\
\hline TH & 22890 & $\mathrm{C} 1 /$ & 11.8 & 9.2 \\
\hline $\mathrm{TH}$ & 22907 & $\mathrm{i} / 1$ & 4.3 & 6.7 \\
\hline $\mathrm{TH}$ & 28860 & $\mathrm{i} / 1$ & 5.0 & 6.1 \\
\hline $\mathrm{TH}$ & 22908 & $\mathrm{i} / 2$ & 3.5 & 5.5 \\
\hline $\mathrm{TH}$ & 28860 & $\mathrm{i} / 2$ & 5.5 & 8.3 \\
\hline TH & 28860 & $\mathrm{i} / 2$ & 4.9 & 8.2 \\
\hline Bar & 212'99 & $\mathrm{c} / 1$ & 8.3 & 6.3 \\
\hline $\mathrm{TH}$ & 22909 & $\mathrm{c} / 1$ & 8.3 & 9.3 \\
\hline TH & 28860 & $\mathrm{c} / 1$ & 12.4 & 9.5 \\
\hline $\mathrm{TH}$ & 28860 & $\mathrm{p} / 3$ & 8.8 & 12.9 \\
\hline $\mathrm{TH}$ & 28860 & $\mathrm{p} / 3$ & 8.8 & 12.7 \\
\hline $\mathrm{TH}$ & 22910 & $\mathrm{p} / 4$ & 8.4 & 6.6 \\
\hline $\mathrm{TH}$ & 28860 & $\mathrm{p} / 4$ & 8.0 & 8.2 \\
\hline $\mathrm{TH}$ & 28860 & $\mathrm{p} / 4$ & 7.5 & 8.5 \\
\hline $\mathrm{TH}$ & 22914 & $\mathrm{~m} / 1$ & 9.7 & 7.8 \\
\hline $\mathrm{TH}$ & 22931 & $\mathrm{~m} / 1$ & 9.8 & 7.8 \\
\hline $\mathrm{TH}$ & 28860 & $\mathrm{~m} / 1$ & - & 8.9 \\
\hline $\mathrm{TH}$ & 28860 & $\mathrm{~m} / 1$ & 9.9 & 8.5 \\
\hline $\mathrm{TH}$ & 22915 & $\mathrm{~m} / 2$ & 11.2 & 9.8 \\
\hline $\mathrm{TH}$ & 22917 & $\mathrm{~m} / 2$ & 11.2 & 9.8 \\
\hline $\mathrm{TH}$ & $93-53$ & $\mathrm{~m} / 2$ & 11.0 & 10.1 \\
\hline $\mathrm{TH}$ & 28860 & $\mathrm{~m} / 2$ & 11.3 & 10.5 \\
\hline $\mathrm{TH}$ & 28860 & $\mathrm{~m} / 3$ & 13.9 & 11.3 \\
\hline $\mathrm{TH}$ & 28860 & $\mathrm{~m} / 3$ & 14.4 & 11.2 \\
\hline $\mathrm{TH}$ & 23529 & $\mathrm{dC} /$ & 5.1 & 3.7 \\
\hline
\end{tabular}

Measurements for specimens with the TH prefix from Kelley et al. (2002).
Appendix 4. Ugandapithecus gitongai sp. nov. from Kipsaraman, Tugen Hills, Kenya, with length and breadth measurements (in mm)

\begin{tabular}{cllcc}
\hline Prefix & Number & Tooth & Length & Breadth \\
\hline Bar & $1473^{\prime} 01$ & $\mathrm{C} 1 / \mathrm{f}$ & 9.2 & 7.6 \\
Bar & $215^{\prime} 02$ & $\mathrm{M} 1 /$ & 12.6 & 13.2 \\
Bar & $737^{\prime} 02$ & $\mathrm{M} 1 /$ & 12.1 & 14.3 \\
Bar & $210^{\prime} 02$ & $\mathrm{M} 2 /$ & 14.2 & 16.7 \\
Bar & $35^{\prime} 02$ & $\mathrm{M} 2 /$ & 13.3 & $12.4+$ \\
Bar & $282^{\prime} 02$ & $\mathrm{dc} / 1$ & 8.0 & 7.1 \\
Bar & $2201^{\prime} 01$ & $\mathrm{c} / 1$ & - & -13.8 \\
TH & 18690 & $\mathrm{~m} / 2$ & 14.9 & 12.7 \\
Bar & $213^{\prime} 02$ & $\mathrm{~m} / 3$ & 16.1 & \\
\hline
\end{tabular}

Measurements for TH 18690 are from Hill et al. (1991).

+ , tooth is somewhat wider than this value. 
Appendix 5. Prohylobates kipsaramanensis sp. nov. from Kipsaraman and Keturo, Tugen Hills, Kenya, with length and breadth measurements (in $\mathrm{mm}$ )

\begin{tabular}{|c|c|c|c|c|c|}
\hline Prefix & Number & Tooth & Length & $\begin{array}{l}\text { Mesial } \\
\text { breadth }\end{array}$ & $\begin{array}{r}\text { Distal } \\
\text { breadth }\end{array}$ \\
\hline Bar & $1222 ’ 99$ & I1/ & 5 & 3.7 & - \\
\hline Bar & $1475^{\prime} 01$ & I1/ & 4.9 & 4.3 & - \\
\hline Bar & $1478^{\prime} 01$ & $\mathrm{I} 1 /$ & 5.1 & 4.3 & - \\
\hline Bar & 779’02 & I1/ & 5.5 & 4 & - \\
\hline Bar & $763^{\prime} 02$ & $\mathrm{I} 2 /$ & 4 & 4 & - \\
\hline Bar & 1003 '99 & $\mathrm{C} 1 / \mathrm{f}$ & 5.6 & 5.6 & - \\
\hline Bar & $1238^{\prime} 99$ & $\mathrm{C} 1 / \mathrm{m}$ & - & - & - \\
\hline Bar & 1192'99 & P3/ & - & - & - \\
\hline Bar & $7700^{\prime} 02$ & P3/ & 4.5 & 5.5 & - \\
\hline Bar & $1509^{\prime} 00$ & P4/ & 4.3 & 4.9 & - \\
\hline Bar & 3'00 & P4/ & 4.9 & 7.8 & - \\
\hline Bar & $768^{\prime} 02$ & P4/ & 3.9 & 6.7 & - \\
\hline Bar & 774'02 & $\mathrm{P} 4 /$ & 4.6 & 7.5 & - \\
\hline Bar & $1005^{\prime} 99$ & M1 or 2/ & 7.1 & 9 & 8.1 \\
\hline Bar & $1221 ’ 99$ & M1 or 2/ & 6.2 & 6.9 & 6.5 \\
\hline Bar & $185^{\prime} 02$ & M1 or 2/ & 6.2 & 7.2 & 7.1 \\
\hline Bar & $186^{\prime} 02$ & M1 or 2/ & 6.1 & 7.2 & 6.4 \\
\hline Bar & 2178’01 & M1 or 2/ & 6.5 & 7 & 6.4 \\
\hline Bar & 2179’01 & M1 or $2 /$ & 6.6 & 7.2 & 7 \\
\hline Bar & $226^{\prime} 02$ & M1 or 2/ & 7 & 8.2 & 7.8 \\
\hline Bar & $295^{\prime} 02$ & M1 or $2 /$ & 6.2 & 7.7 & 7.3 \\
\hline Bar & 44’02 & M1 or 2/ & 6.4 & 6.7 & 6.3 \\
\hline Bar & $766^{\prime} 02$ & M1 or 2/ & 6.3 & 7.6 & 6.1 \\
\hline Bar & $767^{\prime} 02$ & M1 or 2/ & 6.2 & 7.6 & 7 \\
\hline Bar & 777’02 & M1 or 2/ & 6 & 6.9 & 6.1 \\
\hline Bar & 1203 '99 & M1 or $2 /$ & - & - & - \\
\hline Bar & $1007^{\prime} 99$ & M3/ & 6.1 & 7.2 & 5.5 \\
\hline Bar & $1508^{\prime} 00$ & M3/ & 5.9 & 7.4 & 5.1 \\
\hline Bar & $223^{\prime} 02$ & M3/ & 5.9 & 7.4 & 5.5 \\
\hline Bar & $298^{\prime} 02$ & M3/ & 5.8 & 7.5 & 5.3 \\
\hline Bar & 609'01 & M3/ & 6 & 6.8 & 5.1 \\
\hline Bar & $783^{\prime} 02$ & M3/ & 6.3 & 7.5 & 5.9 \\
\hline Bar & $823^{\prime} 01$ & M3/ & 5.6 & 6.3 & 4.6 \\
\hline Bar & $86 ’ 99$ & M3/ & 6.1 & 7.1 & 5.9 \\
\hline Bar & $1487^{\prime} 01 \mathrm{a}$ & $\mathrm{dC} 1 /$ & 3.8 & 3.4 & - \\
\hline Bar & $1487^{\prime} 01 \mathrm{~b}$ & $\mathrm{dC} 1 /$ & 3.8 & 3.2 & - \\
\hline Bar & $1185^{\prime} 99$ & dP4/ & 5.2 & 5.4 & 4.8 \\
\hline Bar & $1412^{\prime} 02$ & dP4/ & 4.7 & 5.1 & 5 \\
\hline Bar & $1510^{\prime} 00$ & dP4/ & 5.2 & 5.8 & 5.7 \\
\hline Bar & $610^{\prime} 01$ & dP4/ & 5.2 & 5.4 & 5.3 \\
\hline Bar & $785^{\prime} 02$ & dP4/ & 5.1 & 5.6 & 5 \\
\hline Bar & $221^{\prime} 02$ & dP4/ & 6.1 & 7.4 & 7 \\
\hline Bar & 2089’01 & dP4/ & - & - & - \\
\hline Bar & 1484’01 & $\mathrm{i} / 1$ & 3.6 & 3.5 & - \\
\hline Bar & $780 ’ 02$ & $\mathrm{i} / 1$ & 3.4 & 4.2 & - \\
\hline Bar & $1010 ’ 99$ & $\mathrm{i} / 1$ & 3.8 & 4.4 & - \\
\hline Bar & $1485^{\prime} 01$ & $\mathrm{i} / 2$ & 2.6 & 3.9 & - \\
\hline Bar & $41^{\prime} 02$ & $\mathrm{i} / 2$ & 2.7 & 4 & - \\
\hline Bar & 1239 '99 & $\mathrm{i} / 2$ & - & - & - \\
\hline Bar & $762 ’ 02$ & $\mathrm{c} / 1$ & 5.6 & - & - \\
\hline Bar & $606^{\prime} 01$ & $\mathrm{c} / 1$ & 5.9 & 3.6 & - \\
\hline Bar & $1482 ’ 01$ & $\mathrm{p} / 3$ & 7.2 & 3.5 & - \\
\hline Bar & $42^{\prime} 02$ & $\mathrm{p} / 3$ & 6 & 3.4 & - \\
\hline Bar & $607^{\prime} 01$ & $\mathrm{p} / 3$ & 5.8 & 3.6 & - \\
\hline Bar & 2088'01 & $\mathrm{p} / 4$ & 4.5 & 5.4 & - \\
\hline Bar & $229^{\prime} 02$ & $\mathrm{p} / 4$ & 4.7 & 4.7 & - \\
\hline Bar & $776^{\prime} 02$ & $\mathrm{p} / 4$ & 6.2 & 5.1 & - \\
\hline Bar & 299’02 & $\mathrm{p} / 4$ & - & 6 & - \\
\hline Bar & $1232 ’ 99$ & $\mathrm{~m}$ frag & - & - & - \\
\hline
\end{tabular}

Appendix 5. (continued)

\begin{tabular}{|c|c|c|c|c|c|}
\hline Prefix & Number & Tooth & Length & $\begin{array}{l}\text { Mesial } \\
\text { breadth }\end{array}$ & $\begin{array}{c}\text { Distal } \\
\text { breadth }\end{array}$ \\
\hline Bar & $608^{\prime} 01$ & $\mathrm{~m} / 1$ or 2 frag & - & 7.9 & - \\
\hline Bar & $788^{\prime} 02$ & $\mathrm{~m}$ frag & - & - & - \\
\hline Bar & 789'02 & $\mathrm{m} / 1$ or 2 frag & 6.1 & 5 & - \\
\hline Bar & $827^{\prime} 01$ & $\mathrm{~m}$ frag & - & - & - \\
\hline Bar & $1474^{\prime} 01$ & $\mathrm{~m} / 1$ or 2 & 7.6 & 6.8 & 6.5 \\
\hline Bar & $222^{\prime} 02$ & $\mathrm{~m} / 1$ or 2 & 6.6 & 7 & 6.8 \\
\hline Bar & $224^{\prime} 02$ & $\mathrm{~m} / 1$ or 2 & 7 & 6.6 & 6.2 \\
\hline Bar & $225^{\prime} 02$ & $\mathrm{~m} / 1$ or 2 & 6.8 & 6.4 & 6 \\
\hline Bar & $228^{\prime} 02$ & $\mathrm{~m} / 1$ or 2 & 6.1 & 5.6 & 5.2 \\
\hline Bar & 39'02 & $\mathrm{m} / 1$ or 2 & 6.5 & 6.1 & 5.6 \\
\hline Bar & 43'02 & $\mathrm{m} / 1$ or 2 & 6.8 & 5.8 & 5.3 \\
\hline Bar & 40’02 & $\mathrm{m} / 1$ or 2 & 6.6 & 6.1 & 5.7 \\
\hline Bar & $769^{\prime} 02$ & $\mathrm{~m} / 1$ or 2 & 6.1 & 5.4 & 5.4 \\
\hline Bar & $781^{\prime} 02$ & $\mathrm{~m} / 1$ or 2 & 7 & 6.8 & 6.9 \\
\hline Bar & $784^{\prime} 02$ & $\mathrm{~m} / 1$ or 2 & 6.9 & 6.7 & 6.8 \\
\hline Bar & $787^{\prime} 02$ & $\mathrm{~m} / 1$ or 2 & 6.1 & 5.1 & 5.1 \\
\hline Bar & $827^{\prime} 02$ & $\mathrm{~m} / 1$ or 2 & 6.6 & 6.3 & - \\
\hline Bar & $\begin{array}{c}219^{\prime} 02 \\
\text { type }\end{array}$ & $\mathrm{M} / 2$ & 7.3 & 6.8 & 6.5 \\
\hline Bar & $1411^{\prime} 02$ & $\mathrm{~m} / 3$ & 8.7 & 6.1 & 5.1 \\
\hline Bar & $1476 ’ 01$ & $\mathrm{~m} / 3$ & 8.8 & 6.6 & 5.3 \\
\hline Bar & $1477^{\prime} 01$ & $\mathrm{~m} / 3$ & 8.3 & 6.4 & 4.8 \\
\hline Bar & 2096'01 & $\mathrm{m} / 3$ & - & - & - \\
\hline Bar & $2177^{\prime} 01$ & $\mathrm{~m} / 3$ frag & 5.7 & - & - \\
\hline Bar & $220^{\prime} 02$ & $\mathrm{~m} / 3$ & 7.7 & 6 & 5.3 \\
\hline Bar & $38^{\prime} 02$ & $\mathrm{~m} / 3$ & 8 & 5.7 & 4.9 \\
\hline Bar & $771 ’ 02$ & $\mathrm{~m} / 3$ & 8 & 6.4 & 5.2 \\
\hline Bar & $917 ’ 99$ & $\mathrm{~m} / 3$ & 7.3 & 5.7 & 4.4 \\
\hline Bar & 786’02 & $\mathrm{dp} / 4$ & - & 4.7 & - \\
\hline Bar & 1032 '99 & $\mathrm{dp} / 4$ & 5.3 & 3.9 & - \\
\hline Bar & 1413 '02 & $\mathrm{dp} / 4$ & 5.6 & 4.4 & 4.5 \\
\hline
\end{tabular}

In Figure 24, Figure 25, and Figure 27, the serial position of isolated first and second molars is estimated on the basis of size, but doubt remains about the precise position of these teeth. 